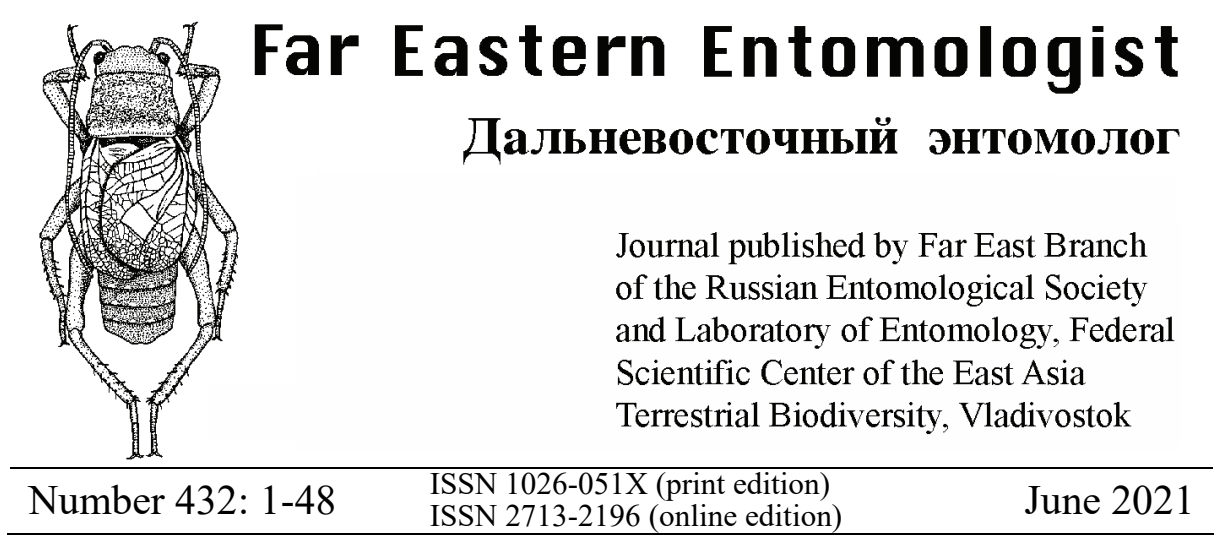

https://doi.org/10.25221/fee.432.1

http://zoobank.org/ References/8EBC19E9-BA98-44AF-ACEB-11C085CF06B6

\title{
REVIEW OF THE GENUS ANAPHES HALIDAY, 1833 \\ (HYMENOPTERA: MYMARIDAE) IN RUSSIA, PART 1: SUBGENUS ANAPHES S. STR.
}

\begin{abstract}
S. V. Triapitsyn
Entomology Research Museum, Department of Entomology, University of California, Riverside, California, 92521, USA.E-mail: serguei.triapitsyn@ucr.edu

Summary. Species of the nominotypical subgenus of Anaphes Haliday, 1833 (Hymenoptera: Mymaridae) in Russia are reviewed. A key to females of the 18 Palaearctic species of the subgenus is given. Ten species are newly recorded from Russia (two of them based on tentative identifications), and new records of the extralimital specimens examined are also provided. Three new species are described from the eastern Palaearctic region: Anaphes (Anaphes) csabai sp. n. (Kuril Islands), Anaphes (Anaphes) maxim sp. n. (Primorskii krai and Sakhalin Island), and Anaphes (Anaphes) rfe sp. n. (Primorskii krai and Beijing, China). Several historical records of some species of Anaphes in Russia are critically analyzed in the unfortunal absence of most voucher specimens, having in mind that some of them were likely misidentified.

Key words: fairyfly, Mymaridae, taxonomy, new species, key, fauna, new records, Palaearctic region.

С. В. Тряпицын. Обзор рода Anaphes Haliday, 1833 (Hymenoptera: Mymaridae) России, часть 1: подрод Anaphes s. str. // Дальневосточный энтомолог. 2021. N 432. C. 1-48.
\end{abstract}


Резюме. Ревизованы виды номинативного подрода рода Anaphes Haliday, 1833 (Hymenoptera: Mymaridae) фауны России. Дана определительная таблица 18 палеарктических видов подрода по самкам. Впервые для России приводятся 10 видов (два из которых по предварительному определению), а также новые указания для ряда исследованных видов. Описаны три новых для науки вида из восточной части Палеарктики: Anaphes (Anaphes) csabai sp. n. (Курильские острова), Anaphes (Anaphes) maxim sp. n. (Приморский край и остров Сахалин) и Anaphes (Anaphes) rfe sp. n. (Приморский край и окрестности Пекина в Китае). Критически проанализированы прежние указания для России ряда видов, которые, ввиду отсутствия достоверного материала, вероятно, основаны на неверном определении некоторых видов рода Anaphes.

\section{INTRODUCTION}

Species of the fairyfly genus Anaphes Haliday, 1833 (Hymenoptera: Mymaridae) in Russia have been awaiting a thorough review for more than a century, since Rimsky-Korsakov (1917) first mentioned an unidentified Anaphes sp. from the country. However, that was impossible to do because taxonomy of the genus in the Palaearctic region had been in total disarray until recently, when Huber \& Thuróczy (2018) reviewed and keyed (females only) its European species and classified them in two subgnera. In addition to providing a useful world catalog of Anaphes species with thorough lists of the synonyms and the type localities of all the nominal species, they also gave regional lists of species and habitus illustrations of all the European ones, thus enabling at least a possibility for their positive identification. That, however, often remains challanging even in Europe, as intraspecific variation is poorly known within most of the species, and limits of some of them are not well defined. As the result, quite a significant number of European specimens would either not key to any particular valid species or, otherwise, key to two or more known species, while not exacly matching any of them. Here I list these under "remarks" for the described species to which they seem to be most similar and possibly fitting.

Huber \& Thuróczy (2018) provided detailed diagnoses of Anaphes and its two recognized subgenera, the nominotypical subgenus $A$. (Anaphes), in which the clava of female antenna is entire, and $A$. (Patasson Walker, 1846), in which the clava of female antenna is 2-segmented (occasionally only partially divided). They also synonymized 149 nominal species, most of which were described from Europe in the 20th century by Walter Soyka. Thus, his keys, particularly in Soyka $(1949,1950,1954,1955)$, should not be used for identification of the European species of Anaphes, as discussed in Huber \& Thuróczy (2018). Because of that, most if not all the earlier identifications and records of Anaphes species in Europe before the review by Huber \& Thuróczy (2018) should be almost universally considered doubtful until they are thoroghly verified, when that is at all possible (voucher specimens are often nonexistent). Thus, many (likely most) of the earlier published distributional and host records of the currently valid Anaphes species and of their synonyms in Europe cannot be considered reliable, and their listings can only be regarded as tentative, pending confirmation. Therefore, here I purposedly omit these from the distibution notes for the included species.

Because of the availability of a detailed generic diagnosis and of lists of the generic and species synonyms, and of the type specimens and their depositories of all the nominal species globally, as well as of the known hosts of Anaphes (Huber, 1986; Huber \& Thuróczy, 2018; 
Huber et al., 2020), repetition of this information is not necessary. I therefore mostly omit it and just provide a synopsis of the species recognized from Russia, including information on their extralimital records, when such are available. Also included are taxonomic notes on a few others, little known European species which have not yet been recorded from the country but could occur there. The first part of this review treats species in the nominotypical subgenus.

The following species of Anaphes were previously recorded from Russia: A. (Anaphes) flavipes (Foerster, 1841), an egg parasitoid of the cereal leaf beetle Oulema melanopus (L., 1758) [as Lema melanopus] (Coleoptera: Chrysomelidae) in Krasnodarskii krai and Rostovskaya oblast' (Riakhovskiy \& Krakhmal', 1978), and also from Leningradskaya oblast' (Hellén, 1974) and [as A. lemae Bakkendorf, 1970] from the European part of the former USSR including Voronezhskaya oblast' (Trjapitzin, 1978), as well as from Moskovskaya oblast' (Makarova \& Polilov, 2013; Polilov, 2016), Voronezhskaya oblast' (Polilov, 2016), and possibly also from Krasnodar (Krasnodarskii krai) from eggs of Oulema gallaeciana (Heyden, 1870) (Samková et al., 2017); A. (Anaphes) nipponicus Kuwayama, 1932, an egg parasitoid of the rice leaf beetle Oulema oryzae (Kuwayama, 1931) (Chrysomelidae) in Primorskii krai (Storozheva, 1989, 1990a, 1990b); A. (Anaphes) fuscipennis Haliday, 1833 [also as A. pratensis Foerster, 1847] and A. (Patasson) silesicus (Soyka, 1946) [as A. calvescens Debauche, 1948] from Leningradskaya oblast' (Hellén, 1974); and A. (Patasson) luna (Girault, 1914) [as Patasson brachygaster (Debauche, 1948)] from Altayskii krai (Dolgin, 1978) and Tomskaya oblast' (Vecher, 1990), as an egg parasitoid of Chrysolina fastuosa (Scopoli, 1763) (Chrysomelidae), and also [as A. brachygaster Debauche and A. devillei Debauche, 1948] from Leningradskaya oblast' (Hellén, 1974). Of these, identifications of the reared species from known hosts were likely more or less trustworthy although unfortunately, voucher specimens of most of them could not be found with an exception of A. (Anaphes) nipponicus, which are kept in the collection of the Federal Scientific Center of the East Asia Terrestrial Biodiversity, Far Eastern Branch of the Russian Academy of Sciences, Vladivostok, Russia and are in a very poor condition (Maxim Yu. Proshchalykin, personal communication), either badly shriveled (Fig. 73) or incomplete (Fig. 71). However, correctness of the identifications of $A$. (Patasson) luna from eggs of Chrysolina fastuosa in Russia is also very doutful; almost certainly these were misidentifications because they are the only such records of this species from eggs of Chrysomelidae, whereas elsewhere its all other known records are from eggs of Curculionidae (Coleoptera) (Huber, 2006; Noyes, 2019). Most, if not all, other (non-reared) records of the Anaphes species from Russia, including that of $A$. (Anaphes) fuscipennis by Hellén (1974), according to Huber (1992), were also quite likely based on misidentifications because prior to the recent key by Huber \& Thuróczy (2018), correct identification of species in this genus was practically impossible. Indeed, almost all, if not all, of the species of Anaphes keyed and listed by Hellén (1974) from Finland in its current borders turned out to be misidentified (S. V. Triapitsyn, unpublished information), and the same is true for his Anaphes specimens from Leningradskaya oblast' (definitely for A. (Anaphes) flavipes), which were collected there before World War II (in 1920, 1927 and 1936). Generally, in Europe there are just a few more or less easily recognizable species of Anaphes with very wide wings and long ovipositors, and also perhaps with very short funicular segments in females, but the latter are rare. For instance, specimens of the species reported as A. flavipes by Polilov (2016) were collected in a meadow with mixed natural grasses at a forest edge in Moskovskaya oblast' (Alexey A. Polilov, personal communication) and not in or near a cereal field where this species can be found (Samková et al., 2017). According to my own experience in collecting in similar natural meadow habitats in Moskovskaya oblast', A. flavipes is never present in the samples from there (the 
only confirmed specimen of this species was collected by me in yellow pan traps at the edge of a former, abandoned agricultural field turned a meadow where occasional, self-growing remnant wheat plants were present here and there). In natural meadows close to forest habitats in Moskovskaya oblast' and elsewhere in most of Europe, it is rather A. (Patasson) silesicus that is apparently the most common species of the genus. Indeed, after examination of the additional (non-published) scanning electron micrographs of the voucher specimens from Moskovskaya oblast' of the article by Polilov (2016), which were kindly sent to me by A. A. Polilov, I determined that misidentified species to be a typical A. (Patasson) silesicus. Overall, members of $A$. (Patasson) are usually far more common and abundant in Malaise and yellow pan trap and also sweep samples in the Palaearctic region than those of the nominotypical subgenus. An exception to that are some northernmost areas and harsh environments such as on Kuril Islands where members of $A$. (Anaphes) seem to be prevalent.

Anaphes dytiscidarum Rimsky-Korsakov, 1920 (Rimsky-Korsakov, 1920), an egg parasitoid of predaceous diving beetles, was first mentioned by Rimsky-Korsakov (1917) as an Anaphes sp. from eggs of Dytiscidae (Coleoptera) in Leningradskaya oblast'. It is a nomen nudum because not even a brief diagnosis of it was given (Rimsky-Korsakov, 1920). Rimsky-Korsakov's (1940: 232) mentioning of A. dytiscidarum was also that of a nomen nudum, as translated from Russian: "Genus Anaphes. Here a large number of oophagous wasps, parasitizing at the expense of various terrestrial insects. A. dytiscidarum R.-Kors. parasitizes eggs of small Dytiscidae (Ilybius, Agabus), mainly laid in those parts of the aquatic plants that are outside of water, but females also can go down into water, where they do not swim but only keep themselves as floating with the wings open. Found in Leningrad region" (Triapitsyn, 2012). Unfortunately, no voucher specimens of A. dytiscidarum exist. The only positively identified species of Anaphes that was reared elsewhere in Europe from eggs of water beetles was A. (Patasson) longicornis Walker, 1846 in St. Andrews, Fife, Scotland, United Kingdom (Hincks, 1960) [as A. (Patasson) leptoceras Debauche, 1948], from eggs of Ilybius fuliginosus (Fabricius, 1792) (Dytiscidae); Fursov (1995, p. 12, table 2) listed it [as Patasson leptoceras] from both Russia and Ukraine as a parasitoid of Agabus $\mathrm{sp}(\mathrm{p})$. and Ilybius $\mathrm{sp}(\mathrm{p})$. without providing, however, any other details. He did mention that he had made collections of mymarid egg parasitoids of aquatic insects in various localities of both countries. Apparently, he considered (without explicitly stating that) that the Anaphes sp. reported from Leningradskaya oblast' of Russia by Rimsky-Korsakov $(1917,1920,1940)$ could be conspecific with Patasson leptoceras (Fursov, 1995). By oversight, Triapitsyn \& Tselikh (2019) omitted Fursov's (1995) record of A. (Patasson) longicornis from their list of the Anaphes species known from Russia. However, these records also need confirmation in light of the recent changes in the taxonomy of Anaphes by Huber \& Thuróczy (2018).

In this study, all but the following four valid species of $A$. (Anaphes) that are currently known from the Palaearctic region, as listed by Huber \& Thuróczy (2018), were found in Russia: A. (Anaphes) brevicornis (Soyka, 1949), A. (Anaphes) ensipennis (Soyka, 1949), A. (Anaphes) quadraticornis (Soyka, 1949), and A. (Anaphes) wolfsthali (Soyka, 1950). One of them, A. (Anaphes) brevicornis, is newly recorded from another European country and included in the synopsys of the Palaearctic species. However, I treat A. wolfsthali in A. (Patasson) as A. (Patasson) wolfsthali based on evidence to be presented in the forthcoming second part of this review; thus this peculiar species is excluded from the key to the Palaearctic species of the nominotypical subgenus. Indeed, Huber (1992: 56) justifiably placed $A$. wolfsthali in the crassicornis group of Anaphes sensu stricto as it was defined then, which is now within $A$. (Patasson) (Huber \& Thuróczy, 2018), but these authors included this species in their key to the European species of $A$. (Anaphes) without providing any explanation. Brief diagnoses [since the review by Huber \& Thuróczy (2018) does not provide any, which makes positive 
identifications of the European species often challenging], detailed illustrations, verified distributions, and more or less reliable host associations are given for all the taxa included in this review. Three new species are also described, all from the Russian Far East (one of them is also known from the Palaearctic part of China).

Outside of Europe, besides the above-mentioned records from the Asian part of Russia, very little is known about the Palaearctic species of Anaphes except for A. (Anaphes) nipponicus, which was first reported from Japan (Kuwayama, 1932) and is also known in the Oriental region from Fujian in mainland China (Bai, 2007) and Taiwan (Samková et al., 2017). Also, Tarla \& Tarla (2017) reported A. (Patasson) lineipennis (Soyka, 1949) [as Anaphes chrysomelae (Bakkendorf, 1960)] from eggs of Chrysolina herbacea (Duftschmid, 1825) (Chrysomelidae) in the Asian part of Turkey, and Lotfalizadeh (2015) listed two unidentified species of Anaphes from Iran. Anwar et al. (2019) described two new, distinctive species of Anaphes from the Oriental region.

A key to the Palaearctic species of Anaphes (for females only) is derived from that of the European ones in Huber \& Thuróczy (2018), with additions of the newly described and recorded species and some modifications that reflect the gained knowledge of the intraspecific variation in some of the taxa. In Europe and the entire Palaearctic region, Anaphes specimens can be recognized using the generic keys in Samková et al. (2020) and Triapitsyn \& Huber (2000), respectively.

Males of Palaearctic Anaphes differ from females in the normal sexually dimorphic features of genitalia and having filiform, 12-segmented antennae. Female features are used extensively as one of the main diagnostic tools for species recognition in the genus and in the keys. Because of that identification of most males of Anaphes is practically impossible morphologically, even to subgenus, without rearing them together or by having a genetic match using molecular methods. Associating them through collecting the sexes together at one time and place also does not work in most instances because more than one species of Anaphes can commonly occur there. Therefore, in most cases it is not the species that is differentiated but only females of the species. Males of some species are still unknown or were likely misidentified.

Using this opportunity, I am clarifying the record of Anagrus incarnatus Haliday, 1833 (Mymaridae) from "Terijoki” (USSR) by Hellén (1974: 23). I examined two card-mounted specimens, a female and a male (deposited in the collection of Zoological Museum, Finnish Museum of Natural History, University of Helsinki, Helsinki, Finland) from Zelenogorsk, Kurortnyi rayon, Saint Petersburg, Russia, both identified by W. Hellén as Anagrus incarnatus and labeled only as “Terijoki. Hellén.”. The female stands under W. Hellén's number 104 on faded light brown paper; in the unpublished W. Hellén's notebooks in the same museum, this number on this color of paper corresponds to the following information (M. Koponen, personal communication): collected on 12.VI 1927 at a side of railway tracks. Following slide-mounting, I confirm that the female belongs to Anagrus (Anagrus) incarnatus. The male stands under W. Hellén's number 315 on faded light brown paper; in the unpublished W. Hellén's notebooks, this number corresponds to the following information (M. Koponen, personal communication): collected on 14.VI 1927 (dunes). The male, which was also slidemounted, is an Anagrus (Anagrus) sp. from the incarnatus species group; however, it definitely belongs to some other species because it has a pair of adnotaular setae on the midlobe of the mesoscutum which are absent in A. (Anagrus) incarnatus.

\section{MATERIAL AND METHODS}

This study is based on numerous non-type specimens from Russia and elsewhere in the Palaearctic region; these are listed under "Material examined" and "Extralimital material 
examined" sections. Overall, at least 2000 dry-mounted individuals were examined, from which some were selected for further slide mounting.

The following acronyms are used to designate depositories of specimens: CAS - California Academy of Sciences, San Francisco, California, USA; CNC - Canadian National Collection of Insects, Arachnids and Nematodes, Ottawa, Ontario, Canada; ELKU - Entomological Laboratory, Faculty of Agriculture, Kyushu University, Fukuoka, Japan; EMEC - Essig Museum of Entomology, University of California, Berkeley, California, USA; FMNH Zoological Museum, Finnish Museum of Natural History, University of Helsinki, Helsinki, Finland; IBPV - Federal Scientific Center of the East Asia Terrestrial Biodiversity, Far Eastern Branch of the Russian Academy of Sciences, Vladivostok, Russia; ISNB - Institut Royal des Sciences Naturelles de Belgique, Brussels, Belgium; MVMA - Entomology Collection, Museum Victoria, Melbourne, Victoria, Australia; UCRC - Entomology Research Museum, University of California, Riverside, California, USA; ZIN - Zoological Institute, Russian Academy of Sciences, Saint Petersburg, Russia (also abbreviated elsewhere as ZISP).

Collecting and preservation methods of the material from Primorskii krai of Russia were described by Triapitsyn \& Berezovskiy (2001). More than 500 specimens of Anaphes from the Palaearctic region, mainly females, were dissected and slide-mounted in Canada balsam by V.V. Berezovskiy using the technique described in Huber (2015), with some modifications by V.V. Berezovskiy and S.V. Triapitsyn (unpublished). The slides were examined under a Zeiss Axioskop 2 plus compound microscope and photographed using the Auto-Montage $\mathbb{R}$ system by Syncroscopy; the photographs were then retouched where necessary using Adobe Photoshop ${ }^{\circledR}$.

Terms used for morphological features are those of Gibson (1997) and Huber \& Thuróczy (2018), with a few modifications. All measurements were taken from the slide-mounted specimens, unless stated otherwise, and are given in micrometers $(\mu \mathrm{m})$, as length or, for the wings, as length:width. Relative length of metatorsomeres 1 and 2 is measured according to Huber \& Thuróczy (2018, p. 72, fig. 45). Abbreviations used are: $\mathrm{F}=$ funicular segment of the female antenna or flagellomere of the male antenna; $\mathrm{mps}=$ multiporous plate sensillum or sensilla on the antennal flagellar segments (= longitudinal sensillum or sensilla or sensory ridge(s) of other authors); MT = Malaise trap; YPT = yellow pan trap(s). New country distribution records are denoted with an asterisk $(*)$.

\section{Key to females of the Palaearctic species of the subgenus Anaphes}

1. F2-F4 without mps, F5 and F6 notably wider than preceding funiculars (Fig. 43); fore wing with posterior margin slightly outcurved (Fig. 44) A. (Anaphes) fuscipennis

- At least one of F2-F4 with mps on at least one antenna, F5 and F6 not notably wider than preceding funiculars; fore wing with posterior margin slightly incurved 2

2. Mesosoma with conspicuous reticulate sculpture, stronger on metanotum and propodeum (Fig. 18) A. (Anaphes) csabai sp. n.

- Mesosoma either smooth or at most with faint, inconspicuous sculpture

3

3. F2 with at least $1 \mathrm{mps}$ on at least one antenna .......................................

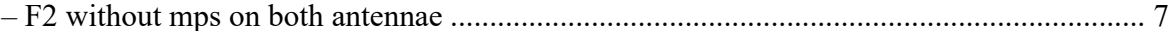

4. All funiculars either shorter than or at most as long as pedicel

- At least some funiculars distinctly longer than pedicel A. (Anaphes) quadraticornis

5. Metatarsomere 1 distinctly longer than metatarsomere 2 (Fig. 12)

A. (Anaphes) crassipennis (part)

- Metatarsomere 1 at most about as long as metatarsomere 2 
6. Antenna (Fig. 66) with F2-F6 relatively shorter, clava at most $3.3 \times$ as long as wide; fore wing (Fig. 67) with longest marginal seta at most $1.2 \times$ maximum wing width; ovipositor about as long as metatibia

A. (Anaphes) ?nigrellus

- Antenna (Fig. 56) with F2-F6 relatively longer, clava at least 3.6× as long as wide; fore wing (Fig. 57) with longest marginal seta at least $1.3 \times$ maximum wing width; ovipositor at most $0.8 \times$ (usually $0.7 \times$ ) as long as metatibia

A. (Anaphes) maxim sp. n.

7. All funiculars either shorter than or at most as long as pedicel ....................................... 8

- Two or more funiculars at least slightly longer than pedicel ....................................... 10

8. F4 with 1 or $2 \mathrm{mps}$

- F4 without mps

(Anaphes) globosicornis

9. Antenna (Fig. 5) with all funiculars at least slightly shorter than pedicel, F3 the longest funicular A. (Anaphes) brevicornis

- Antenna (Fig. 91) with F4 and F6 the longest funiculars, equal in length and about as long as pedicel (either F3 or F5 sometimes the same length as them) ...... A. (Anaphes) rfe sp. n.

10. F4 either without mps or with $1 \mathrm{mps}$ on one antenna or on both antennae ...............11

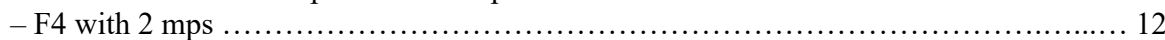

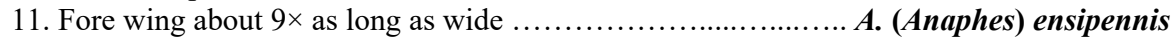

- Fore wing (Fig. 78) at most about $7 \times$ as long as wide ................. A. (Anaphes) ovipositor

12. Metatarsomere 1 distinctly longer than metatarsomere 2 (Fig. 12)

\section{A. (Anaphes) crassipennis (part)}

- Metatarsomere 1 either just slightly longer or shorter than metatarsomere 2, or these about equal in lengh

13. Combined length of F1 and F2 at least slightly shorter than F3 ..................... 14

- Combined length of F1 and F2 either longer than F3 or about as long as F3 .............. 16

14. Clava at most $3.0 \times$ as long as wide (egg parasitoid of Curculionidae)

A. (Anaphes) gauthieri

- Clava at least $3.1 \times$ as long as wide (egg parasitoids of Chrysomelidae, Lema spp. and Oulema spp.) 15

15. Nearctic (introduced) and western Palaearctic (egg parasitoid of Lema spp. and Oulema spp. other than Oulema oryzae) A. (Anaphes) flavipes (part)

- Eastern Palaearctic and Oriental (egg parasitoid of Oulema oryzae on rice)

16. Fore wing (Fig. 2) at most $4.7 \times$ as long as wide .................... A. (Anaphes) arenbergi

A. (Anaphes) nipponicus (part)

- Fore wing at least $4.9 \times$ as long as wide A. (Anaphes) arenbergi

17. Clava usually at least $3.9 \times$ as long as wide (egg parasitoids of Lema spp. and Oulema spp. in cereal crops) [however, in some specimens clava $3.1-3.8 \times$ as long as wide] ....... 18

- Clava at most 3.8× as long as wide (egg parasitoids of other insects, when host associations are known)

18. Nearctic (introduced) and western Palaearctic (egg parasitoid of Lema spp. and Oulema spp. other than Oulema oryzae) A. (Anaphes) flavipes (part)

- Eastern Palaearctic and Oriental (egg parasitoid of Oulema oryzae on rice)

19. Fore wing (Fig. 63) at most $5.5 \times$ as long as wide ...................... A. (Anaphes) medius A. (Anaphes) nipponicus (part)

- Fore wing at least $5.8 \times$ as long as wide 20

20. Clava at least slightly $(1.1 \times)$ longer than combined length of F5 and F6 (Figs 81, 87) ...

- Clava at most as long as combined length of F5 and F6 (Fig. 96) 


\section{SYNOPSIS OF SPECIES (in alphabetical order)}

\section{Anaphes (Anaphes) ?arenbergi Debauche, 1948}

Figs $1-4$

Anaphes (Anaphes) arenbergi Debauche, 1948: 166-168, plates XVI-XVII (illustrations). Anaphes arenbergi Debauche: Huber, 1992: 72 (list).

Anaphes (Anaphes) arenbergi Debauche: Huber \& Thuróczy, 2018: 25 (list, type information), 45 (key), 86 (illustration).

MATERIAL EXAMINED. Russia: Sakhalinskaya oblast', Sakhalin Island, $6 \mathrm{~km}$ E of Sokol, near Belaya River, 31.VII 2001 (D. J. Bennett, T. Anderson) [1 +, CAS].

DIAGNOSIS. FEMALE (specimen from Russia). Antenna (Fig. 1) with scape (excluding radicle) $3.0 \times$ as long as wide, with inconspicuous cross-ridges; F3-F6 longer than pedicel, F2 $3.0 \times$ as long as wide and slightly shorther than following funiculars, F3 the longest funicular, mps on F3-F6 ( 2 on each); clava with $6 \mathrm{mps}, 2.4 \times$ as long as wide, $0.8 \times$ as long as combined length of F5 and F6. Fore wing (Fig. 2) $4.7 \times$ as long as wide; longest marginal seta about $0.9 \times$ maximum wing width; marginal space separated from medial space by 2 lines of setae. Hind wing (Fig. 2) about $18 \times$ as long as wide; longest marginal seta $3.2 \times$ maximum wing width, disc with 1 irregular row of setae apically. Metatarsomere 1 about as long as metatarsomere 2 (Fig. 4). Ovipositor (Fig. 3) occupying entire length of gaster (but not extending forward under mesosoma), not exserted beyond apex of gaster posteriorly, and $1.4 \times$ length of metatibia.

MALE. Unknown.

DISTRIBUTION. ?Russia*; Belgium. Other records (Noyes, 2019) need verification.

HOSTS. Unknown.

COMMENTS. I only tentatively assign this specimen to $A$. (Anaphes) arenbergi because its fore wing is slightly narrower and with marginal setae a little longer than what Huber \& Thuróczy (2018) indicated for females of the latter species: at most $4.4 \times$ as long as wide and less than $0.8 \times$, respectively. Besides, the hind wing of the type specimens from Belgium apparently has two irregular rows of setae on the disc apically (Huber \& Thuróczy, 2018).

\section{Anaphes (Anaphes) ?brevicornis (Soyka, 1949)}

Figs 5-8

Mymar brevicornis Soyka, 1949: 316-317.

Anaphes brevicornis (Soyka): Huber, 1992: 73 (list).

Anaphes (Anaphes) brevicornis (Soyka): Huber \& Thuróczy, 2018: 25 (list, type information), 45 (key), 86 (illustration).

EXTRALIMITAL MATERIAL EXAMINED. Hungary: Vas County, W of Köszeg, 47²3'09'’N 16 31'19'’'E, 355 m, 16-20.VI 2009 (I. Mikó) [1 q, UCRC].

DIAGNOSIS. FEMALE (specimen from Hungary). Body length (slide-mounted specimen) about $0.7 \mathrm{~mm}$. Antenna (Fig. 5) with scape (excluding radicle) $3.8 \times$ as long as wide, without cross-ridges; all funiculars at least slightly shorter than pedicel, F2 $2.2 \times$ as long as wide and slightly shorther than following funiculars, F3 the longest funicular and almost as long as pedicel, mps on F3 (2), F4 (1 on one antenna or 2 on the other antenna), F5 (2) and F6 (2); clava with $6 \mathrm{mps}, 2.7 \times$ as long as wide, $1.3 \times$ as long as combined length of F5 and F6. Fore wing (Fig. 6) $6.5 \times$ as long as wide; longest marginal seta $1.4 \times$ maximum wing width; marginal space separated from medial space by 2 lines of setae. Hind wing (Fig. 6) about $19 \times$ as long 
as wide; longest marginal seta $3.5 \times$ maximum wing width, disc with 1 irregular row of setae apically. Metatarsomere 1 a little shorter than metatarsomere 2 (Fig. 8). Ovipositor (Fig. 7) occupying about $0.8 \times$ length of gaster (and thus not extending forward under mesosoma), not exserted beyond apex of gaster posteriorly, and about $1.1 \times$ length of metatibia.

MALE. Unknown.

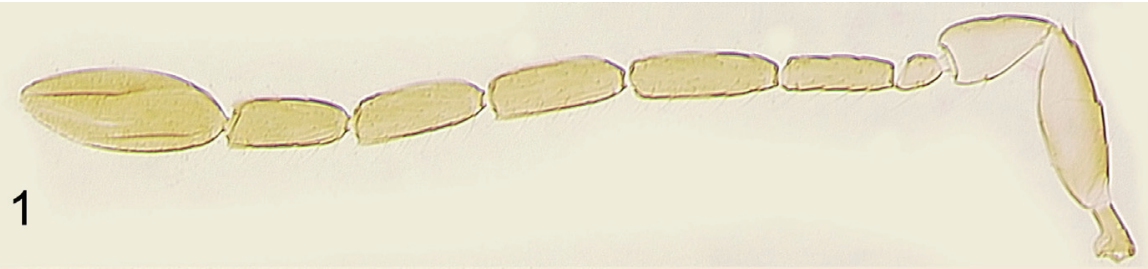

2
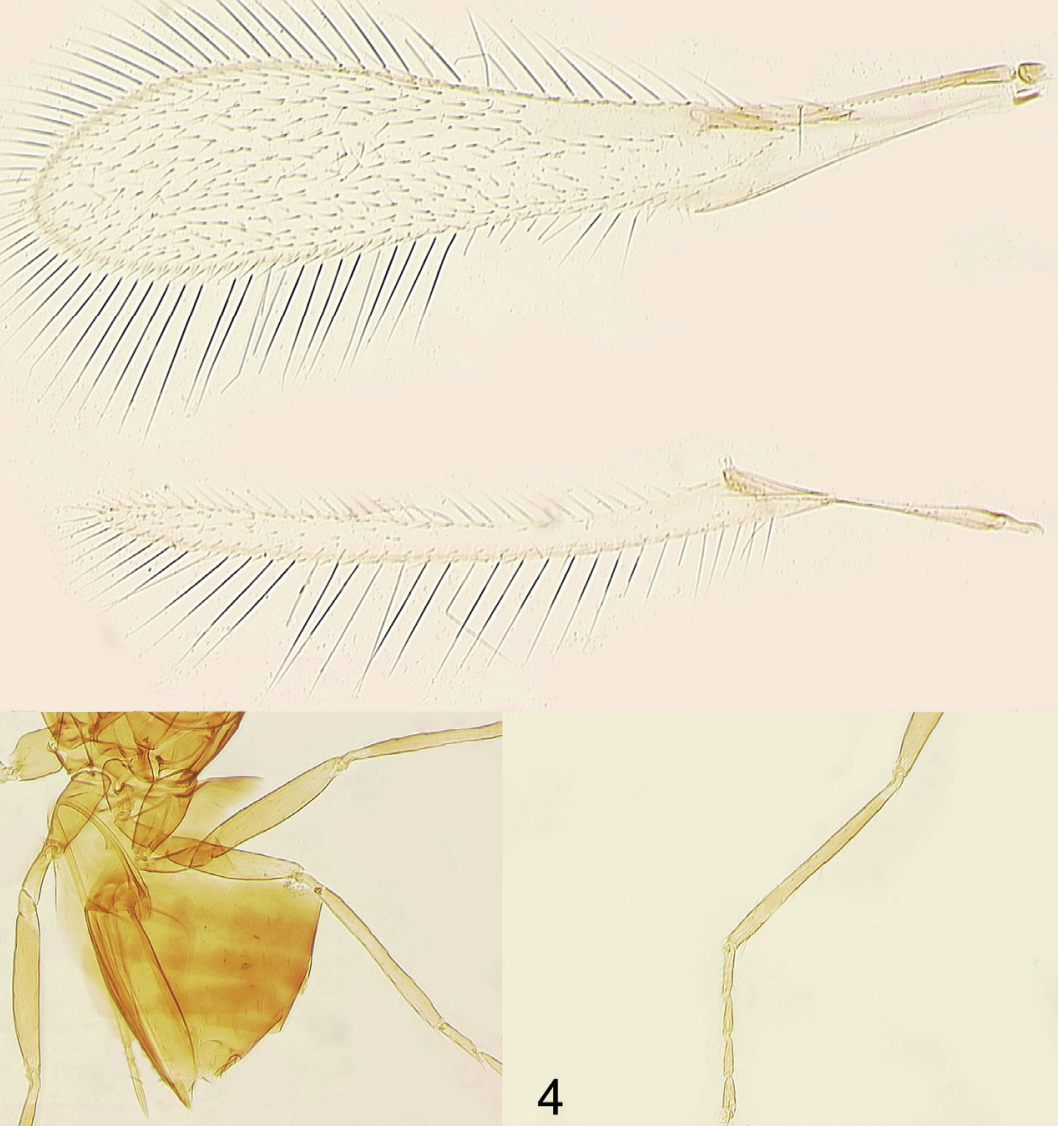

4

Figs 1-4. Anaphes (Anaphes) ?arenbergi, female (6 km E of Sokol, Sakhalin Island, Sakhalinskaya oblast', Russia). 1) Antenna, 2) wings, 3) ovipositor, 4) metatibia and metatarsus. 
DISTRIBUTION. ?Hungary*, Netherlands.

HOSTS. Unknown.

COMMENTS. I only tentatively assign this specimen to A. (Anaphes) brevicornis because female of the latter has a slightly shorter F2 (at most $2.0 \times$ as long as wide) and the clava is the same length as F5 and F6 together (Huber \& Thuróczy, 2018), although Soyka (1949: 317) provided slightly different proportions for its holotype from Valkenburg in the Netherlands, which are similar to those in the female from Hungary.

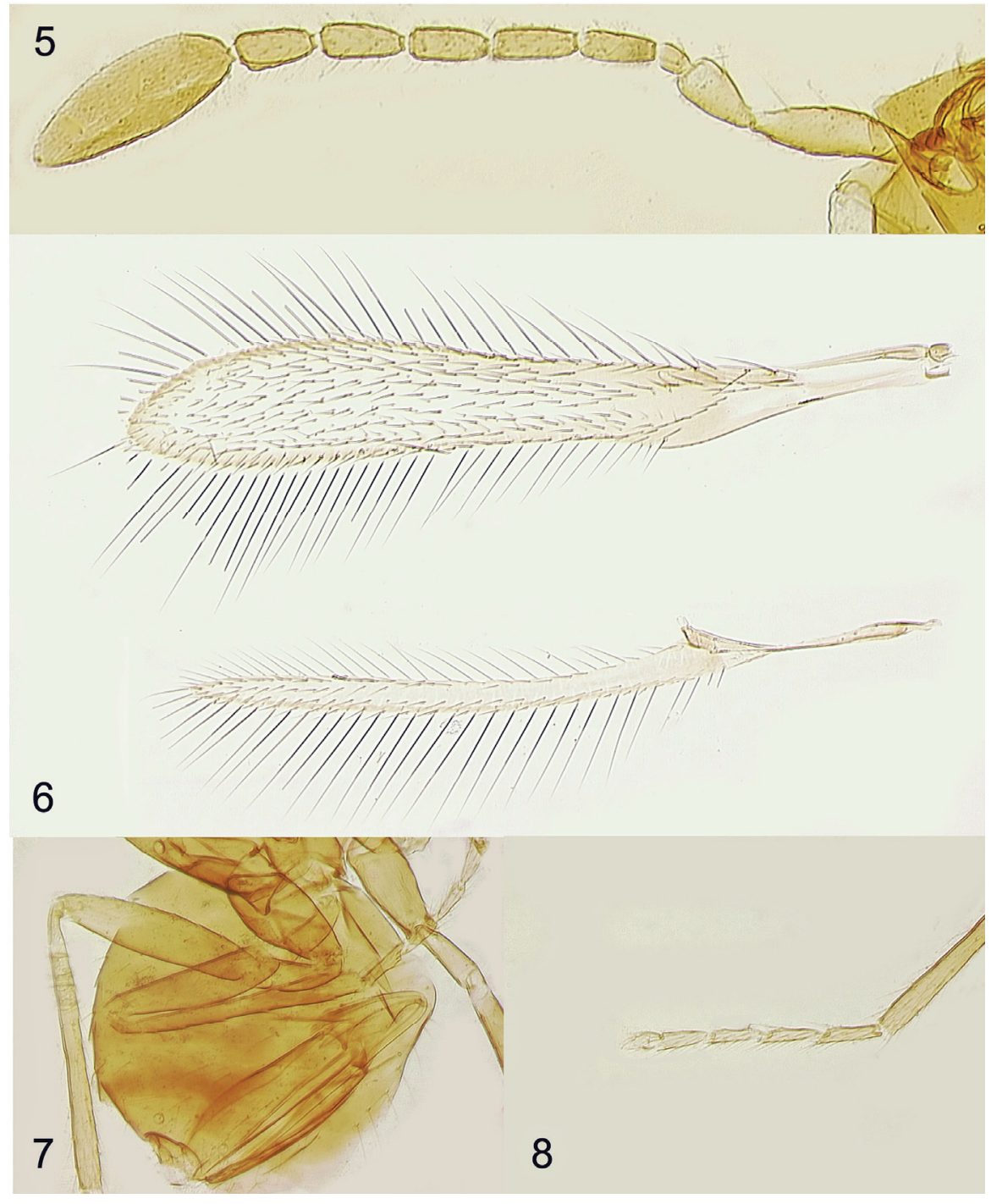

Figs 5-8. Anaphes (Anaphes) ?brevicornis, female (W of Köszeg, Vas County, Hungary). 5) Antenna, 6) wings, 7) ovipositor, 8) metatarsus. 
Anaphes (Anaphes) crassipennis Soyka, 1946

Figs 9-12

Anaphes crassipennis Soyka, 1946: 41.

Anaphes brachygaster Debauche, 1948 (misidentification): Hellén, 1974: 26-27 (in part, record from "Terijoki”, USSR).

Anaphes crassipennis Soyka: Huber, 1992: 73 (list).

Anaphes (Anaphes) crassipennis Soyka: Huber \& Thuróczy, 2018: 25 (list, type information, synonyms), 45 (key), 48 (host), 87 (illustration); Triapitsyn et al., 2020: 569-570 (records from Finland, distribution, host).

MATERIAL EXAMINED. Russia: Leningradskaya oblast', Vsevolozhskiy rayon, Vaganovo, $60^{\circ} 05^{\prime} 24.5^{\prime}$ 'N $31^{\circ} 02^{\prime} 08.3$ ' E, 25 m, 15-30.VI 2016 (A. A. Knyshov) [1 ㅇ, UCRC]. Moskovskaya oblast': Noginskiy rayon, Fryazevo (M. E. Tretiakov): 25.VI-2.VII 2000 [1, , UCRC]; 25.VII 2002 [1 9 , UCRC]. Pushkinskiy rayon, Pushkino, Mamontovka, 5-15.VII 2001 (E.Ya. Shuvakhina) [1 +, UCRC]. Saint Petersburg, Kurortnyi rayon, Zelenogorsk, 12.VI 1927 (W. Hellén), at railway tracks [1 + , FMNH] (misidentified by W. Hellén as $A$. brachygaster). Sakhalinskaya oblast', Sakhalin Island, $6 \mathrm{~km}$ E of Sokol, near Belaya River, 16.VIII 2001 (D.J. Bennett, T.R. Anderson) [1 9 , CAS].

EXTRALIMITAL MATERIAL EXAMINED. Belgium: Liège, Wanze, Antheit, Corphalie (R. Detry): 14-28.VII 1989 [1 ᄋ, ISNB]; 6-20.X 1989 [1 9 , ISNB]. France: Languedoc, La Gard ou Gordon, 435' 45'’N 4²3'25' E, 10-13.VI 2005 (J. George) [1 +, UCRC].

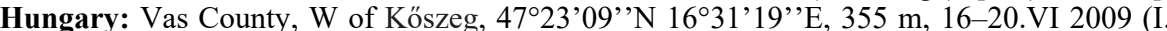
Mikó) [2 + , UCRC].

DIAGNOSIS. FEMALE (specimens from the European part of Russia, Belgium, France and Hungary). Body length (slide-mounted specimens) 0.8-0.9 mm. Antenna (Fig. 9) with scape (excluding radicle) $3.5-3.7 \times$ as long as wide, without distinct cross-ridges; F2-F6 longer than pedicel, F2 $4.2-5.0 \times$ as long as wide, F3 the longest funicular, F2 usually without mps but in one specimen with $1 \mathrm{mps}$, F3-F6 each with $2 \mathrm{mps}$; clava with $6 \mathrm{mps}, 3.8-4.1 \times$ as long as wide, 1.1-1.2× as long as combined length of F5 and F6. Fore wing (Fig. 10) 4.9$5.3 \times$ as long as wide; longest marginal seta $0.8-0.9 \times$ maximum wing width; marginal space separated from medial space by $1-2$ lines of setae. Hind wing (Fig. 10) $18-20 \times$ as long as wide; longest marginal seta 2.9-3.3× maximum wing width, disc with 1-2 irregular rows of setae apically. Metatarsomere 1 distinctly longer than metatarsomere 2 (Fig. 12). Ovipositor (Fig. 11) occupying usually about $0.9 \times$ length of gaster but occasionally its entire length (and thus not extending forward under mesosoma), not exserted beyond apex of gaster posteriorly, and about $1.0 \times$ length of metatibia.

MALE. Known (Huber \& Thuróczy, 2018).

DISTRIBUTION. Russia*; Austria, Belgium, Finland, France*, Germany, Hungary*, Netherlands, Norway, Romania, Sweden, United Kingdom. Some of these records (Noyes, 2019) may need verification.

HOST. Tenthredinidae (Hymenoptera): Macrophya punctumalbum (L., 1767) (Huber \& Thuróczy 2018) and also an unidentified sawfly species, probably either Tenthredo sp. or Rhogogaster sp. (Triapitsyn et al., 2020).

COMMENTS. I examined a card-mounted female (in FMNH) from Zelenogorsk, Kurortnyi rayon, Saint Petersburg, Russia, identified by W. Hellén as Anaphes brachygaster Debauche, 1948 and labeled only as "Terijoki. Hellén." and "140"; in the unpublished W. Hellén's notebooks in the FMNH, this number on light brown paper corresponds to the following information (M. Koponen, personal communication): collected on 12.VI 1927 at a side of railway tracks. Following slide-mounting, I determined it to belong to A. (Anaphes) crassipennis.

I also examined the following specimen that keys to A. (Anaphes) crassipennis in Huber \& Thuróczy (2018) but are more or less different from the positively identified ones of this species in one or several characteristics: Belgium: Walloon Brabant, Waterloo, 30.VIII-9.IX 1992, in garden (P. Dessart) [1 9 , ISNB]. 


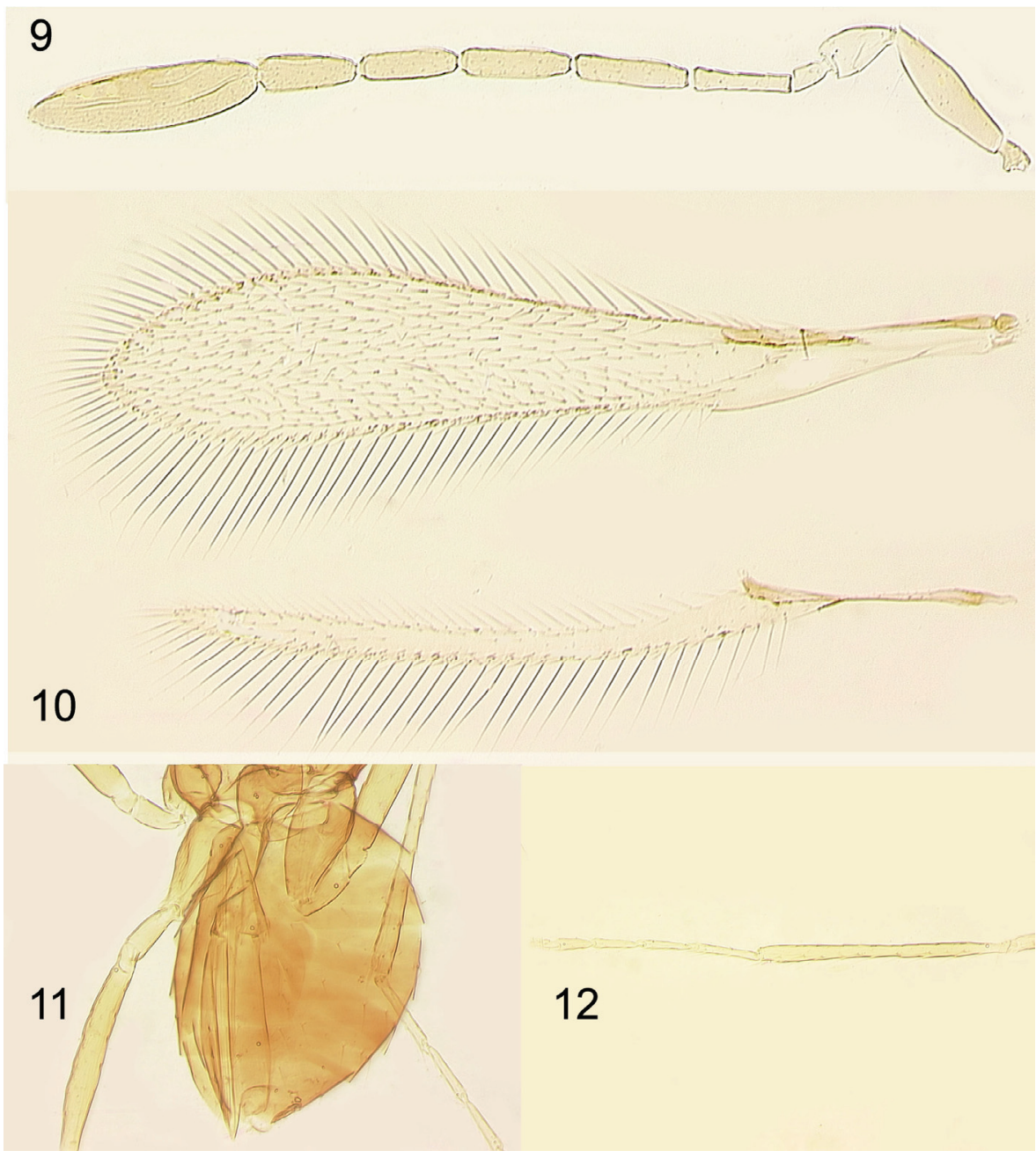

Figs 9-12. Anaphes (Anaphes) crassipennis, female (Mamontovka, Pushkino, Pushkinskiy rayon, Moskovskaya oblast', Russia). 9) Antenna, 10) wings, 11) ovipositor, 12) metatibia and metatarsus.

\section{Anaphes (Anaphes) csabai Triapitsyn, sp. n.}

http://zoobank.org/NomenclaturalActs/76D6FB95-F6DC-4AEB-8B4F-B5AA0BC67EE4 Figs $13-26$

TYPE MATERIAL. Holotype female [CAS] on slide (Fig. 15): Russia: Sakhalinskaya oblast', Kuril Islands, Shiashkotan Island, inland of SW Zakatnaya bukhta [Sunset Bay], $48^{\circ} 46.83^{\prime} \mathrm{N} 154^{\circ} 01.85^{\prime} \mathrm{E}, 29$.VII 2000 (D.J. Bennett), SA-00-DJB-033C (IKIP 2000). Paratypes: Russia: Sakhalinskaya oblast', Kuril Islands: Kharimkotan Island, Northwest corner: 


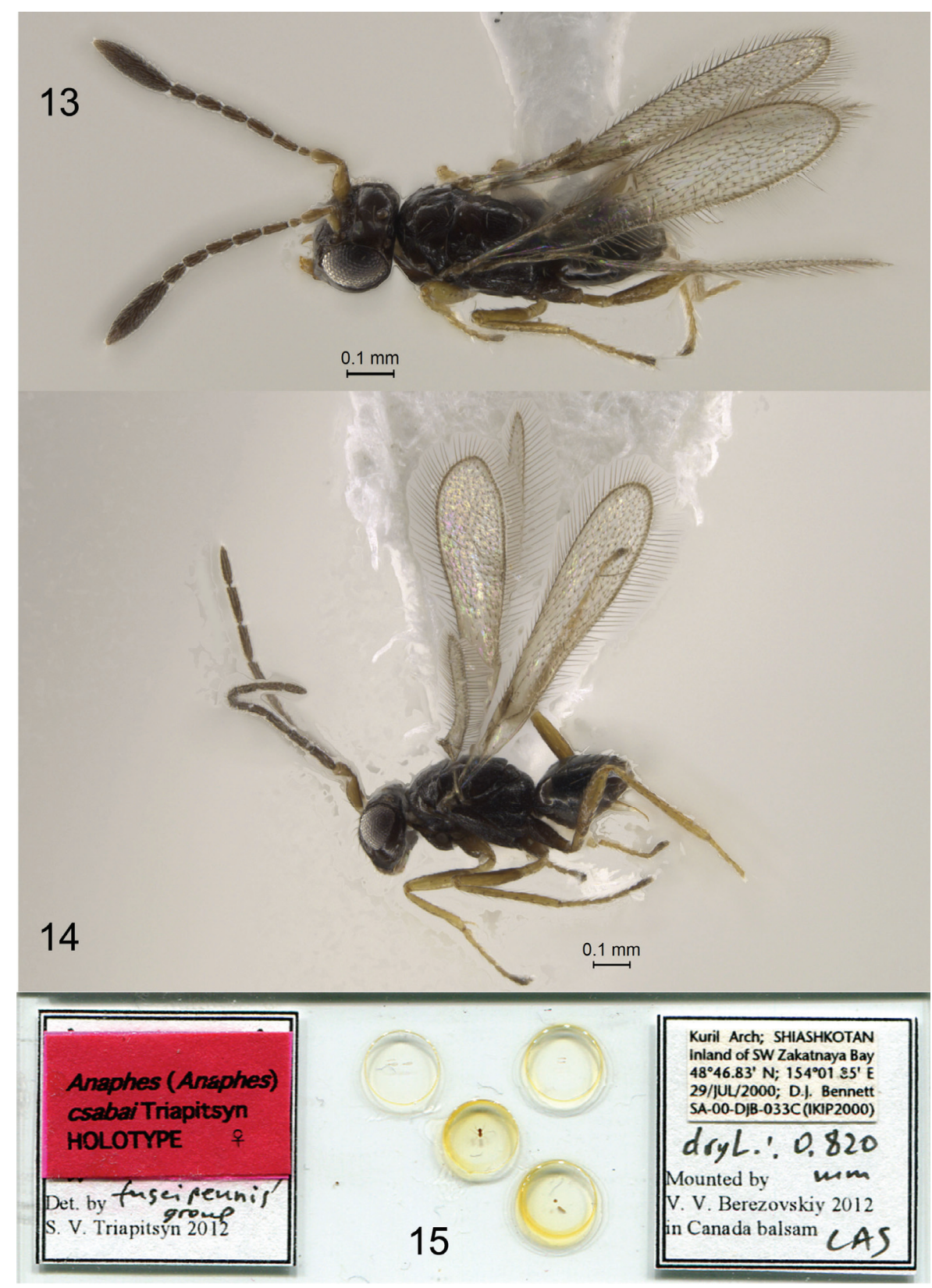

Figs 13-15. Anaphes (Anaphes) csabai sp. n. 13) Habitus of female in dorsal view (paratype, Raikoke Island, Kuril Islands, Sakhalinskaya oblast', Russia), 14) habitus of male in lateral view (paratype, Kharimkotan Island, Kuril Islands, Sakhalinskaya oblast', Russia), 15) holotype slide. 


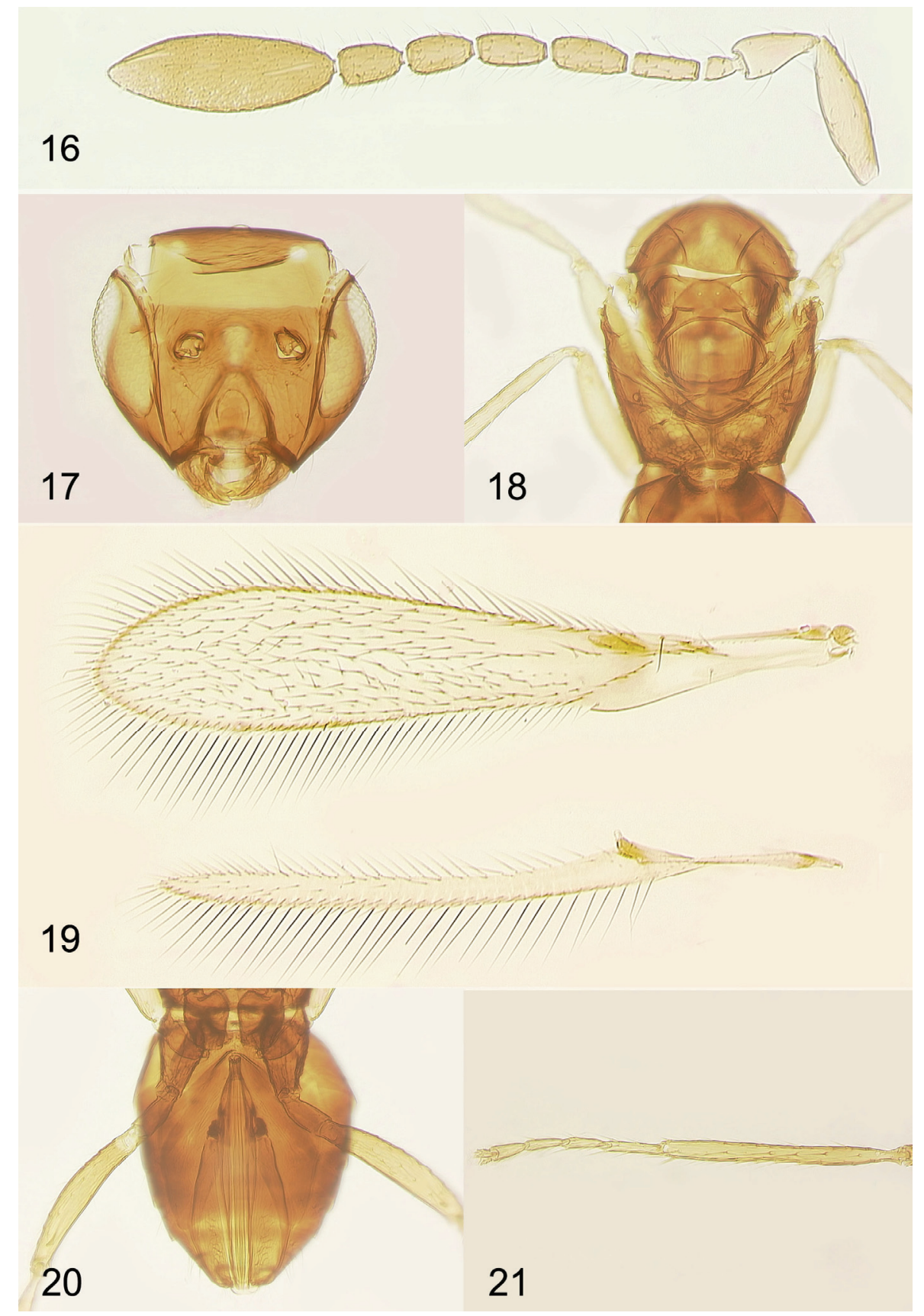

Figs 16-21. Anaphes (Anaphes) csabai sp. n., female (holotype). 16) Antenna, 17) head in frontal view, 18) mesosoma, 19) wings, 20) ovipositor, 21) metatibia and metatarsus. 
$49^{\circ} 08.67^{\prime} \mathrm{N} 154^{\circ} 27.44^{\prime} \mathrm{E}, 28 . \mathrm{VII} 2000$ (T.R. Anderson): KH-00-ATR-027 (IKIP 2000) [1 $\mathrm{P}$, $2 \delta^{\lambda}$ on points, CAS], KH-00-ATR-028 (IKIP 2000) [1 + , 1 o on points, CAS]; 49 $08.93^{\circ} \mathrm{N}$ 154²8.09’E, 28.VII 2000 (D.J. Bennett), KH-00-DJB-030 (IKIP 2000) [1 ô on point,

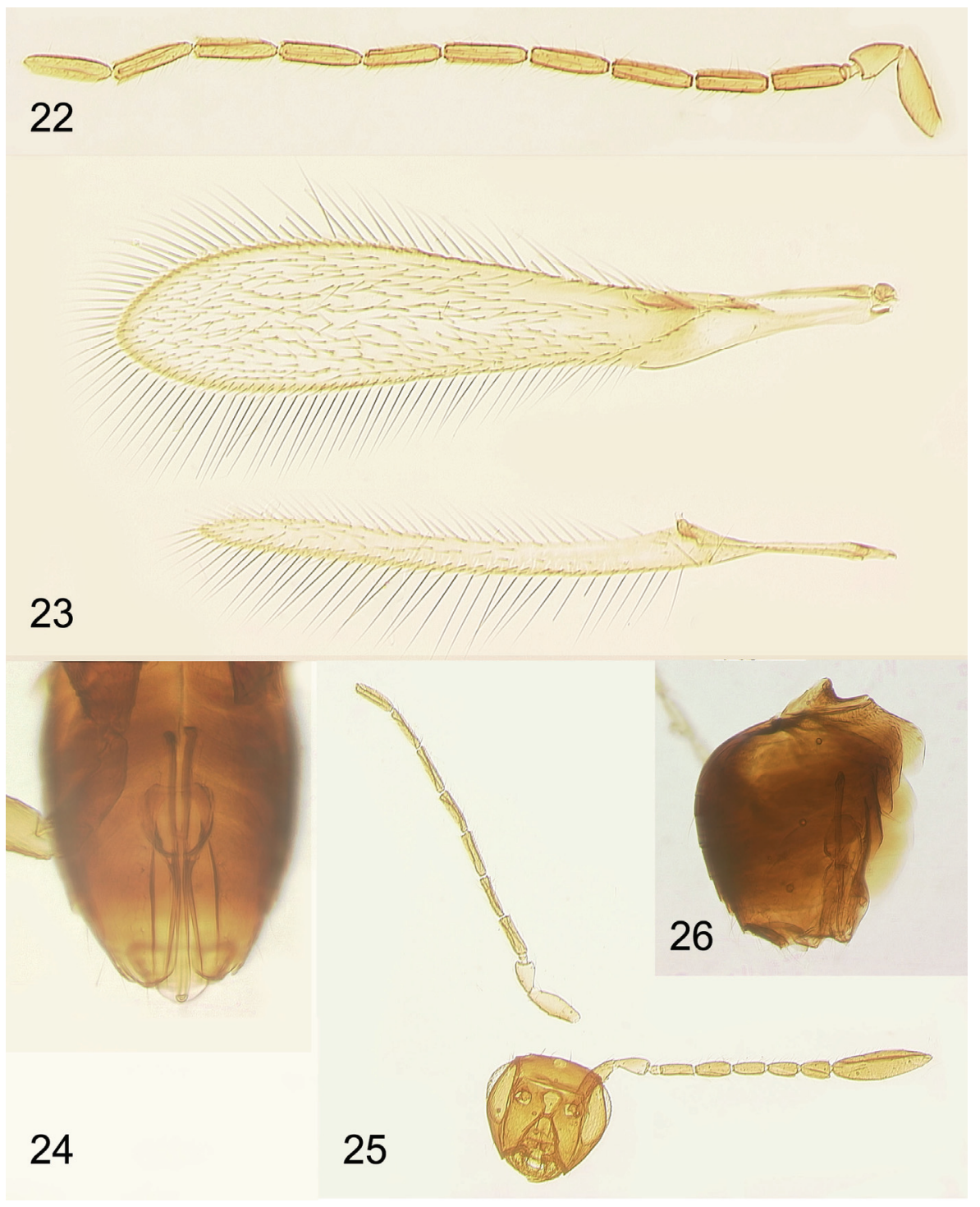

Figs 22-26. Anaphes (Anaphes) csabai sp. n. (paratypes, Kuril Islands, Sakhalinskaya oblast', Russia: 22-24, Shiashkotan Island; 25, 26, Onekotan Island). 22) Male antenna, 23) male wings, 24) male genitalia, 25) head and antennae of the gynandromorph, 26) genitalia of the gynandromorph. 
CAS]; 4908.75’N 154²7.64'E, 28.VII 2000 (D.J. Bennett), KH-00-DJB-029 (IKIP 2000)

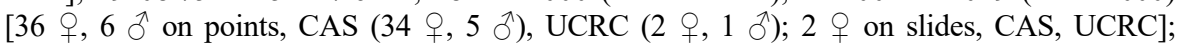
$49^{\circ} 08.60^{\prime} \mathrm{N} 154^{\circ} 28.10^{\prime} \mathrm{E}, 28 . \mathrm{VII} 2000$ (D.J. Bennett), KH-00-DJB-032C (IKIP-00) [2 2 on points, CAS]. Onekotan Island, inland and $\mathrm{S}$ of bukhta Nemo [Nemo Bay], 49 $36.57^{\prime} \mathrm{N}$ 154²49.24'E, 27.VII 2000 (T.R. Anderson), ON-00-ATR-023 (IKIP 2000) [1 gynandromorph on slide, CAS]. Raikoke Island, inland from eastern side, $48^{\circ} 17.90^{\prime} \mathrm{N} 153^{\circ} 15.67^{\prime} \mathrm{E}, 30$.VII 2000 (T.R. Anderson), RK-00-ATR-049 (IKIP 2000) [1 9 on point, CAS]. Shiashkotan Island,

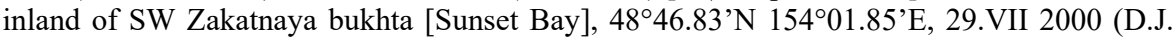

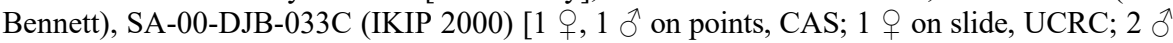
on slides, CAS, UCRC].

DESCRIPTION. FEMALE (holotype). Body black, scape, pedicel and F1 brown and remainder of flagellum dark brown, coxae dark brown and remainder of legs light brown to brown. Head (Fig. 17) with reticulate sculpture, more pronounced on vertex and occiput; mesosoma with conspicuous reticulate sculpture, stronger on metanotum and propodeum; coxae and base of first gastral tergum reticulate. Antenna (Fig. 16) with scape (excluding radicle) $3.5 \times$ as long as wide, almost smooth (faintly sculptured); pedicel at least a little longer than any funicular, F2 $2.7 \times$ as long as wide, F3 the longest funicular, F2 without mps and F3-F6 each with $2 \mathrm{mps}$; clava large, with 6 short mps, $2.8 \times$ as long as wide, a little longer than combined length of F4-F6. Mesosoma (Fig. 18) as long as metasoma (Fig. 20). Fore wing (Fig. 19) $5.1 \times$ as long as wide, with disc notably infuscate (brown); longest marginal seta about $0.8 \times$ maximum wing width; marginal space separated from medial space by 1 line of setae. Hind wing (Fig. 19) $18 \times$ as long as wide, with disc infuscate; longest marginal seta $2.8 \times$ maximum wing width, disc with 2 irregular rows of setae apically. Metatarsomere 1 distinctly longer than metatarsomere 2 (Fig. 21). Ovipositor (Fig. 20) occupying $0.85 \times$ length of gaster (and thus not extending forward under mesosoma), not exserted beyond apex of gaster posteriorly, and as long as metatibia.

Measurements $(\mu \mathrm{m})$ of the holotype. Body (of the dry-mounted specimen prior to slidemounting) 820; mesosoma 375; metatibia: 321; metasoma 375; ovipositor 318. Scape (minus radicle) 133; pedicel 73; F1 24; F2 57; F3 67; F4 62; F5 58; F6 55; clava 197. Fore wing 999:197; longest marginal seta 152. Hind wing 923:51; longest marginal seta 145.

Variation (paratypes). Body length (dry-mounted specimens, Fig. 13) $0.76-0.89 \mathrm{~mm}$. Slide-mounted specimen: antenna with scape (excluding radicle) $3.3 \times$ as long as wide, F2 $3.2 \times$ as long as wide, clava $3.0 \times$ as long as wide; fore wing $5.4 \times$ as long as wide; hind wing $20 \times$ as long as wide, longest marginal seta $3.1 \times$ maximum wing width; ovipositor occupying about $0.8 \times$ length of gaster.

MALE (paratypes). Body length (dry-mounted specimens, Fig. 14) 0.63-0.86 mm. Body black, scape and pedicel brown and flagellum dark brown, legs light brown to brown except coxae dark brown. Antenna (Fig. 22) with flagellum 10-segmented, scape 3.0-3.3× as long as wide. Fore wing (Fig. 23) 5.0× as long as wide. Genitalia (Fig. 24) length 212-222 $\mu \mathrm{m}$.

GYNANDROMORPH (paratype). This specimen has male genitalia (Fig. 26) and both female and male antennae, flagellum of the latter being only 8-segmented, with F1 very short and the apical segment clava-like (Fig. 25).

DIAGNOSIS. This species, which was identified as "Anaphes n. sp. 1" by J. T. Huber in 2003, is very similar to $A$. alaskae Annecke \& Doutt, 1961: 47-49, described from one female holotype (Figs 27-30) and 2 male paratypes (one of which is an allotype), all deposited in EMEC, and collected at Point Barrow, North Slope Borough, Alaska, USA (Annecke \& Doutt, 1961). In A. (Anaphes) csabai, the female antenna (Fig. 16) consistently bears $2 \mathrm{mps}$ on F3-F6, whereas that of A. (Anaphes) alaskae has $2 \mathrm{mps}$ on F6 and either $1 \mathrm{mps}$ on F4-F5 (Annecke \& Doutt, 1961) (that is probably incorrect as F3 of its holotype antenna appears to 
bear an mps, Fig. 27) or 1 mps on F3-F5 (Figs 32-33) (Huber, 1992). Both species have a similar sculpture on the mesosoma (Figs 18, 28, 31). Ultimately, a genetic comparison between these two nominal species using molecular methods would be needed to confirm their current separation based on the number of mps on these funiculars, which could potentially be subject of intraspecific variability.

ETYMOLOGY. This species is named after Csaba Thuróczy as an acknowledgment for his contributions to the taxonomy of the European Anaphes and hospitality during my first visit to Köszeg, Hungary, in September 2002.

HOSTS. Unknown.

COMMENTS. Anaphes alaskae was redescribed by Huber (1992: 44-45), who also identified female specimens from Northwest Territories and Yukon, Canada. Huber \& Thuróczy (2018: 24) and Huber et al. (2020: 65) listed it under the nominotypical subgenus as A. (Anaphes) alaskae; the former publication provided information on the types and the latter provided information on its taxonomic history and distribution. To facilitate its recognition, illustrated here are the antennae (Figs 32-33) and mesosoma (Fig. 31) of the slide-mounted female specimen of A. (Anaphes) alaskae in CNC, determined as A. alaskae in 1987 by J. T. Huber (Canada: Northwest Territories, Victoria Island, $71^{\circ} 17^{\prime} \mathrm{N} 114^{\circ} \mathrm{W}, 8^{-}$ 10.VII 1975 (G. \& M. Wood), "pan traps on south facing tundra slope"). Also illustrated here is the holotype of A. alaskae (Figs 27-30).

\section{Anaphes (Anaphes) flavipes (Foerster, 1841)}

Figs 34-42

Gonatocerus flavipes Foerster, 1841: 45.

Anaphes flavipes (Foerster) [or as Förster]: Riakhovskiy \& Krakhmal', 1978: 31-32 (host in Russia); Huber, 1992: 36 (key), 47-50 (taxonomic history, synonymy, type information, redescription, distribution, hosts, discussion), 74 (list), 100, 104 (illustrations); Samková et al., 2017: 677-690 (neotype designation, taxonomic history, synonymy, redescription, comparison with A. nipponicus Kuwayama, 1932, distribution, host associations); Triapitsyn \& Tselikh, 2019: 194 (list).

Anaphes lemae Bakkendorf, 1970: Trjapitzin, 1978: 531 (key, distribution in the European part of the USSR, hosts).

Anaphes auripes Walker, 1846: Thuróczy \& O’Connor, 2015: 56 (records from Ireland, lectotype habitus image).

Anaphes (Anaphes) flavipes (Foerster): Huber \& Thuróczy, 2018: 25-26 (list, type information, synonyms), 45 (key), 88 (illustration); Huber et al., 2020: 68-69 (taxonomic history, list of synonyms, hosts and distribution in the Nearctic region).

MATERIAL EXAMINED. Russia: Moskovskaya oblast', Noginskiy rayon, Fryazevo, 9.VII 2002, YPT (S.V. Triapitsyn) [1 9 , UCRC].

EXTRALIMITAL MATERIAL EXAMINED. Germany: North Rhine-Westphalia: Aachen, $50.77876^{\circ} \mathrm{N} 6.03816^{\circ} \mathrm{E}, 197 \mathrm{~m}, 3 . \mathrm{VI} 2011$, from eggs of Oulema sp. on barley (P. Janšta) [3 $9,3{ }^{\lambda}, \mathrm{UCRC}$; , near Aachen, $50.85732^{\circ} \mathrm{N} 6.40682^{\circ} \mathrm{E}, 103 \mathrm{~m}, 1 . \mathrm{VI} 2011$, from eggs of Oulema sp. on barley (P. Janšta) [3 9,3 $\hat{O}$, UCRC].

DIAGNOSIS. FEMALE. Diagnosed, redescribed and illustrated in detail by Samková et al. (2017). Here I provide only illustrations of the habitus (Fig. 34), antenna (Fig. 36), fore and hind wings (Fig. 37), metatarsus (Fig. 39) and ovipositor (Fig. 38) to facilitate its recognition while using the key. The combined length of F1 and F2 either slightly shorter than F3, as in the lectotype (Samková et al., 2017), or about as long as or slightly longer than F3. In the unusual specimen from Fryazevo, Moskovskaya oblast', Russia, F2 with 1 mps on one antenna only. 


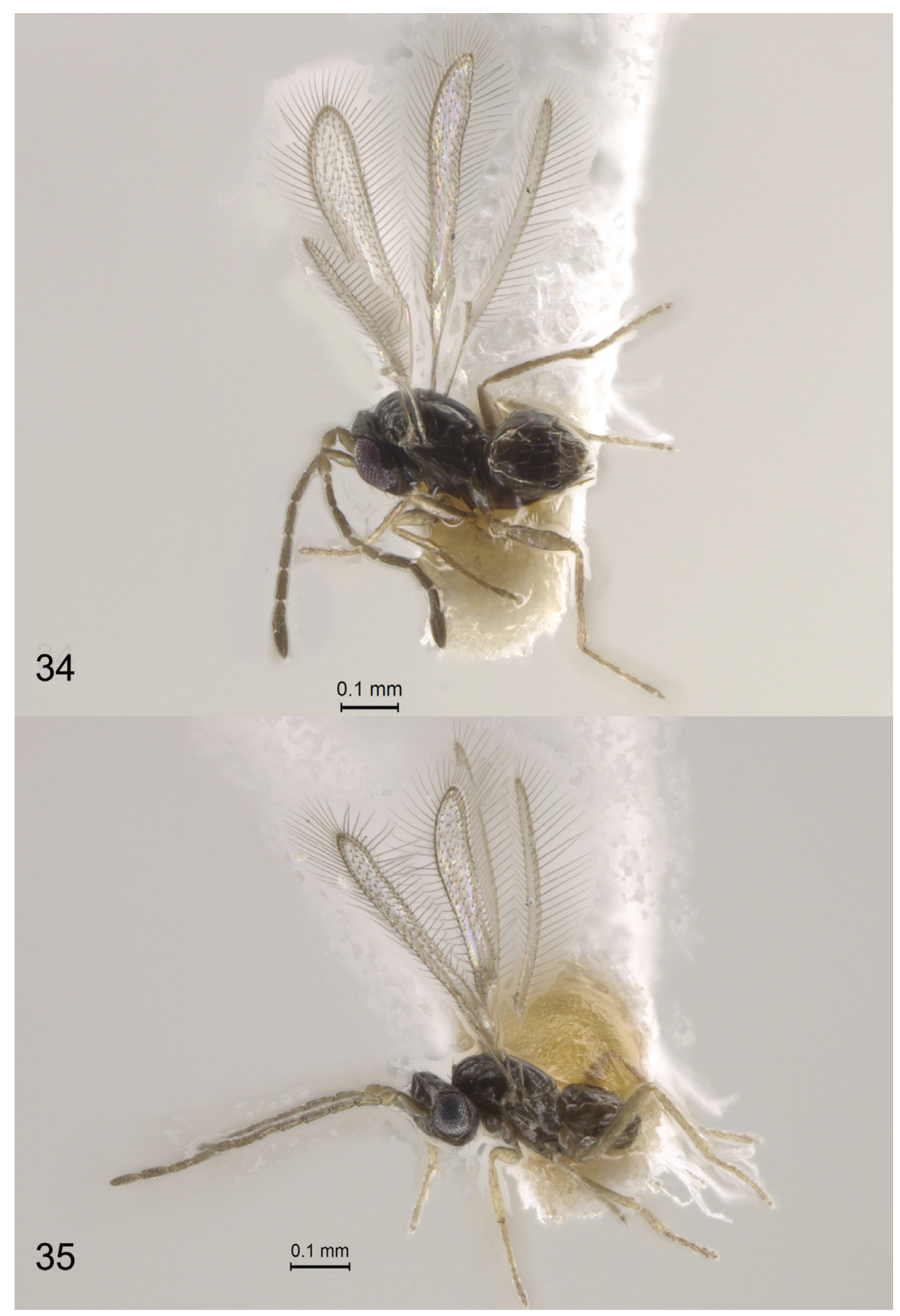

Figs 34, 35. Anaphes (Anaphes) flavipes, habitus in lateral view (near Aachen, North Rhine-Westphalia, Germany). 34) Female, 35) male. 
MALE. Known (Samková et al., 2017), who redescribed it. Here I provide only illustrations of the habitus (Fig. 35), head and antennae (Fig. 40), fore and hind wings (Fig. 42), and genitalia (Fig. 41) to facilitate its recognition.

DISTRIBUTION. Russia; Austria, Bulgaria, Czech Republic, France, Germany, Ireland, Italy, Netherlands, Poland, Romania, Serbia, Ukraine, United Kingdom. Widespread in Europe;

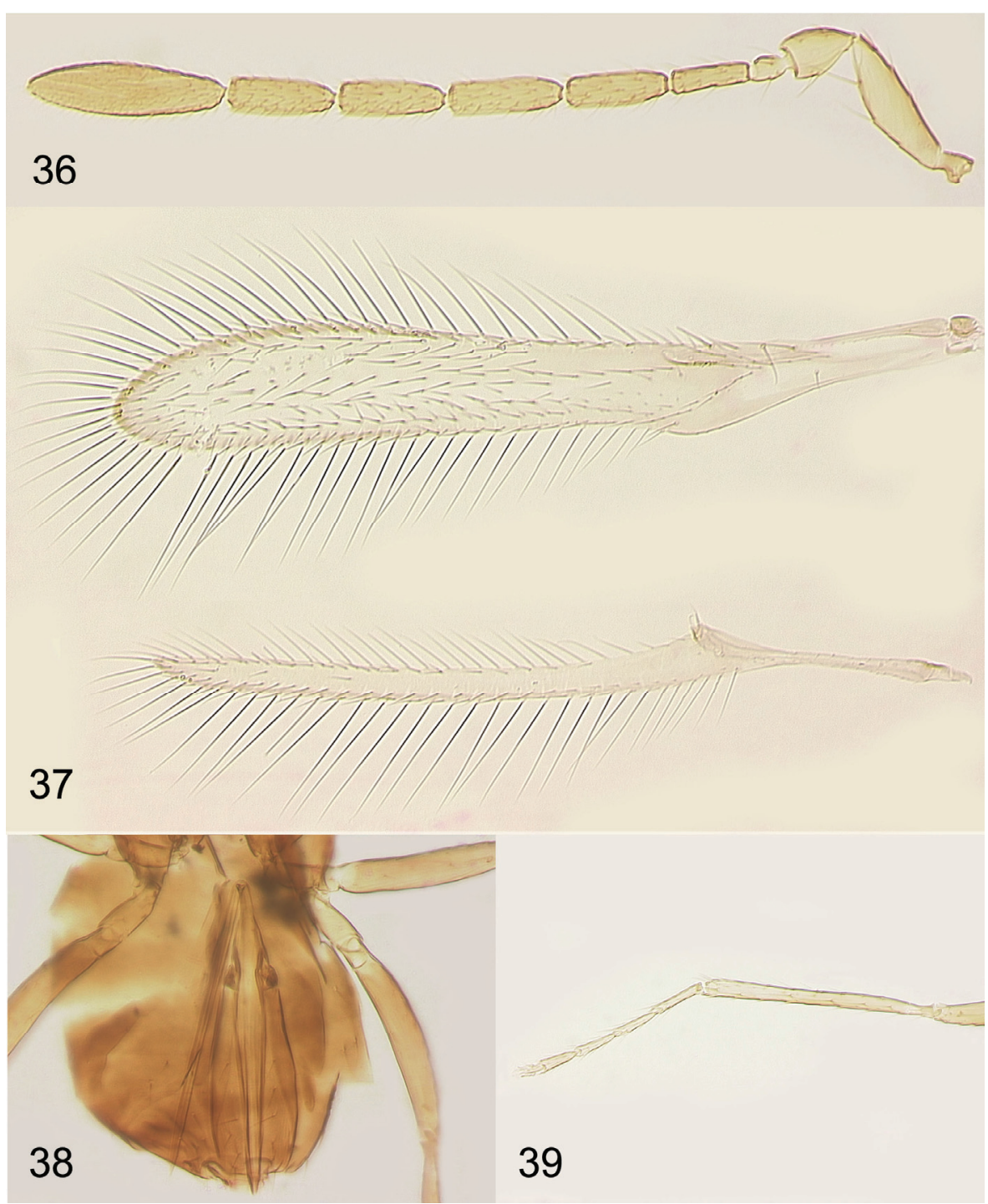

Figs 36-39. Anaphes (Anaphes) flavipes, female (Aachen and vicinity, North RhineWestphalia, Germany). 36) Antenna, 37) wings, 38) ovipositor, 39) metatibia and metatarsus. 
introduced into North America and established in eastern Canada and USA (Huber, 1992; Samková et al., 2017; Huber \& Thuróczy, 2018). Some other records (Noyes, 2019) need verification.

HOSTS. Chrysomelidae: Lema spp. and Oulema spp. including O. duftschmidi (Redtenbacher, 1874), O. gallaeciana (Heyden, 1870) and O. melanopus (L., 1758) (Donev, 1987; Huber, 1992; Samková et al., 2017, 2020; Huber et al., 2020).

Various aspects of biology and parasitism of A. (Anaphes) flavipes were studied by Donev (1987) and Samková et al. (2019a, 2019b, 2019c, 2020).

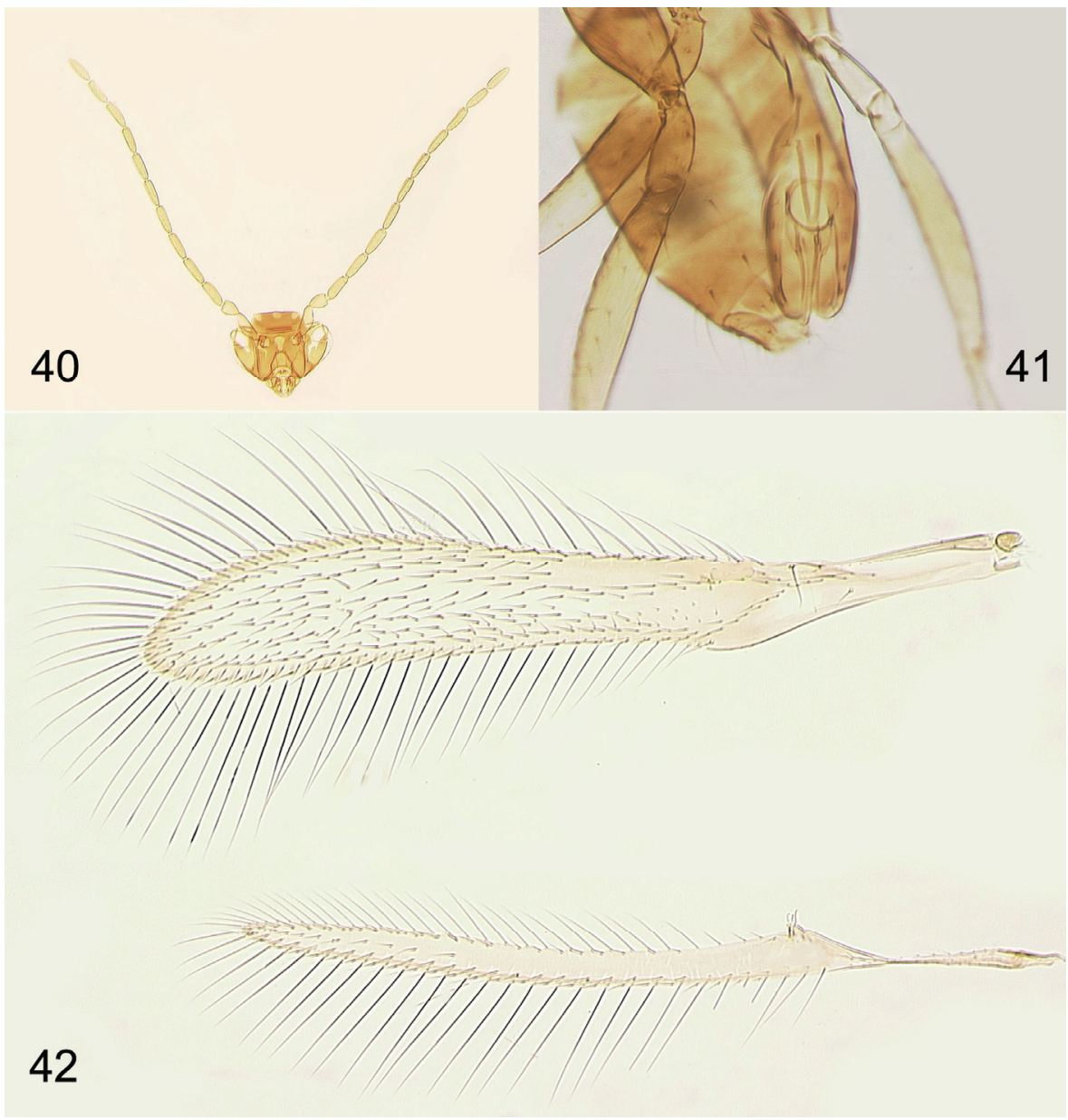

Figs 40-42. Anaphes (Anaphes) flavipes, male (Aachen and vicinity, North RhineWestphalia, Germany). 40) Head and antennae, 41) genitalia, 42) wings.

COMMENTS. As noted above in the Introduction, the record of this species from Leningradskaya oblast' of Russia by Hellén (1974) was based on a misidentification. Indeed, I examined a card-mounted female specimen (in FMNH) from Zelenogorsk, Kurortnyi rayon, 
Saint Petersburg, Russia, labeled only as "flavipes 25, 3,2" (in blue ink, "autumnalis" in pencil on the undesrside), "Terijoki. Hellén.", and "355"; in the unpublished W. Hellén's notebooks in the FMNH, this number on light brown paper corresponds to the following information (M. Koponen, personal communication): collected on 16.VI 1927 in a garden. It is definitely not $A$. (Anaphes) flavipes because it bears $2 \mathrm{mps}$ on F2 of the only remaining antennal flagellum and also has a very long fore wing. Following slide-mounting, I confirmed its identity as A. (Patasson) lineipennis (Soyka, 1949); it is a new record of this species from Russia.

Due to significant intraspecific variability in females of $A$. (Anaphes) flavipes, as documented by Samková et al. (2017), I find it very difficult, if not impossible, to separate this species in the key from A. (Anaphes) nipponicus, A. (Anaphes) regulus and A. (Anaphes) stygius based on any more or less stable, measurable morphological characteristics, as these seem to overlap, including those used in the key by Huber \& Thuróczy (2018). Thus, I agree with the opinion of Huber \& Thuróczy (2018: 44) that the features they used to distinguish $A$. (Anaphes) flavipes, A. (Anaphes) medius, A. (Anaphes) regulus, and A. (Anaphes) stygius are weak, although perhaps I was able to recognize and separate $A$. (Anaphes) medius in the key with some confidence. Ultimately, validity of these nominal species will need to be tested using genetic evidence, which for now is missing.

Those female specimens of $A$. (Anaphes) flavipes and A. (Anaphes) nipponicus that have a very short F2, so that the combined length of F1 and F2 is slightly shorter than F3, as in the lectotype of $A$. (Anaphes) flavipes (Samková et al., 2017), are very difficult to distinguish from the females of A. (Anaphes) gauthieri Debauche, 1948. The clava of the female antenna of the latter species is relatively slightly shorter, being at most $3.0 \times$ as long as wide, whereas in A. (Anaphes) flavipes it is at least $3.2 \times$ as long as wide (Samková et al., 2017) and in $A$. (Anaphes) nipponicus it is at least $3.1 \times$ as long as wide.

\section{Anaphes (Anaphes) fuscipennis Haliday, 1833}

Figs 43-46

Anaphes fuscipennis Haliday, 1833: 346.

Anaphes (Anaphes) fuscipennis Haliday: Graham, 1982: 206-208 (taxonomic history, synonymy, designation of lectotype and paralectotypes, discussion); Huber \& Thuróczy, 2018: 26 (list, type information, synonyms), 45 (key), 89-90 (illustrations); Huber et al., 2020: 69 (taxonomic history, hosts and distribution in the Nearctic region, list of synonyms).

Anaphes fuscipennis Haliday: Huber, 1992: 36 (key), 38-41 (taxonomic history, synonymy, type information, redescription, distribution, hosts, discussion), 74 (list), 95-99 (illustrations); Huber et al., 2011: 122-125 (proposed designation of A. fuscipennis as the type species of Anaphes); ICZN, 2017: 122-124 (designation of A. fuscipennis as type species of Anaphes).

TYPE MATERIAL EXAMINED. Paralectotypes of Anaphes fuscipennis Haliday, here designated: apparently 4 females and 5 males [MVMA] on individual F. Walker-style cards on 3 pins ( 3 cards per pin) without any original labels, labeled later: "NATIONAL MUSEUM VICTORIA 50718-30 Anaphes fuscipennis Europe"; some cards have illegible numbers in pencil near the pinholes. I consider these to be part of the original syntype series of A. fuscipennis because the numbers written in pencil are characteristic of F. Walker specimens, and it is known that A. H. Haliday, F. Walker, and J. Curtis exchanged/shared specimens freely (Graham, 1982). Moreover, the almost certain type locality of the lectotype female of $A$. fuscipennis, designated by Graham (1982), was vicinity of Southgate (formerly in Middlesex, 
now within London Borough of Enfield, England, United Kingdom) (Huber \& Thuróczy, 2018), one of F. Walker's favorite collecting sites (Graham, 1982). It is likely that more than one species of Anaphes are present among these nine paralectotypes of A. fuscipennis in MVMA.

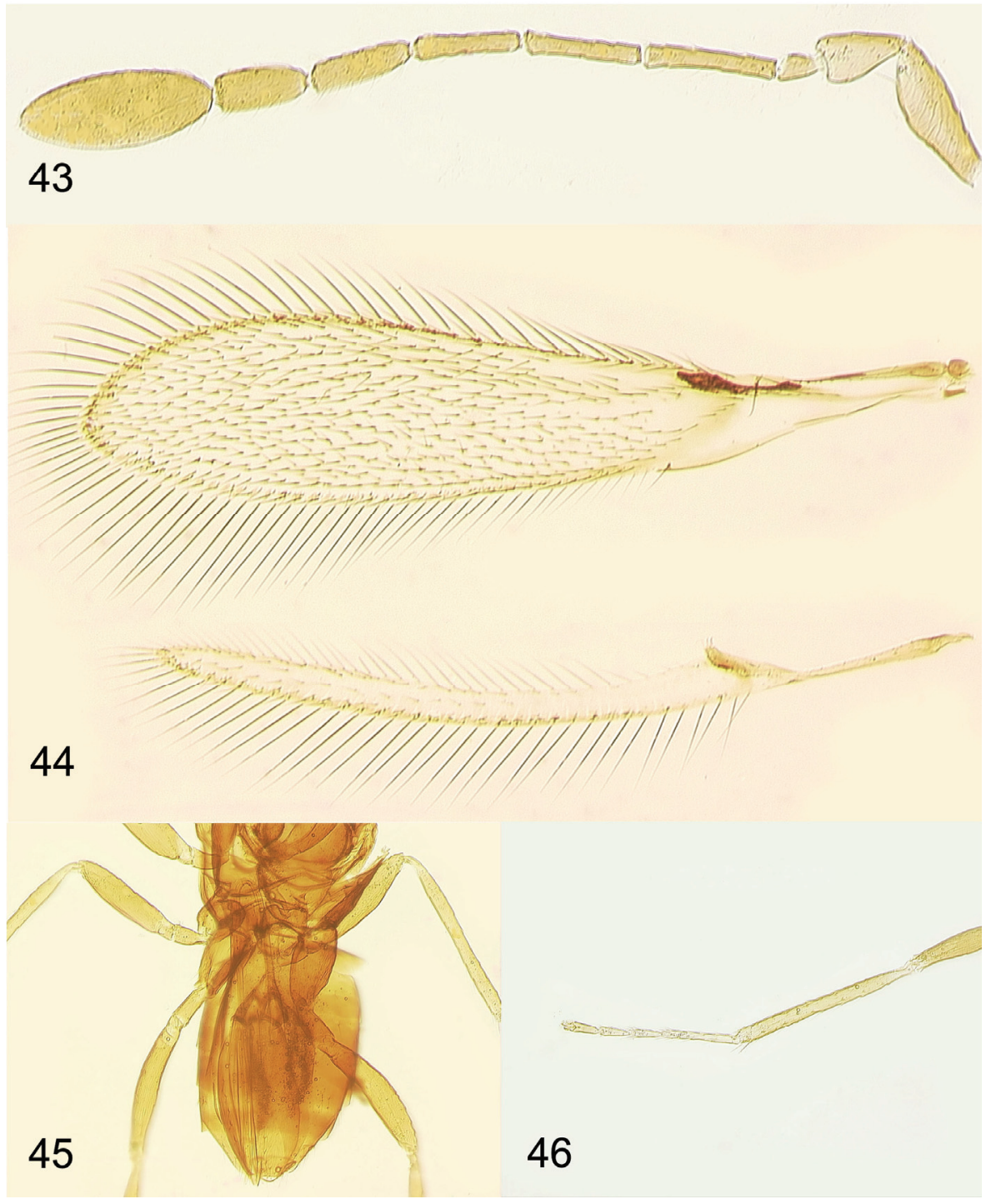

Figs 43-46. Anaphes (Anaphes) fuscipennis, female (Vaganovo, Vsevolozhskiy rayon, Leningradskaya oblast', Russia). 43) Antenna, 44) wings, 45) ovipositor, 46) metatibia and metatarsus. 
MATERIAL EXAMINED. Russia: Leningradskaya oblast', Vsevolozhskiy rayon, Vaganovo, $60^{\circ} 05^{\prime} 24.5^{\prime}$ 'N 31 $1^{\circ} 02^{\prime} 08.3^{\prime}$ 'E, 25 m, 15-30.VI 2016 (A.A. Knyshov) [1 ㅇ, UCRC].

EXTRALIMITAL MATERIAL EXAMINED. Spain: Navarre, Iratibizkar, $1120 \mathrm{~m}$, 16.V 2000, in Fagus sylvatica forest (E. Baquero) [1 9 , UCRC]. USA: New York, Seneca County, 4.5 mi. SW of Lodi, 42 ${ }^{\circ} 33^{\prime} 45.5^{\prime}$ 'N 76 52'27.2' 'W, 202 m, Silver Thread Vineyard, 24.V 2011 (S.V. Triapitsyn, G. Loeb) [1 9 , UCRC].

DIAGNOSIS. FEMALE (specimens from the European part of Russia and Spain). Body length (slide-mounted specimens) $0.83-0.9 \mathrm{~mm}$. Antenna (Fig. 43) with scape (excluding radicle) $2.8-3.0 \times$ as long as wide, with cross-ridges on inner suface; F2-F5 longer than pedicel, F2 5.1-5.5× as long as wide and the longest funicular, F5 and F6 notably wider than preceding funiculars, mps on F5 (usually 1 but 2 on one antenna in the specimen from Spain) and F6 (2); clava with $6 \mathrm{mps}, 2.6-2.7 \times$ as long as wide, about as long as combined length of F5 and F6. Fore wing (Fig. 44) 4.5-4.6× as long as wide, with posterior margin slightly outward (convex); longest marginal seta $0.8-1.0 \times$ maximum wing width; marginal space separated from medial space by $1-2$ lines of setae. Hind wing (Fig. 44) $18-19 \times$ as long as wide; longest marginal seta 2.9-3.3× maximum wing width, disc with 1 irregular row of setae and a few additional setae apically. Metatarsomere 1 much longer than metatarsomere 2 (Fig. 46). Ovipositor (Fig. 45) occupying entire length of gaster, extending forward under mesosoma slightly anterior to level of base of mesocoxa, not or just barely exserted beyond apex of gaster posteriorly, and 1.5-1.7× length of metatibia.

MALE. Known (Graham, 1982; Huber \& Thuróczy, 2018).

DISTRIBUTION. Russia*; Algeria, Austria, Canada, Germany, Hungary, Ireland, Israel, Netherlands, Poland, Spain, Sweden, Tunisia, United Kingdom, USA. In the Palaearctic region, A. fuscipennis has a wide north-south distribution from Sweden to Algeria and Tunisia and east-west distribution from Spain to Hungary (Huber \& Thuróczy, 2018). Introduced into North America and established in Canada and USA (Huber, 1992; Huber \& Thuróczy, 2018) although it could also be a species with a natural Holarctic distribution. Other published records (Noyes, 2019) need verification.

HOSTS. Curculionidae (Huber, 1992; Huber et al., 2020).

COMMENTS. As noted above in the Introduction, the records of this species from Leningradskaya oblast' of Russia and also from Finland by Hellén (1974) were based on misidentifications (Huber, 1992), who stated that Hellén's redescription applied to another species, not $A$. fuscipennis (in fact, to a mixture of at least two different species). Indeed, I examined a card-mounted female specimen (in FMNH) from Zelenogorsk, Kurortnyi rayon, Saint Petersburg, Russia, labeled only as "Terijoki. Hellén." and "136"; in the unpublished W. Hellén's notebooks in the FMNH, this number on light brown paper corresponds to the following information (M. Koponen, personal communication): collected on 12.VI 1927 at a side of railway tracks. It is definitely not $A$. (Anaphes) fuscipennis; following slide-mounting, I determined it to belong to A. (Anaphes) medius Soyka, 1946. The same likely applies to Hellén's (1974) record of $A$. pratensis Foerster, 1847, a synonym of $A$. (Anaphes) fuscipennis (Huber \& Thuróczy, 2018), from Leningradskaya oblast'. I examined a card-mounted female specimen (in FMNH) from Vyborg, Vyborgskiy rayon, Leningradskaya oblast', labeled only as "Vyborg" and "Hellén", which unfortunately has no antennae and thus is impossible to identify; it is definitely some other species of Anaphes because the posterior margin of the fore wing is not slightly convex as in A. (Anaphes) fuscipennis. The date of collection of this incomplete specimen is unknown; W. Hellén collected in Vyborg in 1920, 1927 and 1936 (M. Koponen, personal communication). 


\section{Anaphes (Anaphes) gauthieri Debauche, 1948}

Figs 47-50

Anaphes (Anaphes) gauthieri Debauche, 1948: 171-172, plates XVI-XVII (illustrations).

Anaphes devillei Debauche, 1948 (misidentification): Hellén, 1974: 27 (in part, record from "Terijoki”, USSR, female only).

Anaphes gauthieri Debauche: Huber, 1992: 74 (list).

Anaphes (Anaphes) gauthieri Debauche: Huber \& Thuróczy, 2018: 26 (list, type information, synonyms), 45 (key), 91 (illustration).

MATERIAL EXAMINED. Russia: Moskovskaya oblast', Pushkinskiy rayon, Pushkino, Mamontovka, 10-20.VII 2000 (E.Ya. Shuvakhina) [1 +, UCRC]. Primorskii krai, Ussuriyskiy rayon, Gornotayozhnoye, $43.66^{\circ} \mathrm{N} \mathrm{132.25^{ \circ } \mathrm { E } , 2 0 0 \mathrm { m } , 1 5 - 3 0 . I X} 2000$ (M.V. Michailovskaya) [3 +, IBPV, UCRC]. Saint Petersburg, Kurortnyi rayon, Komarovo, 24.VI 1927 (W. Hellén), dunes [1 $9, \mathrm{FMNH}]$ (misidentified by W. Hellén as A. devillei). Stavropol'skii krai: Achikulak, 21.VIII 2002 (V.V. Kostjukov) [1 , , UCRC]. Prietokskiy, 12.VIII 2003 (V.V. Kostjukov) [1 +, UCRC].

EXTRALIMITAL MATERIAL EXAMINED. Italy: Lazio, Viterbo Prov., Ponte San

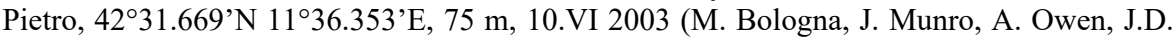

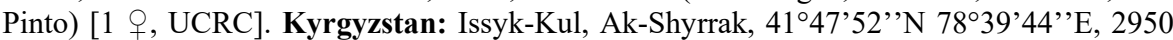
m, 4.VI 1999 (C.H. Dietrich) [5 +, UCRC]. Republic of Korea: Gyeonggi-Do, Suwon-si, Seodun-dong, Seoul National University, 17.IX 2001 (J.-W. Kim) [1 + , UCRC].

DIAGNOSIS. FEMALE (specimens from the European part of Russia and Italy). Antenna (Fig. 47) with scape (excluding radicle) $2.5-3.4 \times$ as long as wide, smooth; F2 shorter than pedicel and F3-F6 at least as long as pedicel (usually longer), F2 2.0-2.6× as long as wide, combined length of F1 and F2 at least slightly shorter than F3, F3 the longest funicular, F3-F6 each with $2 \mathrm{mps}$; clava with $6 \mathrm{mps}, 2.6-3.0 \times$ as long as wide, $0.9-1.1 \times$ as long as combined length of F5 and F6. Fore wing (Fig. 48) 5.4-6.5× as long as wide; longest marginal seta 1.3$1.5 \times$ maximum wing width; marginal space separated from medial space by 2 lines of setae. Hind wing (Fig. 48) $19-22 \times$ as long as wide; longest marginal seta $3.5-4.1 \times$ maximum wing width, disc usually with only admarginal rows of setae but sometimes with an additional short, irregular row of setae at apex. Metatarsomere 1 slightly shorter than metatarsomere 2 (Fig. 50). Ovipositor (Fig. 49) occupying $0.7-0.9 \times$ length of gaster (and thus not extending forward under mesosoma), not exserted beyond apex of gaster posteriorly, and $0.9-1.2 \times$ length of metatibia.

In the specimens from the eastern Palaearctic region, scape (minus radicle) relatively a little longer (up to $4.2 \times$ as long as wide) and clava $3.1 \times$ as long as wide.

MALE. Known (Debauche, 1948)

DISTRIBUTION. Russia*; Austria, Belgium, Germany, Italy*, Kyrgyzstan*, Netherlands, Poland, Republic of Korea*, Serbia. Some other records (Noyes, 2019) need verification.

HOST. Curculionidae: Isochnus sequensi (Stierlin, 1894) (Noyes, 2019).

COMMENTS. One specimen, which has $1 \mathrm{mps}$ on F4 on one antenna but none on the other (Russia: Moskovskaya oblast', Noginskiy rayon, Fryazevo, 9.VII 2002 (S.V. Triapitsyn) $[1$ +, $\mathrm{UCRC}]$ ), otherwise fits $A$. (Anaphes) gauthieri better than A. (Anaphes) ovipositor Soyka, 1946 as it has a very short F2.

I examined two card-mounted specimens, a female and a male (in FMNH) from Komarovo, Kurortnyi rayon, Saint Petersburg, Russia, both identified by W. Hellén as Anaphes devillei Debauche, 1948 and labeled only as "Terijoki Hellén.", the male standing under W. Hellén's number 827 on faded light brown paper; in the unpublished W. Hellén's notebooks 
in the FMNH, this number on this color of paper corresponds to the following information (M. Koponen, personal communication): collected on 24.VI 1927 in Kellomäki (dunes). Following slide-mounting, I determined the female to belong to A. (Anaphes) gauthieri. The male, an Anaphes sp., is not identifiable even to subgenus, so it was not slide-mounted.

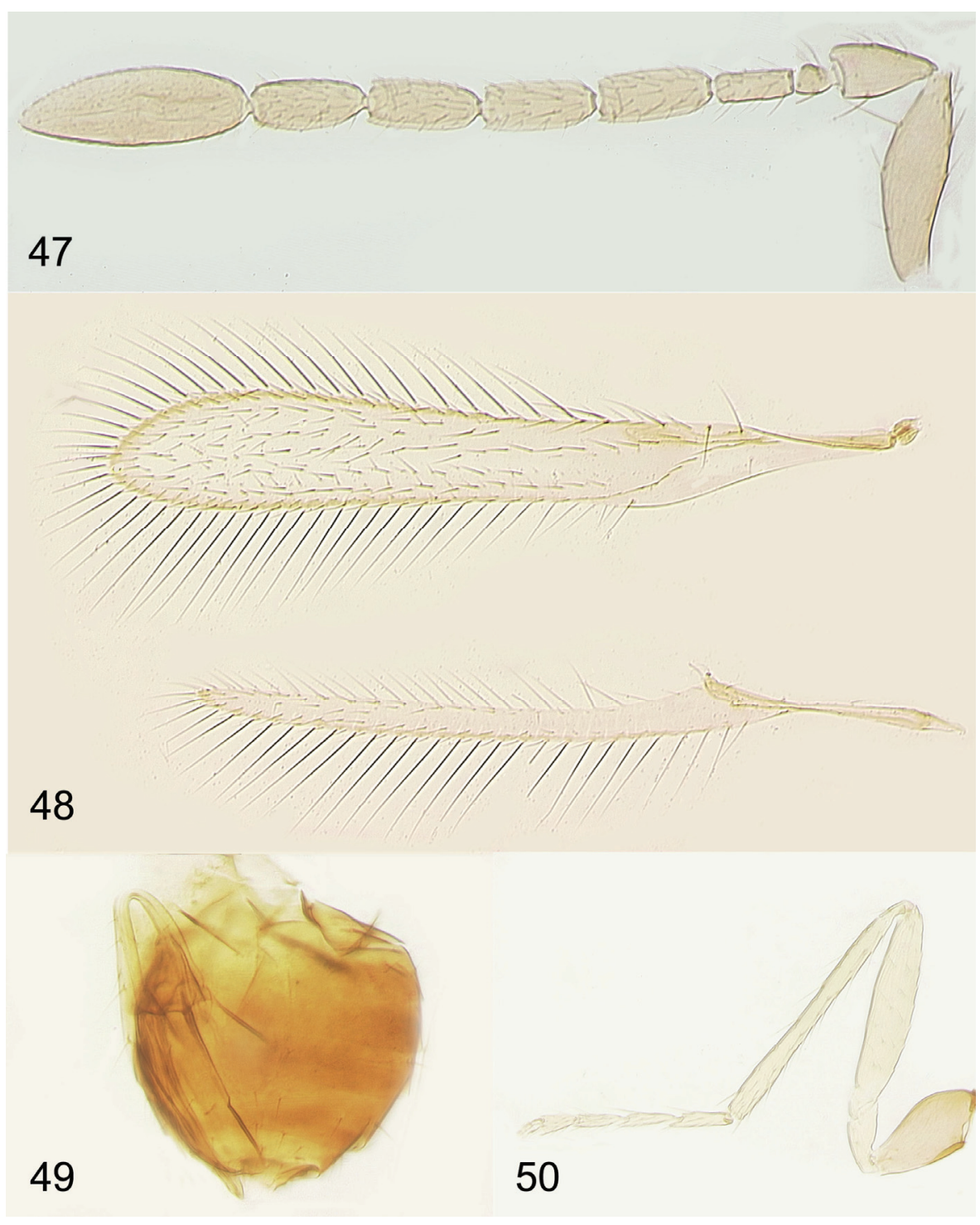

Figs 47-50. Anaphes (Anaphes) gauthieri, female (Prietokskiy, Stavropol'skii krai, Russia). 47) Antenna, 48) wings, 49) ovipositor, 50) hind leg. 


\section{Anaphes (Anaphes) globosicornis (Soyka, 1949)}

Figs 51-54

Mymar globosicornis Soyka, 1949: 322-323.

Anaphes globosicornis (Soyka): Huber, 1992: 74 (list).

Anaphes (Anaphes) globosicornis (Soyka): Huber \& Thuróczy, 2018: 26 (list, type information), 45 (key), 92 (illustration).

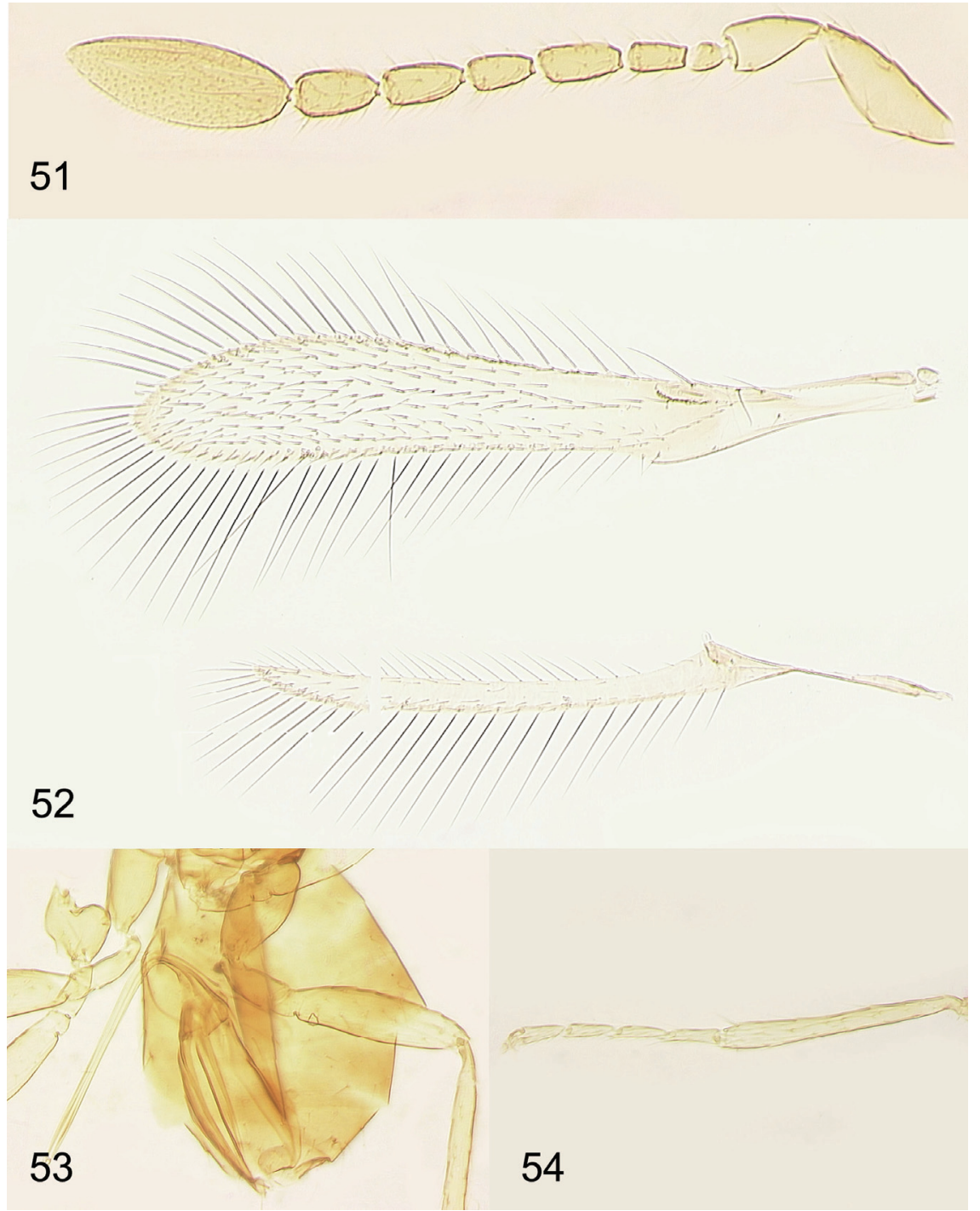

Figs 51-54. Anaphes (Anaphes) globosicornis, female (Mamontovka, Pushkino, Pushkinskiy rayon, Moskovskaya oblast', Russia). 51) Antenna, 52) wings, 53) ovipositor, 54) metatibia and metatarsus. 
MATERIAL EXAMINED. Russia: Moskovskaya oblast', Pushkinskiy rayon, Pushkino, Mamontovka, 10-20.VII 2000 (E.Ya. Shuvakhina) [1 q, UCRC].

DIAGNOSIS. FEMALE (specimen from the European part of Russia). Body length (slidemounted specimen) $0.67 \mathrm{~mm}$. Antenna (Fig. 51) with scape (excluding radicle) $2.9 \times$ as long as wide, smooth; all funiculars shorter than pedicel, F2 2.0 $\times$ as long as wide, F3 and F6 the longest funiculars, F3, F5 and F6 each with $2 \mathrm{mps}$; clava with $6 \mathrm{mps}, 2.7 \times$ as long as wide, $1.4 \times$ as long as combined length of F5 and F6. Fore wing (Fig. 52) $6.2 \times$ as long as wide; longest marginal seta $1.5 \times$ maximum wing width; marginal space separated from medial space by 1-2 lines of setae. Hind wing (Fig. 52) $17.5 \times$ as long as wide; longest marginal seta $3.9 \times$ maximum wing width, disc with 1 irregular row of setae apically. Metatarsomere 1 slightly shorter than metatarsomere 2 (Fig. 54). Ovipositor (Fig. 53) occupying about $0.7 \times$ length of gaster (and thus not extending forward under mesosoma), not exserted beyond apex of gaster posteriorly, and $1.0 \times$ length of metatibia.

MALE. Unknown.

DISTRIBUTION. Russia*; Austria (Huber \& Thuróczy, 2018).

HOSTS. Unknown.

Anaphes (Anaphes) maxim Triapitsyn, sp. $\mathbf{n}$.

http://zoobank.org/NomenclaturalActs/5EC4CFD0-7160-4F11-8625-76742D6B985F

Figs 55-60

TYPE MATERIAL. Holotype female [ZIN] on slide (Fig. 55): Russia: Primorskii krai, Ussuriyskiy rayon, Gornotayozhnoye, $43.66^{\circ} \mathrm{N} 132.25^{\circ} \mathrm{E}, 200 \mathrm{~m}, 15-17$. VII 2000 (M.V. Michailovskaya), MT. Paratypes (all on slides): Russia: Primorskii krai, Ussuriyskiy rayon, Gornotayozhnoye, $43.66^{\circ} \mathrm{N} 132.25^{\circ} \mathrm{E}, 200 \mathrm{~m}$ (M.V. Michailovskaya): 26-31.VIII 2000, MT [1 ㅇ, UCRC]; 15-30.IX 2000, MT [1 ㅇ, IBPV]; 5-20.X 2002, YPT [1 ㅇ, UCRC]. Sakhalinskaya oblast', Sakhalin Island, $2-3 \mathrm{~km}$ E of Sokol, a tributary of Belaya River, $47^{\circ} 14.385^{\prime} \mathrm{N}$ 14246.347’E, 18.VII 2001 (N. Minakawa), MT, SK-01-DJB-128C [1 +, CAS].

DESCRIPTION. FEMALE (holotype). Body dark brown, appendages brown except scape and pedicel light brown and coxae dark brown. Vertex with mesh-like sculpture, mesoscutum and scutellum with faint sculpture. Antenna (Fig. 56) with scape (excluding radicle) $4.7 \times$ as long as wide, almost smooth; F1 longer than wide, F2-F6 much longer than pedicel, F2 4.5× as long as wide, F3 the longest funicular, F2-F6 each with $2 \mathrm{mps}$; clava with $6 \mathrm{mps}, 3.9 \times$ as long as wide, almost as long as combined length of F5 and F6 (just slightly shorter). Fore wing (Fig. 57) $7.2 \times$ as long as wide; longest marginal seta $1.3 \times$ maximum wing width; marginal space separated from medial space by 2 complete lines of setae. Hind wing (Fig. 58) almost $23 \times$ as long as wide; longest marginal seta $3.9 \times$ maximum wing width, disc with 1 short row of 3 or 4 setae apically. Metatarsomere 1 about as long as metatarsomere 2 (Fig. 60). Ovipositor (Fig. 59) occupying about $0.6 \times$ length of gaster (and thus not extending forward under mesosoma), not exserted beyond apex of gaster posteriorly, and $0.7 \times$ length of metatibia.

Measurements $(\mu \mathrm{m})$ of the holotype. Mesosoma 303; metatibia: 297; gaster 327; ovipositor 206. Scape (minus radicle) 128; pedicel 54; F1 24; F2 82; F3 89; F4 85; F5 82; F6 76; clava 154. Fore wing 867:121; longest marginal seta 160 . Hind wing $824: 36$; longest marginal seta 139.

Variation (paratypes). Body length $0.72-0.78 \mathrm{~mm}$ (slide-mounted specimens). Antenna with F2 3.5-3.6× as long as wide, F2-F4 often subequal in length and the longest funiculars, clava about $3.6 \times$ as long as wide. Fore wing $0.79-0.92 \mathrm{~mm}$ long, $7.0-7.1 \times$ as long as wide, longest marginal seta $1.3-1.4 \times$ maximum wing width, marginal space separated from medial space by 1 or 2 lines of setae. Hind wing 20-23× as long as wide, longest marginal seta 3.3$3.8 \times$ maximum wing width, disc with 1 irregular row of 4 to 8 setae apically. Ovipositor $0.7-0.8 \times$ length of metatibia (usually $0.7 \times$ ). 

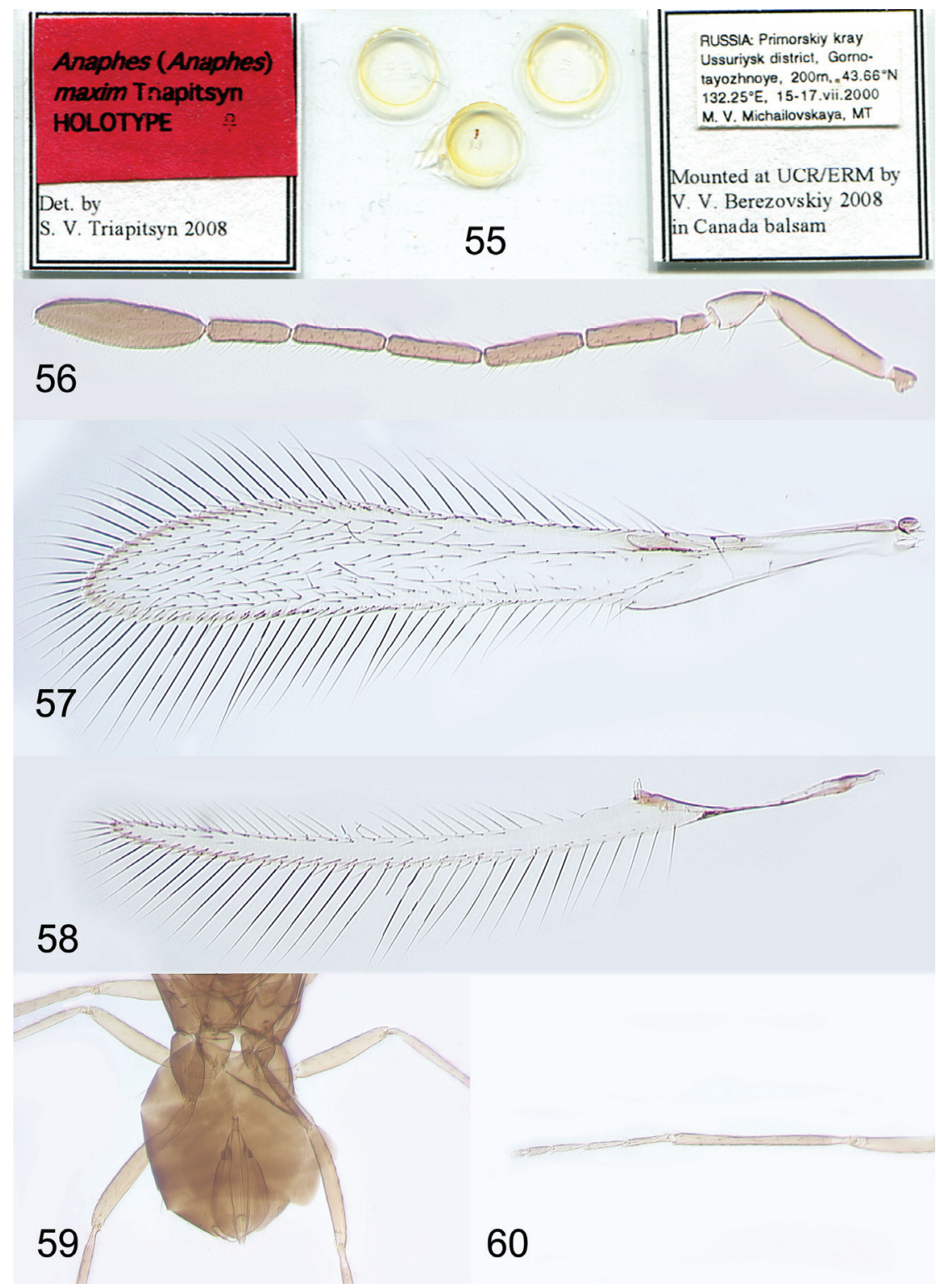

Figs 55-60. Anaphes (Anaphes) maxim sp. n., female (holotype). 55) Slide, 56) antenna, 57) fore wing, 58) hind wing, 59) ovipositor, 60) metatibia and metatarsus.

MALE. Unknown.

DIAGNOSIS. Anaphes (Anaphes) maxim is characterized by the combination of female antenna (Fig. 56) bearing 2 mps on F2, F2-F6 being notably longer than wide and longer than pedicel, and a relatively narrow female fore wing (Fig. 57) which is at least $7.0 \times$ as long 
as wide. This new species is similar to the Nearctic A. (Anaphes) nigrellus Girault, 1911, known from Canada and USA (Huber, 1992), from which it differs mainly by the relatively longer F2-F6 of the female antenna (Fig. 56), a longer female fore wing (at least $0.79 \mathrm{~mm}$ long), and a relatively shorter ovipositor (at most $0.8 \times$ as long as the metatibia, usually $0.7 \times$ ). In the positively identified North American female specimens of $A$. (Anaphes) nigrellus, the fore wing is at most $0.78 \mathrm{~mm}$ long and the ovipositor is about $0.9 \times$ length of the metatibia (Huber, 1992). By its relatively long female fore wing $(0.79-0.92 \mathrm{~mm})$, A. (Anaphes) maxim is also similar to the Nearctic A. (Anaphes) hercules Girault, 1911, known from Illinois, USA, whose female fore wing is, however, less than $5.7 \times$ as long as wide (at least $7.0 \times$ as long as wide in A. (Anaphes) maxim), F2 of the female antenna bears only $1 \mathrm{mps}$, and the ovipositor is a little more than $0.8 \times$ length of the metatibia (Huber, 1992).

ETYMOLOGY. The species name, which is treated as a noun in apposition, is the first name of Maxim Yur'evich Proshchalykin, a fellow hymenopterist who kindly helped me with information on the specimens of Anaphes (Anaphes) nipponicus Kuwayama, 1932 deposited in IBPV.

HOSTS. Unknown.

\section{Anaphes (Anaphes) medius Soyka, 1946}

Figs 61-65

Anaphes medius Soyka, 1946: 40-41.

Anaphes (Anaphes) fuscipennis Haliday, 1833 (misidentification): Debauche, 1948: 159-160, plates XVI-XVII (females only), as clarified by Huber (1992: 41, 58-59).

Anaphes fuscipennis Haliday, 1833 (misidentification): Hellén, 1974: 26 (in part, record from "Terijoki", USSR).

Anaphes intermedius (Soyka, 1949): Huber, 1992: 57 (type information, descriptive notes), 74 (list), 102, 106 (illustrations).

Anaphes medius Soyka: Huber, 1992: 58 (taxonomic history, synonymy, type information, descriptive notes), 75 (list), 102, 106 (illustrations); Müller \& Triapitsyn, 2021: 282 (record from Germany).

Anaphes (Anaphes) medius Soyka: Huber \& Thuróczy, 2018: 26-27 (list, type information, synonyms), 45 (key), 48 (host), 91 (illustration).

MATERIAL EXAMINED. Russia: Krasnodarskii krai, Krasnodar, All-Russian Research Institute of Biological Plant Protection, 31.VIII 2003 (V. V. Kostjukov) [3 $q$, UCRC]. Moskovskaya oblast', Noginskiy rayon, Fryazevo: 25.VI-2.VII 2000 (M. E. Tretiakov) [2 +, UCRC]; 24.VI 2002 (S. V. Triapitsyn) [1 +, UCRC]; 14.VII 2002 (M. E. Tretiakov) [1 9, UCRC]; 1.VIII 2002 (M. E. Tretiakov) [1 9 , UCRC]. Saint Petersburg, Kurortnyi rayon, Zelenogorsk, 12.VI 1927 (W. Hellén), at railway tracks [1 ㅇ, FMNH] (misidentified by W. Hellén as A. fuscipennis). Stavropol'skii krai: NW of Kislovodsk,

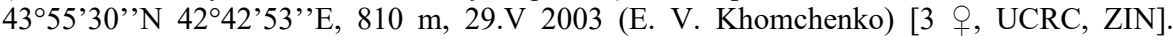
Prietokskiy, (V. V. Kostjukov): 14.VII 2003 [1 क, UCRC]; 12.VIII 2003 [3 , UCRC]. Tambovskaya oblast', Inzhavinskiy rayon, Talinka (7 km S of Pavlovka), 26-27.V 2000 (M. E. Tretiakov) $[1$ \%, UCRC].

EXTRALIMITAL MATERIAL EXAMINED. Belgium: Liège, Wanze, Antheit, Corphalie (R. Detry): 1-14.VII 1989 [1 +., ISNB]; 27.IV-11.V 1990 [1 ㅇ, ISNB]. Walloon Brabant, Waterloo (P. Dessart), in garden: 30.VIII-9.IX 1992 [3 , ISNB]; 10-20.IX 1992

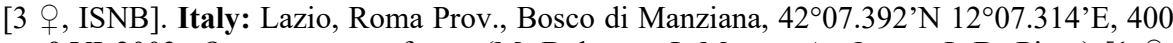
m, 9.VI 2003, Quercus cerris forest (M. Bologna, J. Munro, A. Owen, J. D. Pinto) [1 UCRC]. 


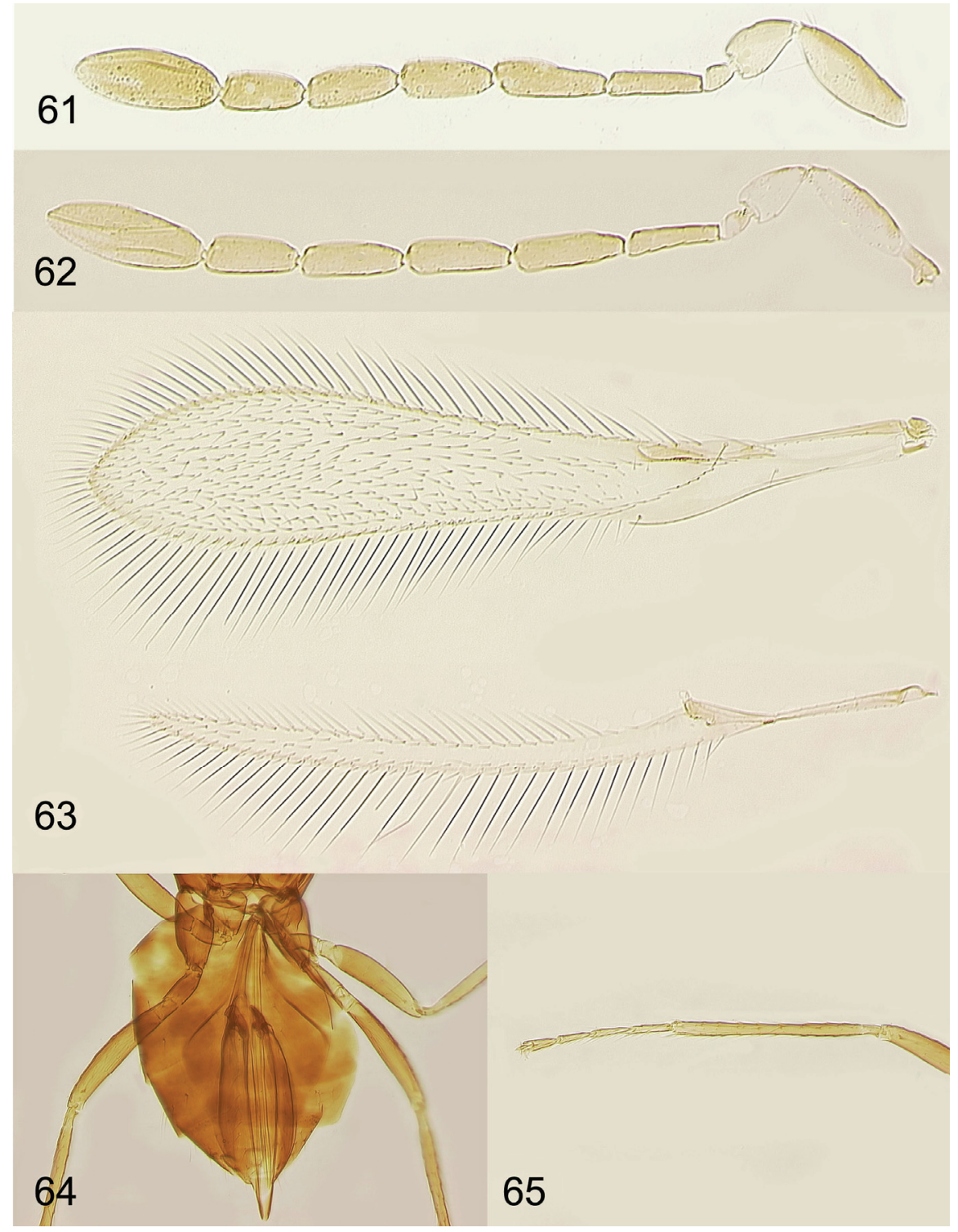

Figs 61-65. Anaphes (Anaphes) medius, female. 61) Antenna (Krasnodar, Krasnodarskii krai, Russia), 62) antenna (Waterloo, Walloon Brabant, Belgium), 63-65 (Bosco di Manziana, Roma Province, Lazio, Italy): 63) wings, 64) ovipositor, 65) metatibia and metatarsus.

DIAGNOSIS. FEMALE (specimens from the European part of Russia, Belgium and Italy). Body length (slide-mounted specimens) $0.8-0.86 \mathrm{~mm}$. Antenna (Figs 61, 62) with scape (excluding radicle) $2.8-3.4 \times$ as long as wide, with faint, inconspicuous cross-ridges; 
F2-F6 longer than pedicel, F2 $3.8-4.5 \times$ as long as wide (2.9 in one tentatively identified, small specimen), F3 the longest funicular, F2 without mps, F3-F6 each with 2 mps; clava with $6 \mathrm{mps}, 2.5-3.2 \times$ as long as wide, $0.8-0.9 \times$ as long as combined length of F5 and F6. Fore wing (Fig. 63) 4.9-5.4× as long as wide; longest marginal seta $0.9-1.0 \times$ maximum wing width; marginal space separated from medial space by 1 complete line of setae. Hind wing (Fig. 63) $18-22 \times$ as long as wide; longest marginal seta 3.1-3.6× maximum wing width, disc with 1 irregular row of setae apically. Metatarsomere 1 either about as long as or slightly shorter than metatarsomere 2 (Fig. 65). Ovipositor (Fig. 64) occupying entire length of gaster, extending forward at most to base of mesocoxa, not or at most barely exserted beyond apex of gaster posteriorly, and 1.1-1.5 $\times$ length of metatibia.

MALE. Known (Huber \& Thuróczy, 2018).

DISTRIBUTION. Russia*; Austria, Belgium (Debauche 1948 [as A. (Anaphes) fuscipennis, females only]; Huber, 1992), Germany, Italy*, Poland, Switzerland. 2018).

HOST. Miridae (Hemiptera): Lygus rugulipennis Poppius, 1911 (Huber \& Thuróczy,

REMARKS. The following specimens also likely belong to A. (Anaphes) medius: China: Beijing, Mentougou District, Liyan Ling, Linshan Mts., $40^{\circ} 00.28^{\prime} \mathrm{N} 115^{\circ} 30.75^{\prime} \mathrm{E}, 1749 \mathrm{~m}$, 2.VIII 2002 (G. Melika) [1 +, UCRC]. Russia: Moskovskaya oblast', Noginskiy rayon, Fryazevo, 14.VII 2002 (M.E. Tretiakov) [1 ㅇ, UCRC].

Anaphes (Anaphes) medius can be easily confused with A. (Anaphes) regulus Walker, 1846 when the key in Huber \& Thuróczy (2018) is used, which separates them very narrowly based on the length of the ovipositor sheaths (not of the ovipositor itself) relative to the metatibia length. Thus, any clearcut separation of these two nominal species is practically impossible by the relative length of the ovipositor (I also have seen female specimens from Finland, to be reported elsewhere, that seem to belong to A. (Anaphes) regulus but whose ovipositor is about $1.1 \times$ length of the metatibia), but it appears that in A. (Anaphes) medius the clava is relatively shorter (slightly shorter than the combined length of F5 and F6) than in $A$. (Anaphes) regulus (at least slightly longer than the combined length of $\mathrm{F} 5$ and $\mathrm{F} 6$ ). Indeed, in both the lectotype (fig. 85, p. 94 in Huber \& Thuróczy, 2018) and the paralectotype (fig. 4, p. 56 in Thuróczy \& O'Connor, 2015) females of $A$. regulus the clava is distinctly longer than the combined length of F5 and F6. Females of both species also separate well by the length to width ratio of the fore wing, as indicated in the key.

\section{Anaphes (Anaphes) ?nigrellus Girault, 1911}

Figs 66-69

Anaphes nigrellus Girault, 1911: 282-284.

Anaphes nigrellus Girault: Huber, 1992: 45-47 (taxonomic history, type information, descriptive notes, distribution, discussion), 75 (list), 100, 104 (illustrations).

Anaphes (Anaphes) nigrellus Girault: Huber \& Thuróczy, 2018: 24 (list, type information).

MATERIAL EXAMINED. Russia: Sakhalinskaya oblast': Kuril Islands, Shikotan

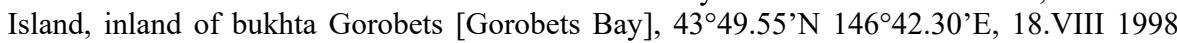
(D.J. Bennett) [1 9 , CAS]. Sakhalin Island, near Belaya River: 2 km E of Sokol, 47²14.56’ N $142^{\circ} 46.56^{\prime}$ E, 24.VII 2001 (D.J. Bennett, T.R. Anderson) [1 9 , CAS ]; ca. 6 km E of Sokol, $47^{\circ} 14.56^{\prime} \mathrm{N} 142^{\circ} 46.56^{\prime} \mathrm{E}, 16 . \mathrm{VIII} 2001$ (D.J. Bennett, T.R. Anderson) [4 ㅇ, CAS (3), UCRC (1)].

DIAGNOSIS. FEMALE (specimens from the Russian Far East). Body length 0.66-0.79 $\mathrm{mm}$ (slide-mounted specimens). Body dark brown, appendages brown except coxae dark brown. Vertex with mesh-like sculpture, mesoscutum and scutellum with faint sculpture. Antenna (Fig. 66) with scape (excluding radicle) $3.7-4.5 \times$ as long as wide, almost smooth; 


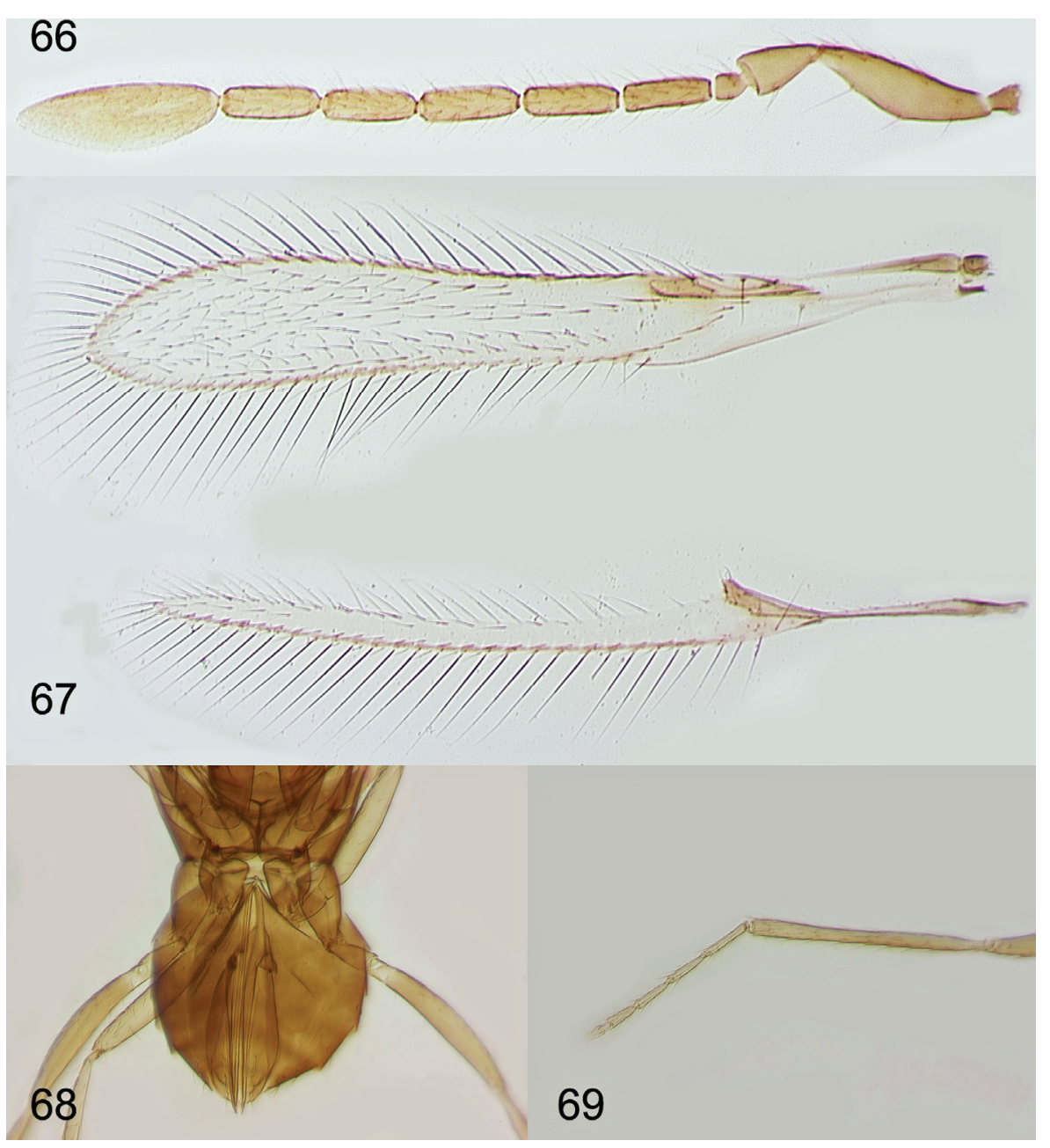

Figs 66-69. Anaphes (Anaphes) ?nigrellus, female (6 km E of Sokol, Sakhalin Island, Sakhalinskaya oblast', Russia). 66) Antenna, 67) wings, 68) ovipositor, 69) metatibia and metatarsus.

F2-F6 longer than pedicel, F2 3.1-3.6× as long as wide, F3 and F4 either the longest funiculars and subequal in length or, sometimes, F3 just slightly longer than F4, F2 either without mps on one antenna and with $1 \mathrm{mps}$ on the other antenna or with $1 \mathrm{mps}$ on both antennae, or with $1 \mathrm{mps}$ on one antenna and $2 \mathrm{mps}$ on the other antenna, and F3-F6 each with $2 \mathrm{mps}$; clava with $6 \mathrm{mps}, 2.9-3.3 \times$ as long as wide, about as long as combined length of F5 and F6 or just barely longer. Fore wing (Fig. 67) $0.75-0.79 \mathrm{~mm}$ long, $6.6-6.9 \times$ as long as wide; longest marginal seta 1.1-1.2× maximum wing width; marginal space separated from medial space by 1 complete line of setae. Hind wing (Fig. 67) 19-21× as long as wide; longest marginal seta 3.1-3.5× maximum wing width, disc with 1-2 irregular, short rows of setae apically. Metatarsomere 1 usually slightly shorter than metatarsomere 2 (Fig. 69) but in one 
specimen as long as metatarsomere 2. Ovipositor (Fig. 68) occupying entire length of gaster (but not extending forward under mesosoma), not exserted beyond apex of gaster posteriorly, and about as long as metatibia.

MALE. Known from North America only (Huber, 1992).

DISTRIBUTION. ?Russia*; Canada, USA.

HOSTS. Curculionidae: Hypera spp. (in Missouri, USA) (Huber, 1992).

COMMENTS. These specimens from Sakhalinskaya oblast' of Russia are only tentatively assigned to the Nearctic A. (Anaphes) nigrellus Girault, 1911 because genetic evidence of their conspecificity is currently lacking; it is quite possible that these in fact rather belong to an undescribed species. Females from the Russian Far East are characterized by the combination of antenna (Fig. 66) bearing at least $1 \mathrm{mps}$ on F2 on at least one antenna while F2-F6 are longer than pedicel. Thus they are almost identical to females of the Nearctic A. (Anaphes) nigrellus known from Canada (Ontario) and USA (Illinois and Missouri), which are just slightly smaller individuals whose body length is at most about $0.6 \mathrm{~mm}$ (Huber, 1992). Females from the eastern Palaearctic region differ from the Nearctic ones mainly by a relatively shorter clava (at most $3.3 \times$ as long as wide) and a relatively slightly longer ovipositor (about as long as the metatibia), whereas the clava is about $3.9 \times$ as long as wide, as calculated from the measurements of the type provided in Huber (1992), and the ovipositor is about $0.9 \times$ length of the metatibia in positively identified specimens from North America (Huber, 1992). The latter difference is very minor and could be within the intraspecific variability, which, however, is not very well known for the North American A. (Anaphes) nigrellus besides the data provided in its redescription by Huber (1992). The noted difference in the relative length to width ratio of the clava of the female antenna is potentially more significant, and thus its variability needs to be further assessed for the specimens from the Nearctic region.

I also examined the following specimens captured by yellow pan traps at the edge of a forest near the type locality of $A$. (Anaphes) nigrellus which could belong either to this species or, rather, to the North American A. (Anaphes) behmani Girault, 1929 because their F2 is short and lacks mps on both antennae: USA: Illinois, Champaign County, Urbana, Brownfield Woods, 7-8.IX 1993 (J.D. Pinto) [4 9 , UCRC]. Their clava is $3.2-3.8 \times$ as long as wide while that of the lectotype of $A$. (Anaphes) behmani is almost $3.4 \times$ as long as wide, as calculated from the measurements of the lectotype provided in Huber (1992). Their fore wing length is $0.51-0.59 \mathrm{~mm}$ and $6.0-6.5 \times$ as long as wide, and the ovipositor is $1.1-1.2 \times$ length of the mesotibia; these more or less fit the measurements of A. (Anaphes) behmani given in Huber (1992).

\section{Anaphes (Anaphes) nipponicus Kuwayama, 1932}

Figs 70-76

Anaphes nipponicus Kuwayama, 1932: 93.

Anaphes nipponicus Kuwayama: Togashi, 1974: 12 (host egg parasitism); Huber, 1992: 75 (list); Storozheva, 1989: 14-16 (host in the Russian Far East); Storozheva, 1990a: 113 (host); Storozheva, 1990b: 29 (parasitism, biology); Triapitsyn \& Proshchalykin, 2012: 207 (list), Samková et al., 2017: 690-697 (taxonomic history, type information, redescription, comparison with $A$. flavipes, distribution, host association); Triapitsyn \& Tselikh, 2019: 194 (list).

Anaphes (Anaphes) nipponicus Kuwayama: Huber \& Thuróczy, 2018: 27 (list, type information).

MATERIAL EXAMINED. Russia: Primorskii krai, Spasskiy rayon, Novosel'skoye, sovkhoz Novosel'skiy, 2.VII 1986 (Buryi), from eggs of Oulema oryzae (Kuwayama, 1931) on rice [ 1 badly shriveled 9 (Fig. 73) +2 incomplete specimens of undetermined sex + parasitized eggs of the host (Figs 70, 71), IBPV], examined virtually (M.Yu. Proshchalykin, 


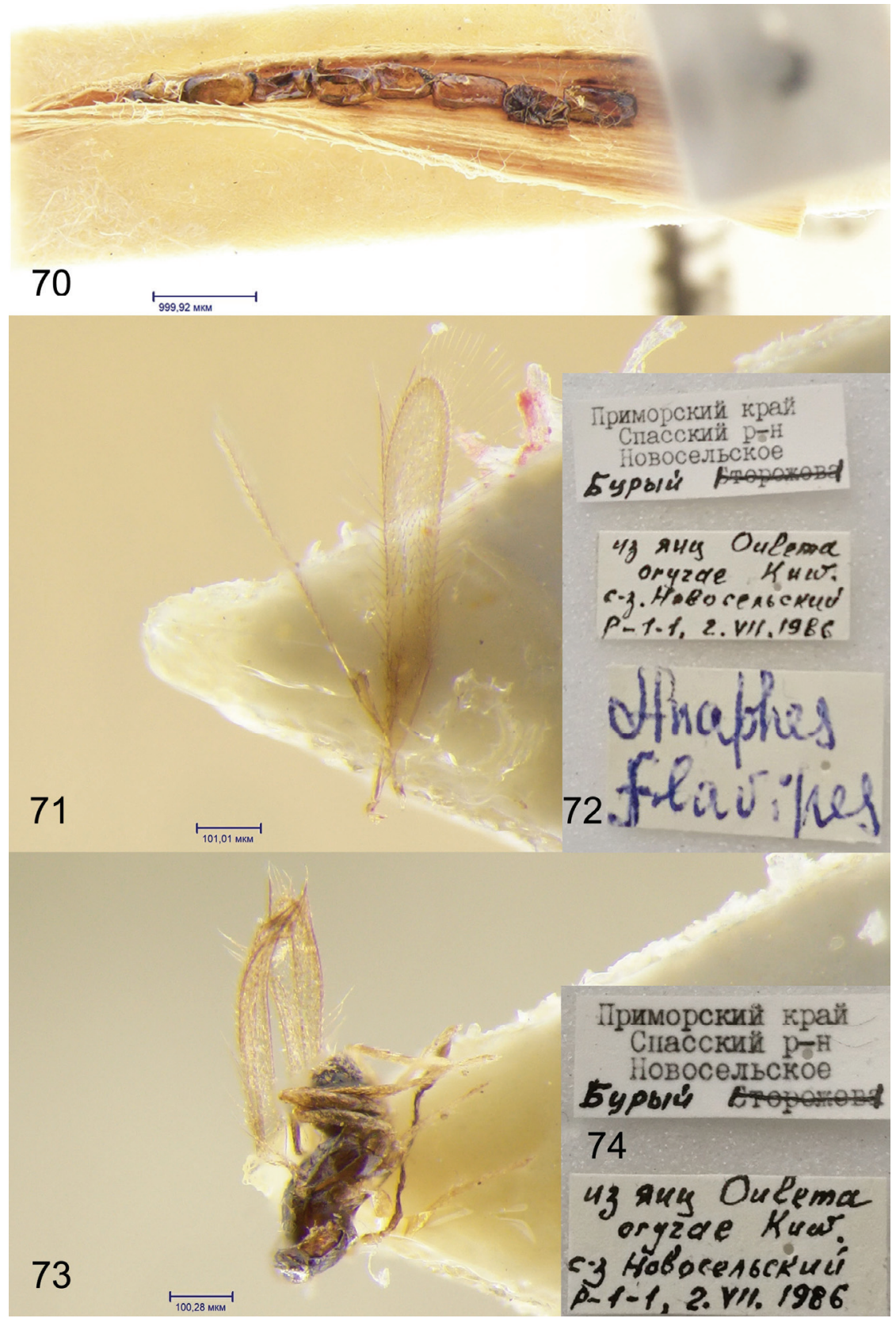

Figs 70-74. Anaphes (Anaphes) nipponicus (Novosel'skoye, Spasskiy rayon, Primorskii krai, Russia). 70) Parasitized eggs of the host, Oulema oryzae, in rice leaf, 71) wings of unknown sex, 72) labels, 73) habitus of female in lateral view, 74) labels. 
personal communication); the original labels (in Russian, Figs 72, 74) also include the initial misidentification as "Anaphes flavipes" (determined by N.A. Storozheva).

EXTRALIMITAL MATERIAL EXAMINED. Japan: Honshu Island: Ishikawa Prefecture, Wajima, VII 1973, from eggs of Oulema oryzae on rice (I. Togashi) [5 9, 3 $\widehat{\jmath}$, ELKU] (determined by T. Tachikawa in 1976). Kanagawa Prefecture, Yokohama, 10.VIII 1920 (C. P. Clausen) [1 9 , UCRC]. Republic of Korea: Kyungki-do, Kwangiu, Dochek, Taehwasan, 5.VIII 1998 (J.-B. Leon, S.-H. Lee) [1 +, UCRC].

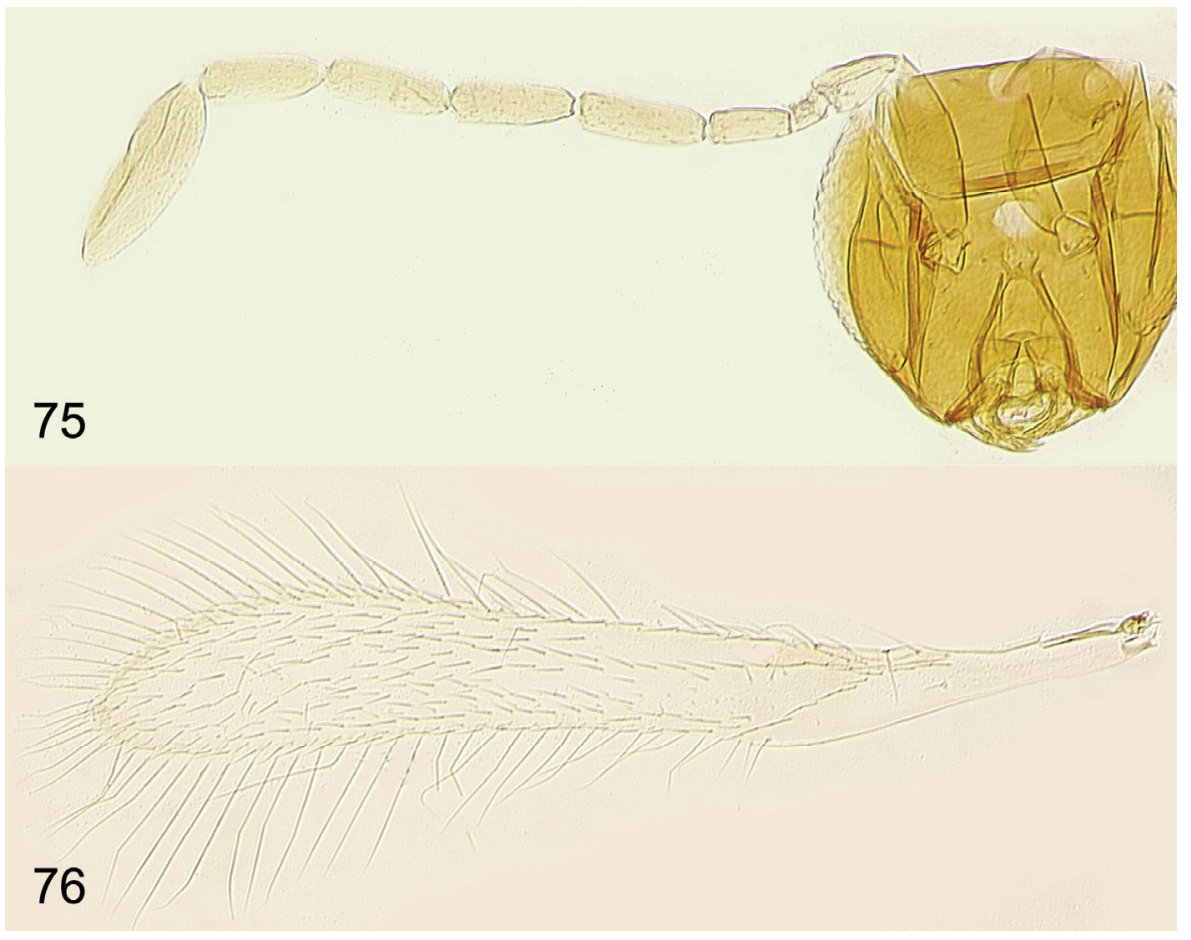

Figs 75, 76. Anaphes (Anaphes) nipponicus, female (Wajima, Ishikawa Prefecture, Honshu Island, Japan). 75) Head and antenna, 76) fore wing.

DIAGNOSIS. FEMALE. Diagnosed, redescribed and illustrated in detail by Samková et al. (2017) except for the clava and the wings. Here I provide illustrations of the antenna (Fig. 75) and fore wing (Fig. 76) to facilitate its recognition while using the key. In the reared specimens from Wajima, Ishikawa Prefecture, Japan, antenna (Fig. 75) with F2 very short and the combined length of F1 and F2 usually slightly shorter than F3 or at most about as long as F3, clava 3.1-3.9× as long as wide, a little shorter (about $0.9 \times$ ) than the combined length of F5 and F6, with $6 \mathrm{mps}$; fore wing (Fig. 76) $0.63 \mathrm{~mm}$ long, $6.4 \times$ as long as wide, longest marginal seta $1.3 \times$ maximum wing width, marginal space separated from medial space by 1 complete line of setae; hind wing about $19 \times$ as long as wide, longest marginal seta $3.3 \times$ maximum wing width, disc with 1 irregular, short row of a few setae apically; metatarsomere 1 at most about as long as metatarsomere 2 .

MALE. Known (Kuwayama, 1932) and redescribed by Samková et al. (2017). 
DISTRIBUTION. Russia; China (Fujian, Taiwan), Japan (Bai, 2007; Samková et al., 2017), and Republic of Korea*.

HOST. Chrysomelidae: Oulema oryzae (Kuwayama, 1931). Under quarantine laboratory conditions in Washington State, USA, Anaphes nipponicus readily attacked, oviposited and successfully completed two generations on eggs of the fictitious host, O. melanopus (Miller \& Roberts, 2009).

REMARKS. I personally looked for the missing syntypes of $A$. nipponicus in the collection of Insect Museum, National Institute for Agro-Environmental Sciences, NARO, Tsukuba, Ibaraki, Japan (ITLJ), to where S. Kuwayama's collection had been moved (Samková et al., 2017), during a brief visit in November 2019, but could not locate any. The examined specimens from Wajima City, Ishikawa Prefecture, Japan are vouchers of the study by Togashi (1974).

Anaphes (Anaphes) nipponicus of Fujian, China origin was evaluated in quarantine in Washington State as a potential neoclassical biological control agent against the cereal leaf beetle O. melanopus; it was concluded that it was not well adapted to the Pacific Northwest of the USA and thus not suitable for introduction and release against this invasive pest (Miller \& Roberts, 2009; Roberts, 2016)

Morphological separation of $A$. (Anaphes) nipponicus from A. (Anaphes) flavipes, as given by Samková et al. (2017), is not clearcut; their diagnosis of the former nominal species was not based on a sufficient number of complete female specimens. Their genetic comparison is thus highly warranted.

\section{Anaphes (Anaphes) ovipositor Soyka, 1946}

Figs $77-80$

Anaphes ovipositor Soyka, 1946: 41.

Anaphes ovipositor Soyka: Huber, 1992: 75 (list).

Anaphes (Anaphes) ovipositor Soyka: Huber \& Thuróczy, 2018: 27 (list, type information, synonyms), 45 (key), 93 (illustration).

MATERIAL EXAMINED. Russia: Moskovskaya oblast', Noginskiy rayon, Fryazevo, 9.VII 2002 (S.V. Triapitsyn) [1 9 , UCRC].

EXTRALIMITAL MATERIAL EXAMINED. Italy: Campania, Caserta Prov., $2.2 \mathrm{~km} \mathrm{SW}$ of Passo di Miralago, $41^{\circ} 23.421^{\prime} \mathrm{N} 14^{\circ} 24.784^{\prime} \mathrm{E}, 1025 \mathrm{~m}, 7-8$.VI 2003 (M. Bologna, J. Munro, A. Owen, J.D. Pinto) [2 9 , UCRC]. Lazio, Viterbo Prov., Ponte San Pietro, 42³1.669’N $11^{\circ} 36.353^{\prime}$ E, 75 m, 10.VI 2003 (M. Bologna, J. Munro, A. Owen, J.D. Pinto) [1

DIAGNOSIS. FEMALE (specimens from the European part of Russia and Italy). Body length (slide-mounted specimens) about $0.54 \mathrm{~mm}$. Antenna (Fig. 77) with scape (excluding radicle) $2.6-2.9 \times$ as long as wide, with faint, inconspicuous cross-ridges; F3 and F5 a little longer than pedicel and F6 either about as long as or slightly shorter than pedicel, F2 and F4 a little shorter than pedicel, F2 $2.8-3.1 \times$ as long as wide $(2.0 \times$ as long as wide in one specimen that otherwise fits this species), F3 and F5 the longest funiculars, F2 and F4 without mps, F3 with 1 or $2 \mathrm{mps}$, F5 and F6 each with $2 \mathrm{mps}$; clava with $6 \mathrm{mps}, 2.7-2.9 \times$ as long as wide, $0.9-1.0 \times$ as long as combined length of F5 and F6. Fore wing (Fig. 78) $5.8-6.3 \times$ as long as wide; longest marginal seta 1.4-1.5× maximum wing width; marginal space separated from medial space by 1 complete line of setae. Hind wing (Fig. 78) $19-20 \times$ as long as wide; longest marginal seta 3.6-3.8 $\times$ maximum wing width, disc with only admarginal rows of setae. Metatarsomere 1 slightly shorter than metatarsomere 2 (Fig. 80). Ovipositor (Fig. 79) occupying $0.9-1.0 \times$ length of gaster and not extending forward under mesosoma, not exserted beyond apex of gaster posteriorly, and 1.0-1.4× length of metatibia.

MALE. Unknown. 


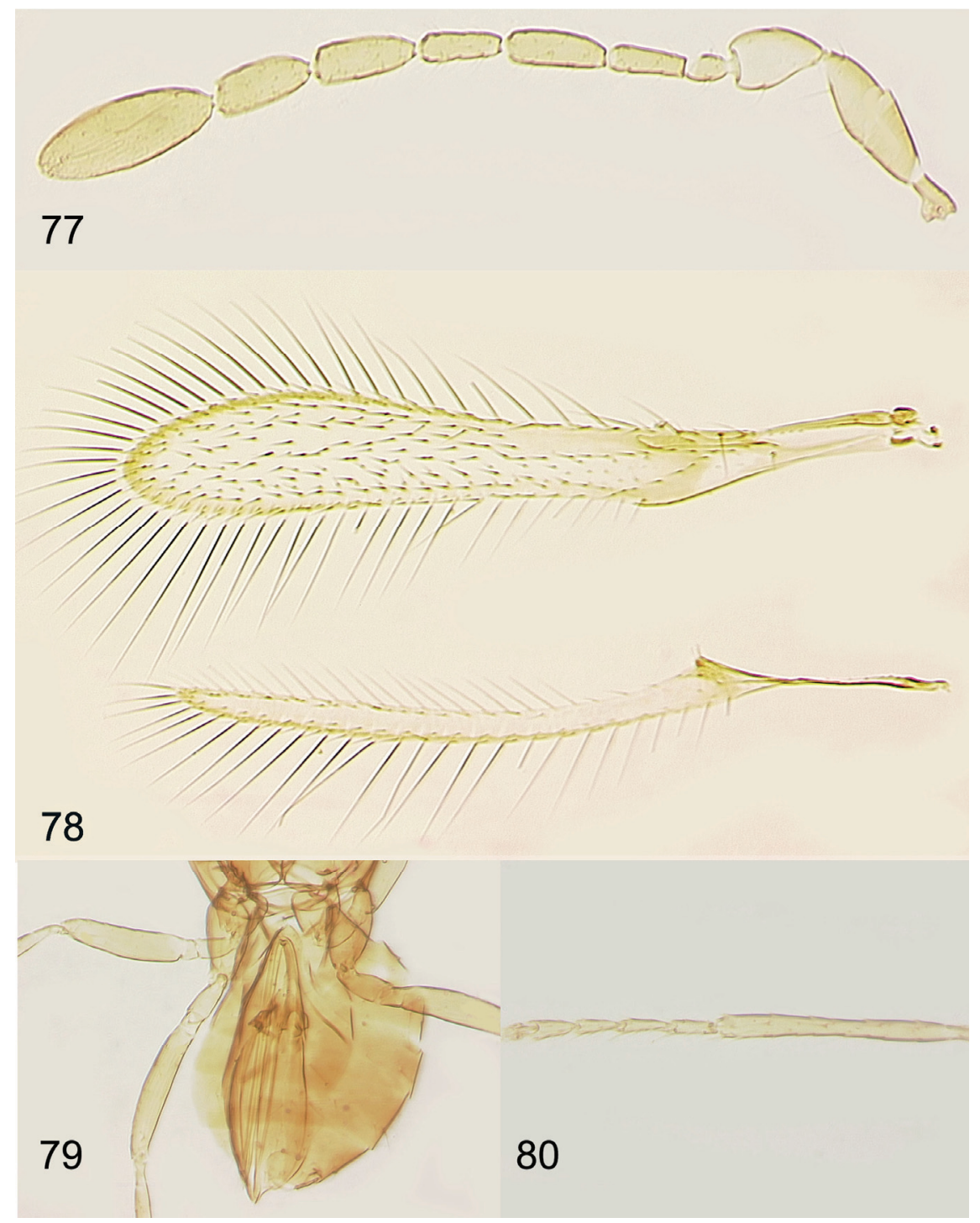

Figs 77-80. Anaphes (Anaphes) ovipositor, female (2.2 km SW of Passo di Miralago, Caserta Province, Campania, Italy). 77) Antenna, 78) wings, 79) ovipositor, 80) metatibia and metatarsus.

DISTRIBUTION. Russia*; Germany, Italy*, Netherlands.

HOSTS. Unknown.

COMMENTS. Because presence and the number of mps on F4 of the female antenna can be potentially variable also in some other species of $A$. (Anaphes), often in the same individual, I found proper definition of $A$. (Anaphes) ovipositor to be particularly difficult. I 
also examined the following specimens that tentatively key to A. (Anaphes) ovipositor in Huber \& Thuróczy (2018) but are more or less different from the positively identified ones of this species in one or several characteristics (like having a notably longer F1 of the female antenna, a relatively longer fore wing (up to $6.9 \times$ as long as wide), or a relatively longer metatarsomere 1 which is as long as metatarsomere 2): Belgium: Walloon Brabant, Waterloo, 1.IV-

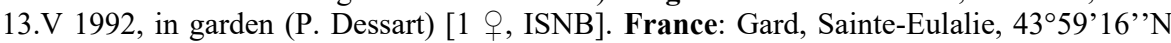
0417'53'’E, 96 m, 10-12.VI 2005 (J. George) [1 q, UCRC]. Kyrgyzstan: Osh: near Bordobo, 39 $29^{\prime} 56^{\prime}$ 'N 7316'03'”E, 3520-3743 m, 11.VII 2000 (C.H. Dietrich) [1 q, UCRC]. Taldyk Pass, 3946'05'’N 7310'09' 'E, 3615 m, 12.VII 2000 (C.H. Dietrich) [1 +, UCRC]. Russia: Moskovskaya oblast', Noginskiy rayon, Fryazevo, 14.VII 2002 (M.E. Tretiakov) [1 +, UCRC].

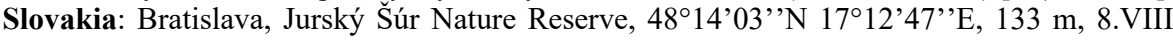
2008, alder forest (B.V. Brown) [1 +, UCRC].

\section{Anaphes (Anaphes) regulus Walker, 1846}

Figs 81-89

Anaphes regulus Walker, 1846: 52.

Anaphes (Anaphes) regulus Walker: Graham, 1982: 208-209 (taxonomic history, synonymy, designation of lectotype and paralectotype, redescription of the lectotype); Huber \& Thuróczy, 2018: 27 (list, type information, synonyms), 45 (key), 94 (illustration); Triapitsyn et al., 2020: 570 (records from Finland, distribution)

Anaphes regulus Walker: Huber, 1992: 76 (list); Thuróczy \& O’Connor, 2015: 56 (records from Ireland, paralectotype images (as corrected by Huber \& Thuróczy, 2018: 27) [as Anagrus regulus Walker]).

MATERIAL EXAMINED. Russia: Sakhalinskaya oblast': Kuril Islands: Kharimkotan Island, Northwest corner, $49^{\circ} 08.75^{\prime} \mathrm{N} 154^{\circ} 27.64^{\prime} \mathrm{E}$, 28.VII 2000 (D.J. Bennett) [2 O, CAS] Matua Island, inland of Dvoynaya bukhta [Double Bay], $48^{\circ} 03.12^{\prime} \mathrm{N} 153^{\circ} 14.60^{\prime} \mathrm{E}, 3$.VIII 1999 (B.K. Urbain) [1 9 , CAS]. Onekotan Island, North rim of Chernoye ozero [Black Lake], 49³5.50’'N 154 50.86’E, 24.VII 1999 (B.K. Urbain) [1 +, UCRC]. Sakhalin Island, 6 $\mathrm{km}$ E of Sokol, near Belaya River (D.J. Bennett, T.R. Anderson): 16.VII 2001 [2 9 , CAS]; 31.VII 2001 [1 9 , CAS].

EXTRALIMITAL MATERIAL EXAMINED. Belgium: Liège, Wanze, Antheit, Corphalie, 25.VIII-8.IX 1989 (R. Detry) [1 ㅇ, ISNB]. Republic of Korea: Gyeonggi-Do, Suwon-si, Seodun-dong, Seoul National University, 17.IX 2002 (J.-W. Kim) [1 + , UCRC].

DIAGNOSIS. FEMALE (specimen from Belgium). Body length (slide-mounted specimen) $0.77 \mathrm{~mm}$. Antenna (Fig. 81) with scape (excluding radicle) $3.6 \times$ as long as wide, almost smooth; F2 slightly shorter than pedicel and $3.1 \times$ as long as wide, F3-F6 longer than pedicel, F4 the longest funicular, F2 without mps, F3-F6 each with $2 \mathrm{mps}$; clava with $6 \mathrm{mps}, 3.1 \times$ as long as wide, $1.1 \times$ as long as combined length of F5 and F6. Fore wing (Fig. 82) $6.2 \times$ as long as wide; longest marginal seta $1.0 \times$ maximum wing width; marginal space separated from medial space by 1 complete line of setae. Hind wing about $20 \times$ as long as wide; longest marginal seta $3.6 \times$ maximum wing width, disc with 1 irregular row of setae apically. Metatarsomere 1 slightly shorter than metatarsomere 2 (Fig. 84). Ovipositor (Fig. 83) occupying $0.9 \times$ length of gaster (and thus not extending forward under mesosoma), not exserted beyond apex of gaster posteriorly, and $0.95 \times$ length of metatibia.

In the specimens from Kuril Islands (Fig. 86) (body length of dry-mounted females $0.56-0.71 \mathrm{~mm}$ ), antenna (Fig. 87) with scape (excluding radicle) $3.1-3.4 \times$ as long as wide, F2 $3.3-3.6 \times$ as long as wide, clava $3.2-3.3 \times$ as long as wide and $1.2 \times$ as long as combined length of F5 and F6; fore wing (Fig. 88) 5.8-6.3× as long as wide, longest marginal seta 1.3$1.4 \times$ maximum wing width; hind wing about $19 \times$ as long as wide, longest marginal seta $3.7-$ $3.8 \times$ maximum wing width; ovipositor (Fig. 85 ) occupying $0.7-0.8 \times$ length of gaster and $0.95 \times$ length of metatibia (Fig. 89 ). 
MALE. Known (Foerster, 1847 [as Anaphes autumnalis Foerster, 1847]) but its true identity is uncertain.

DISTRIBUTION. Russia*; Belgium, Czech Republic, Denmark, Finland, Germany, Iceland, Ireland, Netherlands, Poland, Republic of Korea*, United Kingdom. Some of these records (Noyes, 2019) need to be confirmed.

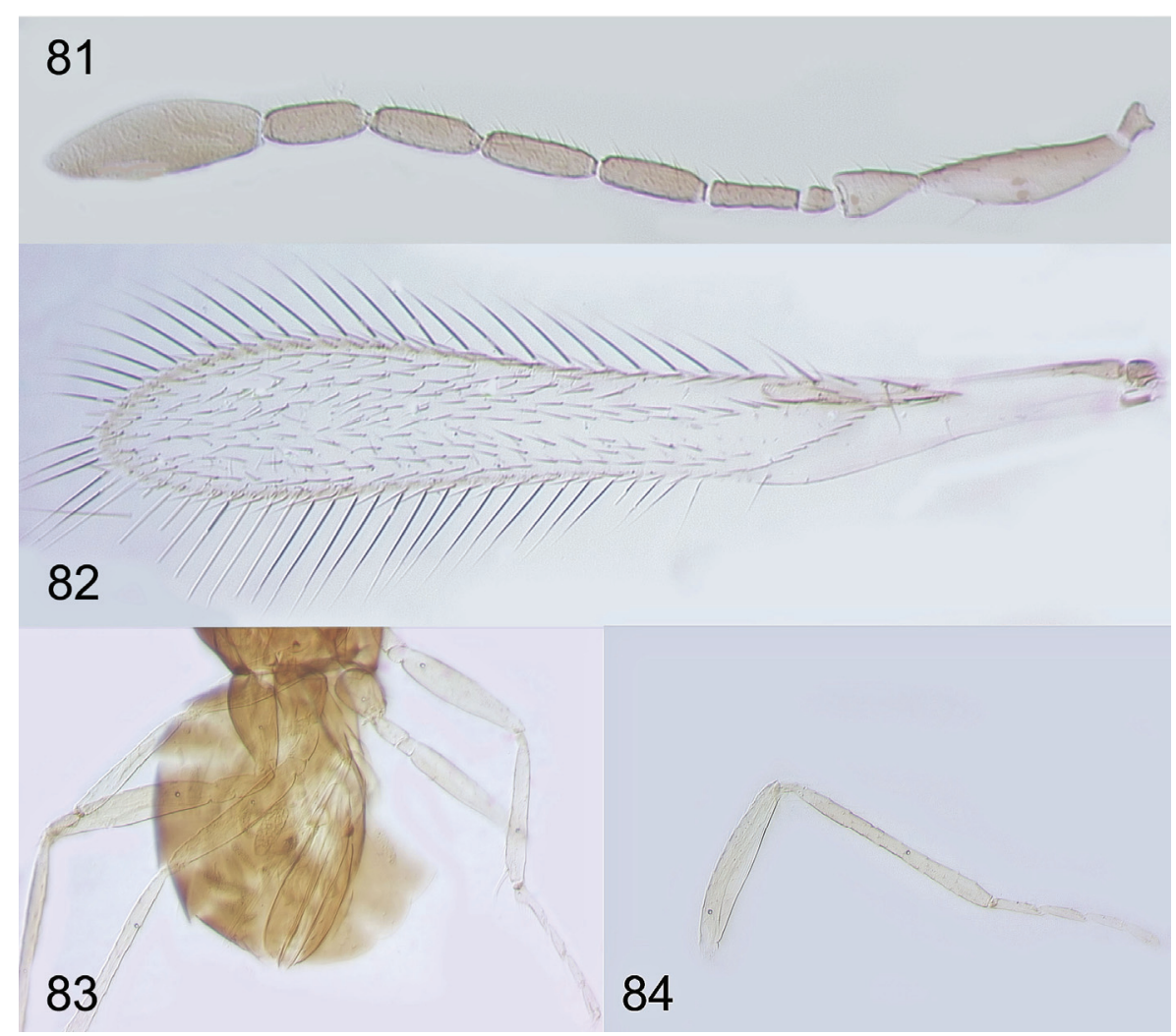

Figs 81-84. Anaphes (Anaphes) regulus, female (Corphalie, Antheit, Wanze, Liège, Belgium). 81) Antenna, 82) fore wing, 83) ovipositor, 84) metafemur, metatibia and metatarsus.

HOSTS. Identifications of the parasitoids from the published host records (i.e. from eggs of Ceutorhynchus assimilis (Paykull, 1792) (Curculionidae) and Tipula autumnalis Loew, 1864 (Diptera: Tipulidae) (Thuróczy \& O’Connor, 2015; Noyes, 2019) (both host names are now outdated), needs to be verified, because specimens of this species are particularly difficult to determine with any confidence, so misidentifications are likely.

COMMENTS. I also examined the following specimens that possibly are $A$. (Anaphes) regulus rather than $A$. (Anaphes) ovipositor, in which $\mathrm{F} 4$ of the female antenna has either 1 mps on both antennae or $1 \mathrm{mps}$ on one antenna and $2 \mathrm{mps}$ on the other: Belgium: Liège, Wanze, Antheit, Corphalie, 3-17.VIII 1990 (R. Detry) [1 +, ISNB]. Russia: Moskovskaya oblast', Noginskiy rayon, Fryazevo, 7-15.VII 2000 (M.E. Tretiakov) [1 + , UCRC]. 

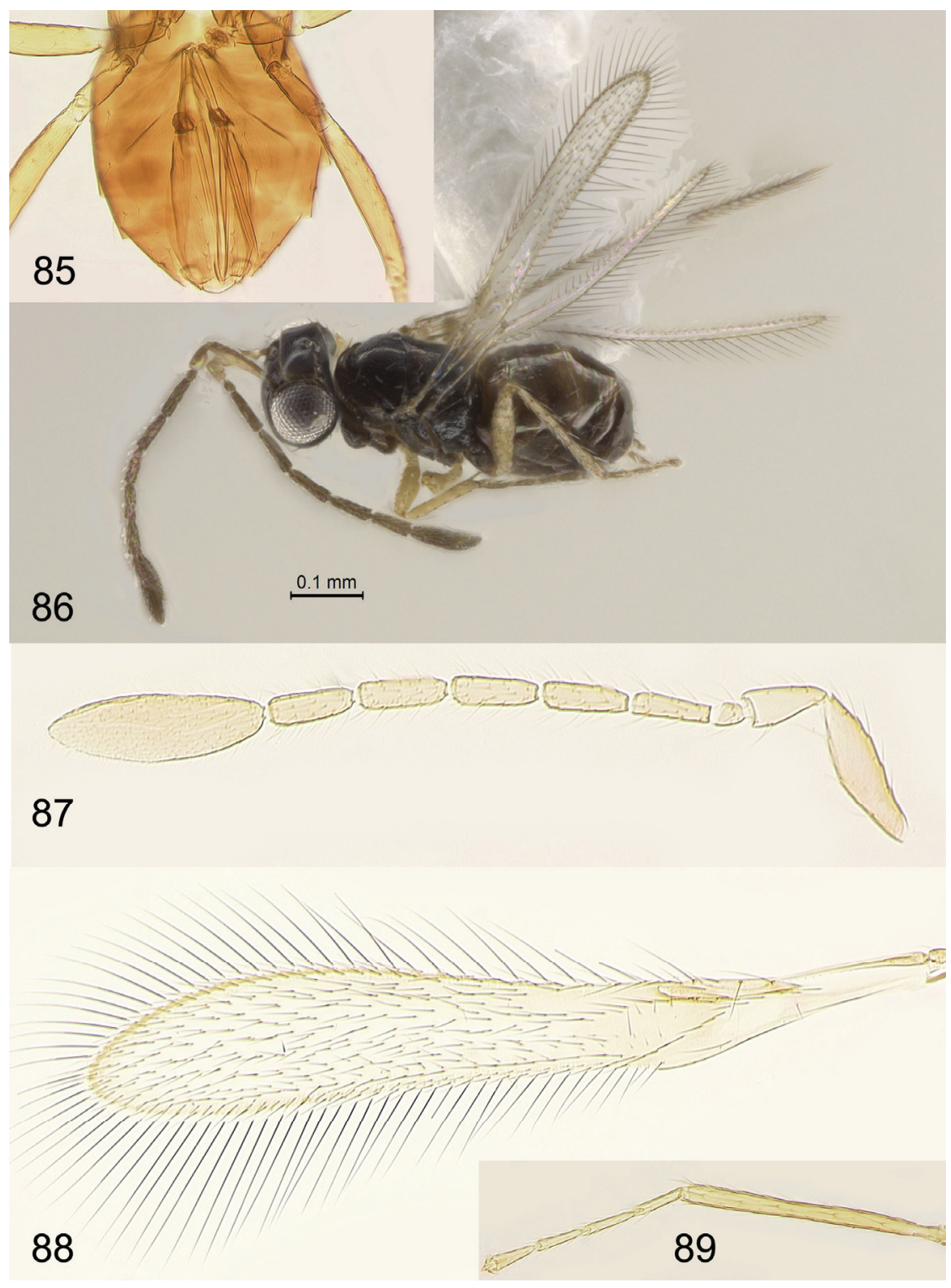

Figs 85-89. Anaphes (Anaphes) regulus, female (Kuril Islands, Sakhalinskaya oblast', Russia). 85) Ovipositor (Matua Island), 86) habitus in lateral view (Kharimkotan Island), 87) antenna (Matua Island), 88) fore wing (Matua Island), 89) metatibia and metatarsus (Matua Island).

I find A. (Anaphes) regulus to be almost indistinguishable from A. (Anaphes) stygius, so their possible conspecificity will need to be further investigated using a combination of molecular methods and a thorough morphometric analysis. By itself, A. (Anaphes) regulus is 
not well defined, despite the available redescription of its lectotype by Graham (1982: 208209), at least in part because the lectotype female is a dry-mounted specimen (Huber \& Thuróczy, 2018: 94, fig. 85). The dry-mounted paralectotype female of this species was illustrated by Thuróczy \& O'Connor (2015: 56, figs 2-4 [as a lectotype of “Anagrus regulus Walker"]), from which an antenna and a pair of wings were remounted onto a microscopic slide by $\mathrm{C}$. Thuróczy.

Anaphes (Anaphes) rfe Triapitsyn, sp. n.

http://zoobank.org/NomenclaturalActs/8A46CF4C-8BFE-410D-9340-66927C89F688

Figs $90-95$

TYPE MATERIAL. Holotype female [ZIN] on slide (Fig. 90): Russia: Primorskii krai, Ussuriyskiy rayon, Gornotayozhnoye, $43.66^{\circ} \mathrm{N} 132.25^{\circ} \mathrm{E}, 200 \mathrm{~m}, 26-31 . \mathrm{VIII} 2000$ (M.V. Michailovskaya), MT. Paratypes (all on slides): China: Beijing, Mentougou District, Liyan

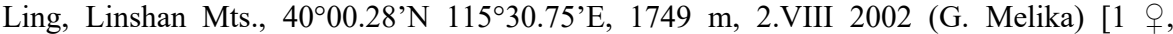
UCRC]. Russia: Primorskii krai, Ussuriyskiy rayon, Gornotayozhnoye, $43.66^{\circ} \mathrm{N} 132.25^{\circ} \mathrm{E}$, 200 m (M.V. Michailovskaya), MT: 5-11.VIII 1999 [1 +, UCRC]; 11-20.VIII 2000 [1 UCRC]; 26-31.VIII 2000 [1 + , IBPV].

DESCRIPTION. FEMALE (holotype). Body (Fig. 92) dark brown; scape and pedicel light brown, flagellum brown; legs light brown except coxae brown. Mesosoma with faint sculpture, that on vertex more conspicuous. Antenna (Fig. 91) with scape (excluding radicle) $3.8 \times$ as long as wide, almost smooth; F2 $2.5-2.6 \times$ as long as wide and shorter than pedicel, combined length of F1 and F2 notably longer than F3; F3, F4 and F6 the longest funiculars, subequal in length and about as long as pedicel; F2 without mps, mps on F3 (1), F4 (2), F5 (2) and F6 (2); clava with $6 \mathrm{mps}, 3.0 \times$ as long as wide, $1.3 \times$ as long as combined length of F5 and F6. Fore wing (Fig. 94) almost $6.8 \times$ as long as wide; longest marginal seta almost $1.7 \times$ maximum wing width; marginal space separated from medial space by 2 lines of setae (medial space very small). Hind wing (Fig. 95) about $22 \times$ as long as wide; longest marginal seta $4.6 \times$ maximum wing width, disc with only admarginal rows of setae on one wing and with 1 additional seta apically on the other wing. Metatarsomere 1 about as long as metatarsomere 2 (Fig. 93). Ovipositor (Fig. 92) occupying entire length of gaster (but not extending forward under mesosoma), not exserted beyond apex of gaster posteriorly, and $1.3 \times$ length of metatibia.

Measurements $(\mu \mathrm{m})$ of the holotype. Body 612 (of the slide-mounted specimen); mesosoma 227; metatibia: 200; gaster 258; ovipositor 258. Scape (minus radicle) 103; pedicel 48; F1 18; F2 38 (39); F3 48; F4 48; F5 45; F6 48; clava 130. Fore wing 615:91; longest marginal seta 151. Hind wing 606:27; longest marginal seta 124.

Variation (paratypes). Body length $0.57-0.66 \mathrm{~mm}$ (slide-mounted specimens). Antenna with scape (excluding radicle) $3.2-3.5 \times$ as long as wide, F2 $2.4 \times$ as long as wide, F3 sometimes slightly shorter than following funiculars and F5 sometimes as long as F4 and F6, F4 with 1 or $2 \mathrm{mps}$, clava $2.8-3.1 \times$ as long as wide and $1.2-1.3 \times$ as long as combined length of $\mathrm{F} 5$ and F6. Fore wing $6.5-6.6 \times$ as long as wide, longest marginal seta $1.6-1.7 \times$ maximum wing width. Hind wing $19-22 \times$ as long as wide, longest marginal seta $3.9-4.5 \times$ maximum wing width, disc with only admarginal rows of setae. Ovipositor 1.4-1.5 $\times$ length of metatibia.

MALE. Unknown.

DIAGNOSIS. Anaphes (Anaphes) rfe is somewhat similar to A. (Anaphes) medius; in the latter species, female antenna (Figs 61, 62) has a relatively longer funiculars including F2, F3 and F4 always bear $2 \mathrm{mps}$ each, and the clava is $0.8-0.9 \times$ as long as combined length of F5 and F6. The female fore wing of $A$. (Anaphes) medius (Fig. 63) is relative wider, 4.9-5.4× as long as wide, with the longest marginal seta $0.9-1.0 \times$ maximum wing width, and the marginal space is separated from medial space by 1 complete line of setae. From A. (Anaphes) regulus, female of which has a more or less similar fore wing (Figs 82, 88) but F3 always bears $2 \mathrm{mps}$, female $A$. (Anaphes) $r f e$ also differs by a relatively longer ovipositor, which in 


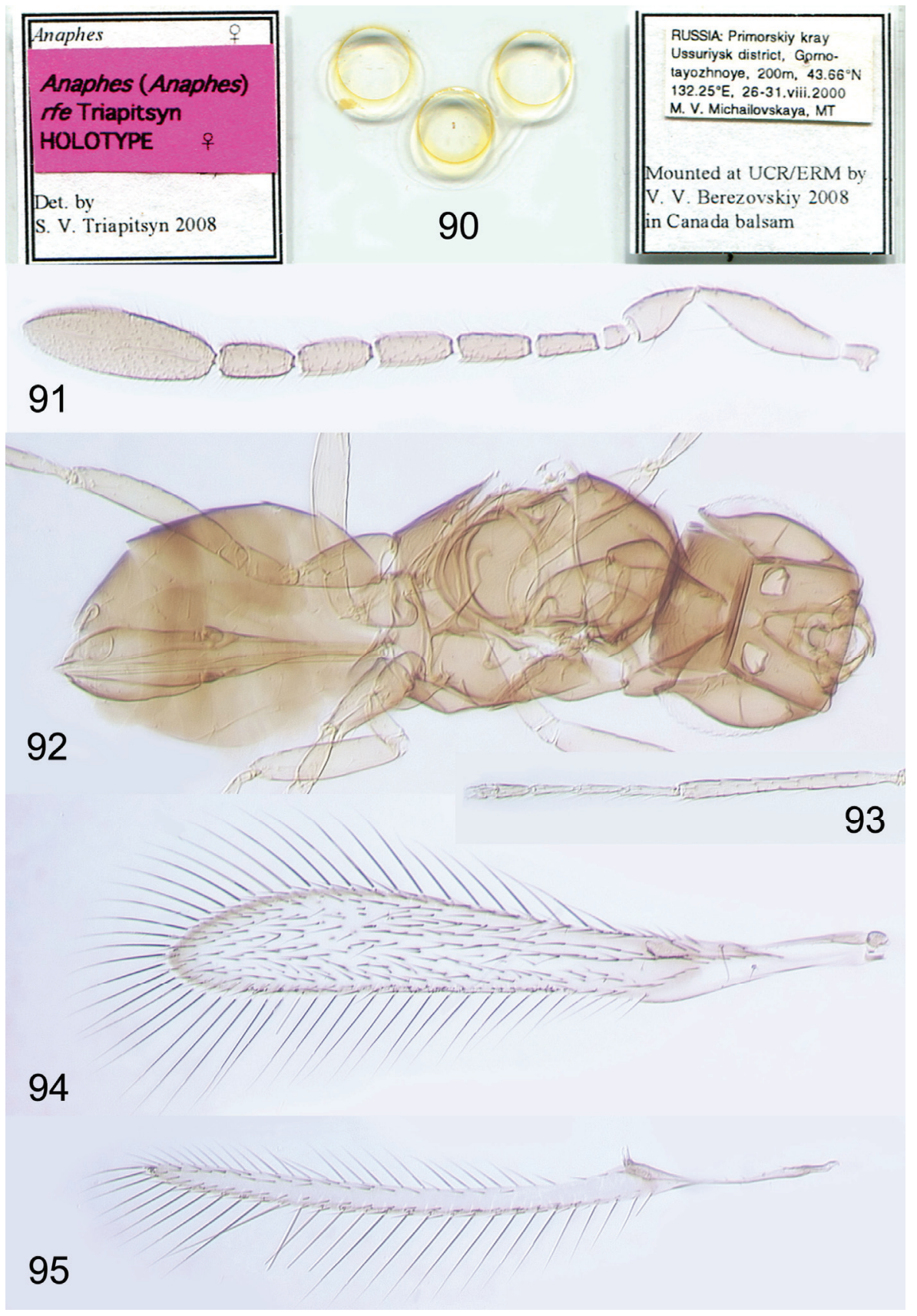

Figs 90-95. Anaphes (Anaphes) rfe sp. n., female (holotype). 90) Slide, 91) antenna, 92) body, 93) metatibia and metatarsus, 94) fore wing, 95) hind wing. 
the former species occupies $0.8-0.9 \times$ length of the gaster and is $0.95-1.0 \times$ length of the metatibia. From the Nearctic A. (Anaphes) behmani Girault, 1929, known from New York, USA (Huber \& Thuróczy, 2018), female A. (Anaphes) rfe differs in having only $1 \mathrm{mps}$ on F3 and by the clava being notably longer than the combined length of F5 and F6, whereas female antenna of the former species has $2 \mathrm{mps}$ on $\mathrm{F} 3$ and its clava is a little shorter than the combined length of F5 and F6 (Huber, 1992). Anaphes (Anaphes) rfe differs from A. (Anaphes) brevicornis, which also has a rather short funicle of the female antenna, by the different proportions of the funiculars, as indicated in the key.

ETYMOLOGY. The species name, which is treated as a noun in apposition, is an abbreviation for the Russian Far East.

HOSTS. Unknown.

\section{Anaphes (Anaphes) stygius Debauche, 1948}

Figs 96-99

Anaphes (Anaphes) stygius Debauche, 1948: 165-166, plates XVI-XVII (illustrations).

Anaphes stygius Debauche: Huber, 1992: 76 (list).

Anaphes (Anaphes) stygius Debauche: Huber \& Thuróczy, 2018: 27 (list, type information), 45 (key), 95 (illustration); Triapitsyn et al., 2020: 570 (record from Finland, distribution).

MATERIAL EXAMINED. Russia: Dagestan, Botlikhskiy rayon, Botlikh, 11.IX 2003 (V.V. Kostjukov) [1 9 , UCRC]. Moskovskaya oblast', Noginskiy rayon, Fryazevo (M.E. Tretiakov): 25.VI-2.VII 2000 [1 q, UCRC]; 20.VII 2001 [1 + , UCRC]; 14.VII 2002 [1 UCRC]. Stavropol'skii krai, Prietokskiy, 14.VII 2003 (V.V. Kostjukov) [1 \&, UCRC].

EXTRALIMITAL MATERIAL EXAMINED. Austria: Lower Austria, $1 \mathrm{~km} \mathrm{~W}$ of Hollern, 4804'22'’N 1652'37'’E, 150 m, 16-17.VI 2007 (S.V. Triapitsyn, C. Thuróczy) [2 , UCRC]. Belgium: Liège, Wanze, Antheit, Corphalie, 28.VII-11.VIII 1989 (R. Detry) [1 ㅇ, ISNB]. Walloon Brabant, Waterloo, in garden (P. Dessart): 30.VIII-9.IX 1992 [1 , ISNB]; 10-20.IX 1992 [2 ㅇ, ISNB]. France: Gard, Sainte-Eulalie, 96 m, 4359'16’'N 0417'53'’E, 10-12.VI 2005 (J. George) [2 ㅇ, UCRC].

DIAGNOSIS. FEMALE (specimens from the European part of Russia, Austria, Belgium, and France). Body length (slide-mounted specimens) $0.65-0.86 \mathrm{~mm}$. Antenna (Fig. 96) with scape (excluding radicle) 3.5-4.2× as long as wide, almost smooth; F3-F6 longer than pedicel, F2 $3.5-4.2 \times$ as long as wide and usually about as long as but sometimes a little longer than pedicel, F3 and F4 the longest funiculars and usually subequal in length (occasionally F4 slightly longer), F2 without mps and F3-F6 each with 2 mps; clava with 6 mps, 3.2-3.7× as long as wide, usually about as long as combined length of F5 and F6 but occasionally slightly shorter. Fore wing (Fig. 97) $6.1-6.9 \times$ as long as wide; longest marginal seta 1.0-1.3× maximum wing width; marginal space separated from medial space by $1-2$ lines of setae. Hind wing (Fig. 97) $19-21 \times$ as long as wide; longest marginal seta $3.1-3.6 \times$ maximum wing width, disc with 1-2 irregular rows of setae apically. Metatarsomere 1 slightly shorter than metatarsomere 2 (Fig. 99). Ovipositor (Fig. 98) occupying 0.8-0.9× length of gaster (and thus not extending forward under mesosoma), not or at most barely exserted beyond apex of gaster posteriorly, and $0.9-1.1 \times$ length of metatibia.

MALE. Unknown.

DISTRIBUTION. Russia*; Austria*, Belgium, Bulgaria, Finland, France*, Greece. The records from Bulgaria and Greece (Noyes, 2019) need to be confirmed.

HOSTS. Unknown.

COMMENTS. I also examined the following specimen that keys to Anaphes (Anaphes) stygius in Huber \& Thuróczy (2018) but has a relatively longer F2: Hungary: Vas County, W of Köszeg, 47²3'09'’N 16³1'19'’E, 355 m, 16-20.VI 2009 (I. Mikó) [1 ㅇ, UCRC]. 
Anaphes (Anaphes) stygius is not very well defined, being almost indistinguishable from A. (Anaphes) regulus, so their possible conspecificity will need to be further investigated using molecular methods. For now, the only diagnostic morphological feature that might help separate them is the length of the clava relative to the combined length of F5 and F6 of the female antenna, as indicated in the key. Indeed, the two almost identical females captured during the same collecting event near Hollern, Lower Austria, Austria, key to both nominal species in Huber \& Thuróczy (2018), one to A. (Anaphes) regulus and the other to A. (Anaphes) stygius.

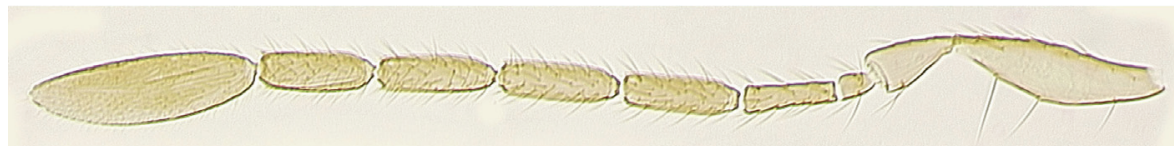

\section{6}

\section{7}

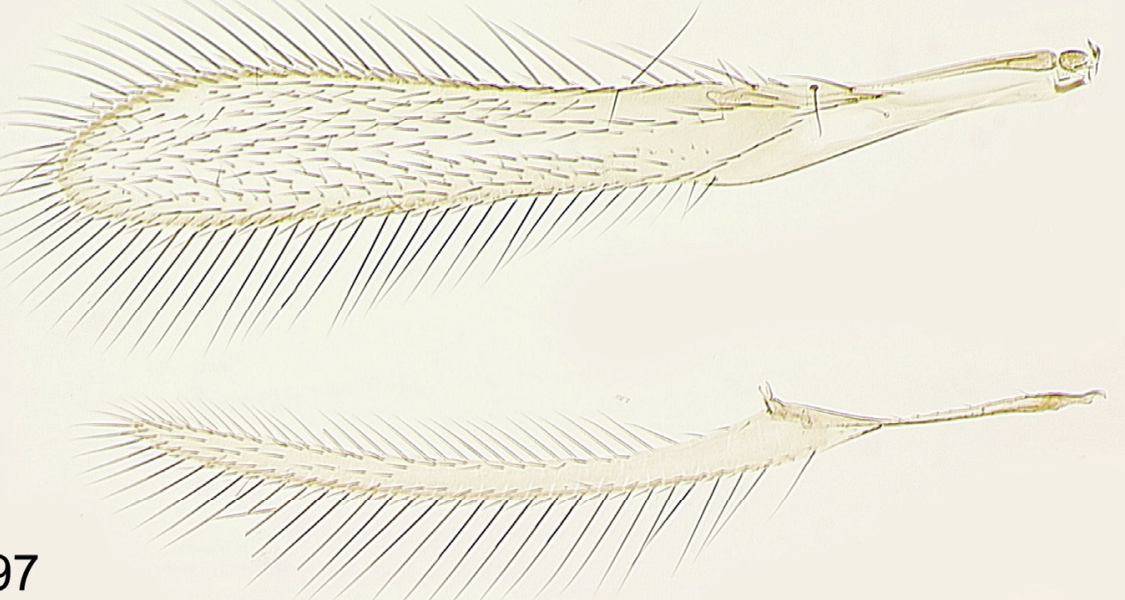

98
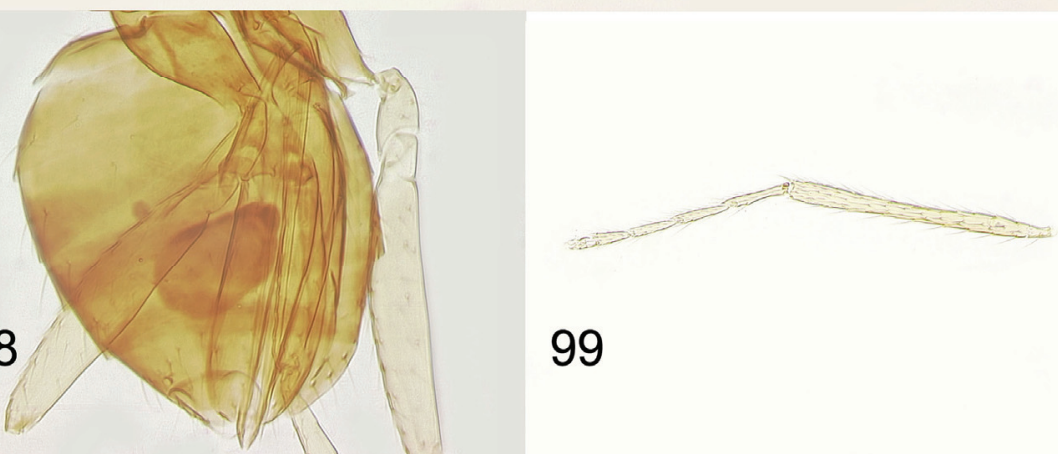

Figs 96-99. Anaphes (Anaphes) stygius, female (Fryazevo, Noginskiy rayon, Moskovskaya oblast', Russia). 96) Antenna, 97) wings, 98) ovipositor, 99) metatibia and metatarsus. 


\section{ACKNOWLEDGMENTS}

Vladimir V. Berezovskiy (UCRC) provided excellent technical assistance since 1999 when we started to study the fauna of Mymaridae of the Russian Far East, particularly with skillful point- and slide-mounting of specimens. Marina V. Michailovskaya (Saint Petersburg, Russia, formerly at Mountain-Taiga Station, Far Eastern Branch of the Russian Academy of Sciences, Gornotayozhnoye, Primorskii krai, Russia), Elisaveta Ya. Shouvakhina, Mikhail E. Tretiakov, Vladimir A. Trjapitzin (Moscow, Russia), Viktor V. Kostjukov (All-Russian Research Institute of Biological Plant Protection, Krasnodar, Krasnodarskii krai, Russia), and many other collectors are gratefully acknowledged for collecting/donating specimens for this study. Toshiharu Mita (ELKU), Juho Paukkunen (FMNH), Ekaterina V. Tselikh (ZIN), Ken Walker and Simon Hinkley (MVMA), and Robert L. Zuparko (CAS) arranged loans of specimens from the respective collections. Maxim Yu. Proshchalykin (IBPV) and Alexey A. Polilov (Entomology Department, Moscow State University, Moscow, Russia) kindly provided information and digital images of the specimens of $A$. (Anaphes) nipponicus from Primorskii krai and A. (Patasson) silesicus from Moscovskaya oblast', respectively. Martti Koponen (Mikkeli, Finland) provided the missing label information on the specimens collected by Wolter Hellén in Leningradskaya oblast' of Russia. Jennifer D. Read and John T. Huber (CNC) shared digital images of the female specimen of A. (Anaphes) alaskae from Canada, and Peter T. Oboyski (EMEC) made available photographs of the holotype of this species.

\section{REFERENCES}

Annecke, D.P. \& Doutt, R.L. 1961. The genera of the Mymaridae Hymenoptera: Chalcidoidea. Entomological Memoirs (Department of Agricultural Technical Services, Republic of South Africa), 5: 1-71.

Anwar, P.T., Zeya, S.B. \& Huber, J.T. 2019. Two new species of Anaphes Haliday (Hymenoptera: Mymaridae) from India and Indonesia. Zootaxa, 4623 (1): 26-40. DOI: https:// doi.org/10.11646/zootaxa.4623.1.2

Bai, B.B. 2007. Collection and importation of an egg parasitoid - Anaphes nipponicus from China to the USA for biological control of the cereal leaf beetle. Avaliable at: https://research.libraries.wsu.edu/xmlui/bitstream/handle/2376/2260/2007\%20Report\%2 0on\%20Collection $\% 20$ of $\% 20$ Anaphes $\% 20$ nipponicusfrom $\% 20$ China $\% 20$-020Bai.pdf? sequence $=1$ \&isAllowed $=y$ (last accessed 14.I 2021).

Debauche, H.R. 1948. Étude sur les Mymarommidae et les Mymaridae de la Belgique (Hymenoptera Chalcidoidea). Mémoires du Musée Royal d'Histoire Naturelle de Belgique, 108: 1-248 + plates I-XXIV and legends on unnumbered pages.

Dolgin, M.M. 1978. Mymarid Patasson brachygaster Debauche (Hymenoptera, Mymaridae) parasite of Chrysolina fastuosa Scop. (Coleoptera, Chrysomelidae) in Altai. Entomologicheskoe Obozrenie, 57(2): 313-315. [In Russian]

Donev, A. 1987. A study of the egg parasites of Oulema melanopus (Linn.) (Col. Chrysomelidae). Plovdivski Universitet "Paisiy Hilendarski", Nauchni Trudove, Biologiya, 25(6): 69-72. [In Bulgarian].

Foerster, A. 1841 (1840). Beiträge zur Monographie [der Familie] der Pteromalinen Nees. I Heft. Aachen: Jacob Anton Mayer : 46 pp. + XLV [figure legends page] + 1 plate.

Foerster, A. 1847. Ueber die Familie der Mymariden. Linnaea Entomologica, 2: 195-233.

Fursov, V. 1995. A review of European Chalcidoidea (Hymenoptera) parasitizing the eggs of aquatic insects. Bulletin of Irish Biogeographical Society, 18(1): 2-12.

Gibson, G.A.P. 1997. Chapter 2. Morphology and terminology. P. 16-44. In: Gibson, G.A.P., Huber, J.T. \& Woolley, J.B. (Eds). Annotated keys to the genera of Nearctic Chalcidoidea (Hymenoptera). NRC Research Press, Ottawa.

Girault, A.A. 1911. Descriptions of North American Mymaridæ with synonymic and other notes on described genera and species. Transactions of the American Entomological Society, 37: 253-324.

Graham, M.W.R. de V. 1982. The Haliday collection of Mymaridae (Insecta, Hymenoptera, Chalcidoidea) with taxonomic notes on some material in other collections. Proceedings of the Royal Irish Academy, B82 (12): 189-243. 
Haliday, A.H. 1833. An essay on the classification of the parasitic Hymenoptera of Britain, which correspond with the Ichneumones minuti of Linnaeus. Entomological Magazine, 1: 259-276, 333-350.

Hellén, W. 1974. Die Mymariden Finnlands (Hymenoptera: Chalcidoidea). Fauna Fennica, 25: $1-31$

Hincks, W.D. 1960 (1959). Some additions to the British Mymaridae (Hym., Chalcidoidea). The Entomologist's Monthly Magazine, 95: 210-216.

Huber, J.T. 1986. Systematics, biology, and hosts of the Mymaridae and Mymarommatidae (Insecta: Hymenoptera): 1758-1984. Entomography, 4: 185-243.

Huber, J.T. 1992. The subgenera, species groups, and synonyms of Anaphes (Hymenoptera: Mymaridae) with a review of the described Nearctic species of the fuscipennis group of Anaphes s.s. and the described species of Anaphes (Yungaburra). Proceedings of the Entomological Society of Ontario, 123: 23-110.

Huber, J.T. 2006 (2004). Review of the described Nearctic species of the crassicornis group of Anaphes s. s. (Hymenoptera: Mymaridae). Journal of the Entomological Society of Ontario, 135: 3-86.

Huber, J.T. 2015. World reclassification of the Gonatocerus group of genera (Hymenoptera: Mymaridae). Zootaxa, 3967(1): 1-184. DOI: http://dx.doi.org/10.11646/zootaxa.3967.1.1

Huber, J.T., Noyes, J.S., Polaszek, A. \& Triapitsyn, S. 2011. Case 3554. Anaphes Haliday, 1833 (Insecta, Hymenoptera): proposed designation of $A$. fuscipennis Haliday, 1833 as the type species. Bulletin of Zoological Nomenclature, 68 (2): 122-126.

Huber, J.T., Read, J.D. \& Triapitsyn, S.V. 2020. Illustrated key to genera and catalogue of Mymaridae (Hymenoptera) in America north of Mexico. Zootaxa, 4773(3): 1-411. DOI: https://doi.org/10.11646/zootaxa.4773.1.1

Huber, J.T. \& Thuróczy, C. 2018. Review of Anaphes Haliday (Hymenoptera: Mymaridae) with key to species in Europe and a world catalogue. Zootaxa, 4376(1): 1-104. DOI: https://doi.org/10.11646/zootaxa.4376.1.1

[ICZN] International Commission on Zoological Nomenclature. 2017. Opinion 2401 (Case 3554) - Anaphes Haliday, 1833 (Insecta, Hymenoptera, Mymaridae): designation of Anaphes fuscipennis Haliday, 1833 as the type species. Bulletin of Zoological Nomenclature, 74(1): 122-124

Kuwayama, S. 1932. Studies on the morphology and ecology of the rice leaf-beetle, Lema oryzae Kuwayama, with special reference to the taxonomic aspects. Journal of the Faculty of Agriculture, Hokkaido Imperial University, 33: 1-132.

Lotfalizadeh, H. 2015. Preliminary checklist of Iranian mymarids (Hymenoptera: Chalcidoidea, Mymaridae). Journal of Entomological and Acarological Research, 47(3) [4838]: 73-78.

Makarova, A.A. \& Polilov, A.A. 2013. Peculiarities of the brain organization and fine structure in small insects related to miniaturization. 2. The smallest hymenopterans (Hymenoptera, Mymaridae, Trichogrammatidae). Zoologicheskiy Zhurnal, 92(6): 695706. [In Russian] English translation: Entomological Review, 93(6): 714-724.

Miller, T.D. \& Roberts, D. 2009. Host testing and environmental assessment of Anaphes nipponicus, a new natural enemy of the cereal leaf beetle. Avaliable at: https://research. libraries.wsu.edu/xmlui/bitstream/handle/2376/2233/Host\%20Testing\%20and\%20Enviro nmental\%20Assessment\%20of\%20Anaphes\%20nipponicus\%20-\%20Miller.pdf? sequence $=1 \&$ isAllowed $=y$ (last accessed 14.I 2021).

Müller, J. \& Triapitsyn, S.V. 2021 (2020). Faunistische Angaben zu Mymaridae (Insecta: Hymenoptera: Chalcidoidea) insbesondere des Erfurter Naturkundemuseums. Thüringer Faunistische Abhandlungen, 25: 279-292.

Noyes, J.S. 2019. Universal Chalcidoidea database. WWW publication. London: the Natural History Museum. Avaliable at: https:/www.nhm.ac.uk/our-science/data/chalcidoids/ index.html (last accessed 8.I 2021).

Polilov, A.A. 2016. Features of the structure of Hymenoptera associated with miniaturization. 1. Anatomy of fairyfly Anaphes flavipes (Hymenoptera, Mymaridae). Zoologicheskiy Zhurnal, 95(5): 567-578. 
Riakhovskiy, V.V. \& Krakhmal', A.I. 1978. Integrated control methods against red-thorax cereal leaf beetle. P. 30-33. In: Materials in aid to agricultural production. Issue 5, part V. Biological and chemical plant protection control methods. Cenral-Chernozem Book Publishing House, Voronezh. [In Russian]

Rimsky-Korsakov, M.N. 1917 (1916). To the fauna of Russian aquatic parasitic Hymenoptera. Russkoe Entomologicheskoe Obozrenie (Revue Russe d'Entomologie) [Protocols of meetings of the Russian Entomological Society for 1916; meeting for 8th November 1916], 16(3-4): LXVII-LXVIII. [In Russian]

Rimsky-Korsakov, M.N. 1920. Parasites of insects injurious to pisciculture. Bulletin of 2nd All-Russian Entomo-Phytopathological Meeting held in Petrograd 25-30 October 1920, 7 [Petrograd, 1 December 1920]: 6-8. [In Russian]

Rimsky-Korsakov, M.N. 1940. Hymenoptera. P. 227-232. In: Zhadin, V.I. (Ed.). Life in fresh waters of the USSR. Publishing House of the Academy of Sciences of the USSR, Moscow, Leningrad. [In Russian]

Roberts, D.E. 2016. Classical biological control of the cereal leaf beetle, Oulema melanopus (Coleoptera: Chrysomelidae), in Washington State and rôle [sic] of field insectaries, a review. Biocontrol Science and Technology, 26(7): 877-893. DOI: https://doi.org/ 10.1080/09583157.2016.1165794

Samková, A., Hadrava, J., Skuhrovec, J. \& Janšta, P. 2019a. Reproductive strategy as a major factor determining female body size and fertility of a gregarious parasitoid. Journal of Applied Entomology, 143: 441-450. DOI: https://doi.org/10.1111/jen.12615

Samková, A., Hadrava, J., Skuhrovec, J. \& Janšta, P. 2019b. Host population density and presence of predators as key factors influencing the number of gregarious parasitoid Anaphes flavipes offspring. Scientific Reports, 9: 6081. https://doi.org/ 10.1038/s41598019-42503-4

Samková, A., Hadrava, J., Skuhrovec, J. \& Janšta, P. 2019c. Effect of adult feeding and timing of host exposure on the fertility and longevity of the parasitoid Anaphes flavipes. Entomologia Experimentalis et Applicata, 167: 932-938. DOI: https://doi.org/10.1111/ eea. 12843

Samková, A., Hadrava, J., Skuhrovec, J. \& Janšta, P. 2020. Host specificity of the parasitic wasp Anaphes flavipes (Hymenoptera: Mymaridae) and a new defence in its hosts (Coleoptera: Chrysomelidae: Oulema spp.). Insects, 11 (3): 175. DOI: https://doi.org/ 10.3390/insects 11030175

Samková, A., Janšta, P. \& Huber, J.T. 2017. Anaphes flavipes: redescription, neotype designation, and comparison with A. nipponicus (Hymenoptera: Chalcidoidea: Mymaridae). Acta Entomologica Musei Nationalis Pragae, 57(2): 677-711.

Samková, A., Janšta, P. \& Huber, J.T. 2020. Illustrated key to European genera, subgenera and species groups of Mymaridae (Hymenoptera), with new records for the Czech Republic. Zootaxa, 4722(3): 201-233. DOI: https://doi.org/10.11646/zootaxa.4722.3.1

Soyka, W. 1946. Revision einiger Mymridengattungen [sic]. Zentralblatt für das Gesamtgebiet der Entomologie, 1(2): 33-44.

Soyka, W. 1949. Monographie der Mymar-Gruppe mit den Gattungen Mymar Curtis, Synanaphes Soyka, Ferrierella Soyka, Anaphoidea Girault, Hofenederia Soyka, Fulmekiella Soyka, und Yungaburra Girault (Hymenoptera, Chalcidoidea, Mymaridae). Revista de Entomologia (Rio de Janeiro), 20: 301-422.

Soyka, W. 1950. Drei neue Mymaridengattungen. Entomologisches Nachrichtenblatt (Burgdorf), 3(11): 120-125.

Soyka, W. 1954. Neue Arten der Gattung Anaphoidea Gir. (Mymaridae, Chalcidoidea, Hymenoptera). Entomologisches Nachrichtenblatt (Vienna), 5 (7/8): 60-66.

Soyka, W. 1955. Neue Revision der Gattung Mymar Curtis (Mymaridae, Chalcidoidea, Hymenoptera). Mitteilungen der Münchner Entomologischen Gesellschaft, 44/45: 460-475.

Storozheva, N.A. 1989. Discovery of an oophage of the rice leaf beetle (Oulema oryzae) Anaphes nipponicus Kuw. in Primorskii krai. P. 14-16. In: Materials of the scientificpractical conference "Actual problems of plant [pest] control and perspectives of using biological control methods in Primorskii krai”. Vladivostok. [In Russian] 
Storozheva, N.A. 1990a. The oophage Anaphes nipponicus Kuw. and other parasites of the rice leaf beetle Oulema oryzae Kuw. in Primorskii krai. P. 113. In: Materials of the Xth Congress of All-Union Entomological Society, Leningrad, 11-15 September 1989. Leningrad. [In Russian]

Storozheva, N.A. 1990b. The oophage Anaphes. Zashchita Rasteniy, [1990] (1): 29. [In Russian]

Tarla, SS. \& Tarla, G. 2017. First report of Anaphes chrysomelae (Hymenoptera: Mymaridae) on the eggs of Chrysolina herbacea (Coleoptera: Chrysomelidae) in Turkey. Florida Entomologist, 100(1): 180-181. DOI: https://doi.org/10.1653/024.100.0128

Thuróczy, C. \& O'Connor, J.P. 2015. Eleven species of fairy fly (Hymenoptera, Chalcidoidea: Mymaridae) new to Ireland. Irish Naturalists' Journal, 34(1): 55-60.

Togashi, I. 1974. The hymenopterous parasites of Oulema oryzae (Kuwayama) (Coleoptera, Chrysomelidae) in Ishikawa Prefecture. Mushi, 48(2): 7-13.

Triapitsyn, S.V. 2012 (2011). Taxonomic notes on Caraphractus (Hymenoptera: Mymaridae). Sahlbergia, 17(2): 20-29.

Triapitsyn, S.V. \& Berezovskiy, V.V. 2001. Review of the Mymaridae (Hymenoptera, Chalcidoidea) of Primorskii krai: genus Mymar Curtis. Far Eastern Entomologist, 100: 1-20.

Triapitsyn, S.V. \& Huber, J.T. 2000. 51 Fam. Mymaridae - mymarids. P. 603-614. In: Lehr, P.A. (Ed.). Keys to the insects of Russian Far East. Vol. IV. Neuropteroidea, Mecoptera, Hymenoptera. Part 4. Dalnauka, Vladivostok. [In Russian]

Triapitsyn, S.V., Koponen, M., Vikberg, V. \& Várkonyi, G. 2020. Taxonomy, annotated new records and a checklist of Mymaridae (Hymenoptera) of Finland, with description of a new species of Eustochus. Acta Entomologica Musei Nationalis Pragae, 60(2): 565-589.

Triapitsyn, S.V. \& Proshchalykin, M.Yu. 2012. 45. Fam. Mymaridae - mymarids. P. 205209. In: Lelej, A.S. (Ed.). Annotated catalogue of the insects of Russian Far East. Vol. I. Hymenoptera. Dalnauka, Vladivostok. [In Russian]

Triapitsyn, S.V. \& Tselikh, E.V. 2019. Family Mymaridae. P. 192-198. In: Belokobylskij, S.A., Samartsev, K.G. \& Il'inskaya, A.S. (Eds.). Annotated catalogue of the Hymenoptera of Russia. Vol. II. Apocrita: Parasitica. Proceedings of the Zoological Institute of the Russian Academy of Sciences, Supplement 8. Zoological Institute RAS, St. Petersburg.

Trjapitzin, V.A. 1978. 18. Fam. Mymaridae - mymarids. P. 516-538. In: Trjapitzin, V.A. (Ed.). Keys to the insects of the European part of the USSR. Volume III. Hymenoptera, Part 2]. Nauka, Leningrad. [In Russian]

Vecher, L.F. 1990. Trophic relationships of the oophages of agrocenoses of vegetable crops in Siberia. P. 26-28. In: Materials of the Xth Congress of All-Union Entomological Society, Leningrad, 11-15 September 1989. Leningrad. [In Russian]

Walker, F. 1846. VIII. - Descriptions of the Mymaridae. The Annals and Magazine of Natural History, 18: 49-54 + viii (Errata and Addenda).

(C) Far Eastern entomologist (Far East. entomol.) Journal published since October 1994. Editor-in-Chief: S.Yu. Storozhenko

Editorial Board: A.S. Lelej, S.A. Belokobylskij, M.G. Ponomarenko, V.A. Mutin, E.A. Beljaev, E.A. Makarchenko, A.V. Gorochov, T.M. Tiunova, M.Yu. Proshchalykin, S.A. Shabalin, V.M. Loktionov

Address: Federal Scientific Center of the East Asia Terrestrial Biodiversity (former Institute of Biology and Soil Science), Far East Branch of the Russian Academy of Sciences, 690022, Vladivostok-22, Russia.

E-mail: storozhenko@biosoil.ru web-site: http://www.biosoil.ru/fee 